2012

\title{
A REMOTE SENSING APPROACH TO CHARACTERIZE THE HYDROGEOLOGY OF MOUNTAINOUS AREAS: APPLICATION TO THE QUITO AQUIFER SYSTEM (QAS), ECUADOR
}

Miriam Rios-Sanchez

Michigan Technological University

Follow this and additional works at: https://digitalcommons.mtu.edu/etds

Part of the Hydrology Commons

Copyright 2012 Miriam Rios-Sanchez

Recommended Citation

Rios-Sanchez, Miriam, "A REMOTE SENSING APPROACH TO CHARACTERIZE THE HYDROGEOLOGY OF MOUNTAINOUS AREAS: APPLICATION TO THE QUITO AQUIFER SYSTEM (QAS), ECUADOR", Dissertation, Michigan Technological University, 2012.

https://doi.org/10.37099/mtu.dc.etds/478

Follow this and additional works at: https://digitalcommons.mtu.edu/etds

Part of the Hydrology Commons 


\title{
A REMOTE SENSING APPROACH TO CHARACTERIZE THE HYDROGEOLOGY OF MOUNTAINOUS AREAS: APPLICATION TO THE QUITO AQUIFER SYSTEM (QAS), ECUADOR
}

\author{
by
}

Miriam Rios-Sanchez

\begin{abstract}
A DISSERTATION
Submitted in partial fulfillment of the requirements for the degree of

DOCTOR OF PHILOSOPHY

In Geological Engineering
\end{abstract}

\section{MICHIGAN TECHNOLOGICAL UNIVERSITY}

2012

(C) 2012 Miriam Rios-Sanchez 
This dissertation, "A Remote Sensing Approach to Characterize the Hydrogeology of Mountainous Areas: Application to the Quito Aquifer System (QAS), Ecuador", is hereby approved in partial fulfillment of the requirements for the degree of DOCTOR OF PHILOSOPHY IN GEOLOGICAL ENGINEERING

Department of Geological and Mining Engineering and Sciences

\section{Signatures}

Dissertation advisor

John S. Gierke

Department Chair

Wayne D. Pennington

Date 
TABLE OF CONTENTS

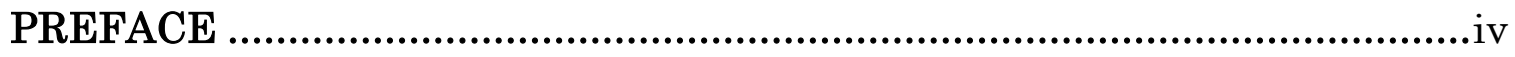

ACKNOWLEDGEMENTS ....................................................................vi

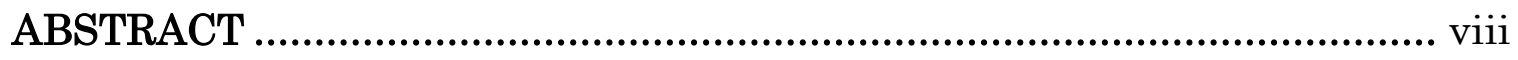

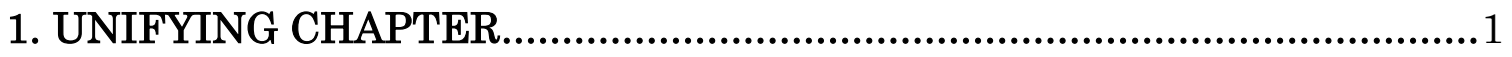

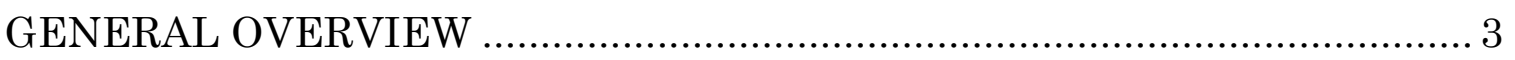

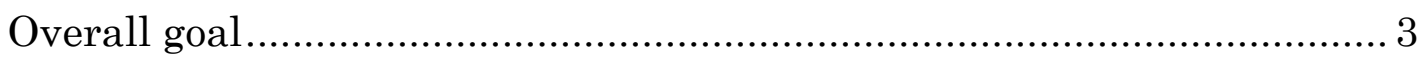

Study framework

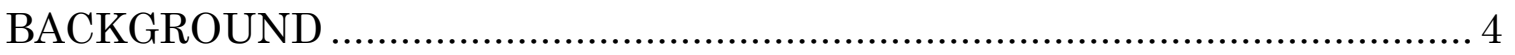

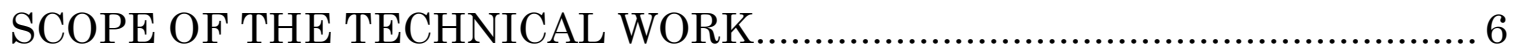

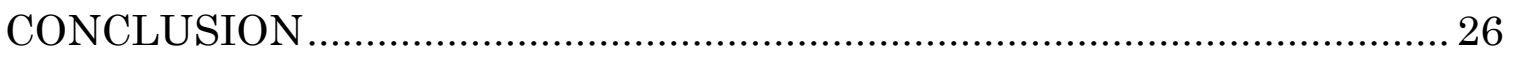

RECOMMENDATIOS FOR FUTURE WORK ……..................................... 27

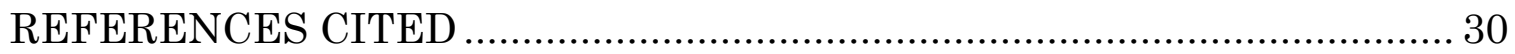

2. PAPER: UTILIZING DIGITAL IMAGE PROCESSING TECHNIQUES TO IDENTIFY AND CHARACTERIZE FRACTURE PATTERNS IN THE QUITO, ECUADOR AQUIFER SYSTEM ...................... 33

3. PAPER :GEOPHYSICAL METHODS FOR FRACTURE DETECTION IN MONTAINOUS VOLCANIC AQUIFERS OF THE PLATEAUS AREA, QUITO ECUADOR ............ Error! Bookmark not defined. 4.PAPER: DEVELOPING A CONCEPTUAL HYDROGEOLOGICAL MODEL FOR A MOUNTAINOUS VOLCANIC AQUIFER IN ECUADOR, BASED ON A MULTIDISCIPLINARY APPROACH..................99

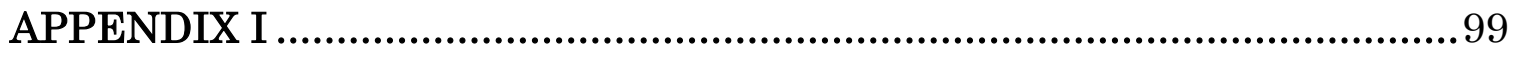

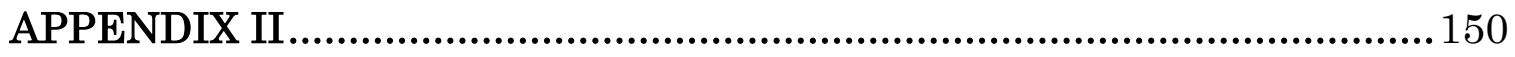




\section{PREFACE}

The following document contains the results of the investigation presented as three journal articles as chapters and two proceeding papers as two appendices.

Chapter 1 is the unifying chapter. It describes the main findings of the research project and connects them to the journal and proceedings papers. Chapter 2, while not yet published, is going to be submitted to the International Journal of Applied Earth Observation and Geoinformation, with Miriam Rios-Sanchez, John S. Gierke, and Ann L. Maclean, as coauthors. Discussion of the subject with the other authors was crucial, but Miriam Rios-Sanchez wrote more than $90 \%$ of the manuscript and completed all the data processing.

Chapter 3, while not yet published, is going to be submitted to the Journal of Environmental \& Engineering Geophysics, with Miriam Rios-Sanchez and John S. Gierke as coauthors. Discussion of the subject with the other author was crucial, but Miriam Rios-Sanchez wrote more than $90 \%$ of the manuscript and completed all the data processing.

Chapter 4, while not yet published, is going to be submitted to the Journal of Hydrogeology, with Miriam Rios-Sanchez, John S. Gierke, Ann L. Maclean, Carla Manciati, Rüdiguer Escobar-Wolf, and Remigio Galárraga as coauthors. Discussion of the subject with other authors was crucial, but Miriam RiosSanchez wrote more than $90 \%$ of the manuscript and completed about $90 \%$ of the data processing. 
Appendix I was published as a proceeding paper of the 2012 World Environmental and Water Resources Congress. The paper is authored by Miriam Rios-Sanchez, John S. Gierke, and Teresa Muñoz-Martínez. Discussion of the subject with the other authors was crucial, but Miriam Rios-Sanchez wrote more than $90 \%$ of the manuscript and completed all of the data processing. The paper in included in the dissertation with permission from the American Society of Civil Engineers (ASCE).

Appendix II was published in Spanish as a proceeding paper for the IX Latin American Conference on Hydrogeology. The paper is authored by Miriam Rios-Sanchez, John S. Gierke, Teresa Muñoz-Martínez, and Oscar Larrea. Discussion of the subject with other authors was crucial, but Miriam RiosSanchez wrote more than $90 \%$ of the manuscript and completed all of the data processing. The translation of the paper in included in the dissertation with permission from the Ecuadorian Chapter of the International Association of Hydrogeologist (GECAIH). 


\section{ACKNOWLEDGMENTS}

Funding for this work was provided by the National Science Foundation through its Partnership for International Research and Education (PIRE) program (NSF 0503109),

I would like to express my gratitude to my advisor Dr. John S. Gierke for his support and guidance throughout all these years.

I would like to thank my committee members: Dr. Ann Maclean, Dr. Alex Mayer and Dr. Remigio Galárraga for their time and input into my research.

I would also like to thank the Department of Geological and Mining Engineering and Sciences at Michigan Technological University. The unique friendly and welcoming environment makes me feel like at home,

I would also like to the Water Utility Company of Quito, Ecuador (EPMAPS), especially to Teresa Muñoz and Oscar Larrea, for providing an invaluable technical and logistical support for the development of this study.

I am also grateful to Vinicio Naranjo, Guillermo Mendoza and Marco Morales (EPMAPS); students in Michigan Tech's Aqua Terra Tech Enterprise; Peace Corps Masters International students Daniel Smith and Jacqueline Houston; Geology students Fernanda Naranjo and Andrea Cordoba at EPN, Ecuador; and Carla Manciati (PhD Student at University of Montpellier) for their participation in the field work.

I want to thank also the Counseling office at Michigan Tech. The support I found and the help would go beyond my years at Michigan Tech. 
I would like to express my gratitude to my family in Colombia who has supported and believed in me. Thanks to my other family: my friends. I don't have enough room to name each of them. They have been an invaluable support for my $\mathrm{PhD}$.

I would like to express my love and gratitude to Todd Sangren. Your love and support made this an accomplished project. 


\section{ABSTRACT}

Climate change, intensive use, and population growth are threatening the availability of water resources. New sources of water, better knowledge of existing ones, and improved water management strategies are of paramount importance. Ground water is often considered as primary water source due to its advantages in terms of quantity, spatial distribution, and natural quality. Remote sensing techniques afford scientists a unique opportunity to characterize landscapes in order to assess groundwater resources, particularly in tectonically influenced areas. Aquifers in volcanic basins are considered the most productive aquifers in Latin America. Although topography is considered the primary driving force for groundwater flows in mountainous terrains, tectonic activity increases the complexity of these groundwater systems by altering the integrity of sedimentary rock units and the overlying drainage networks. Structural controls affect the primary hydraulic properties of the rock formations by developing barriers to flow in some cases and zones of preferential infiltration and subterranean in others. The study area focuses on the Quito Aquifer System (QAS) in Ecuador. The characterization of the hydrogeology started with a lineament analysis based on a combined remote sensing and digital terrain analysis approach. The application of classical tools for regional hydrogeological evaluation and shallow geophysical methods were useful to evaluate the impact of faulting and fracturing on the aquifer system. Given the spatial extension of the area and the complexity of the system, two levels of analysis were applied in this study. At the regional level, a lineament map was created for the QAS. Relationships between fractures, faults and lineaments and the configuration of the groundwater flow on the QAS were determined. At the local level, on the Plateaus region of the QAS, a detailed lineament map was obtained by using high-spatial-resolution satellite imagery and aspect map derived from a digital elevation model (DEM). This map was complemented by the analysis of morphotectonic indicators and shallow geophysics that characterize fracture patterns. The development of the groundwater flow system was studied, drawing upon data pertaining to the aquifer system physical characteristics and topography. Hydrochemistry was used to ascertain the groundwater evolution and verify the correspondence of the flow patterns proposed in the flow system analysis. Isotopic analysis was employed to verify the origin of groundwater. The results of this study show that tectonism plays a very important role for the hydrology of the QAS. The results also demonstrate that faults influence a great deal of the topographic characteristics of the QAS and subsequently the configuration of the groundwater flow. Moreover, for the Plateaus region, the results demonstrate that the aquifer flow systems are affected by secondary porosity. This is a new conceptualization of the functioning of the aquifers on the QAS that will significantly contribute to the development of better strategies for the management of this important water resource. 


\section{UNIFYING CHAPTER}

The present chapter presents the results of this research project, which was aimed at developing and testing a remote sensing approach to characterize the hydrogeology of mountainous areas. The context of this study was focused on the Quito Aquifer System (QAS) in Ecuador. This chapter summarizes the approaches and results of the various facets of this work, which are included subsequently as three journal manuscripts as primary chapters and two proceedings papers included in the appendices. This chapter provides all of the major findings and conclusions, derived from these papers and includes recommendations for future work that builds on the approaches and results presented herein.

The Quito region was chosen for this study because of how important these types of terrains are as sources of groundwater. Volcanic aquifers in mountainous terrains are the most productive aquifers in much of Latin America. Metropolitan areas in Mexico, Guatemala, Ecuador, Bolivia, and other countries with extensive volcanic terrain depend partially on groundwater for drinking water (Anton 1993; Centamore et al. 1996). Figure 1.1 depicts the distribution of volcanic aquifers (primarily the Cenozoic and Tertiary Rocks) in Latin America. Most of these areas have too little information to manage groundwater resources in a sustainable manner (Zektser and Everett 2004). Moreover, most of these aquifers are located in very complex tectonic areas in which the impacts of the faulting and fracturing on the hydrogeology have not been evaluated. 


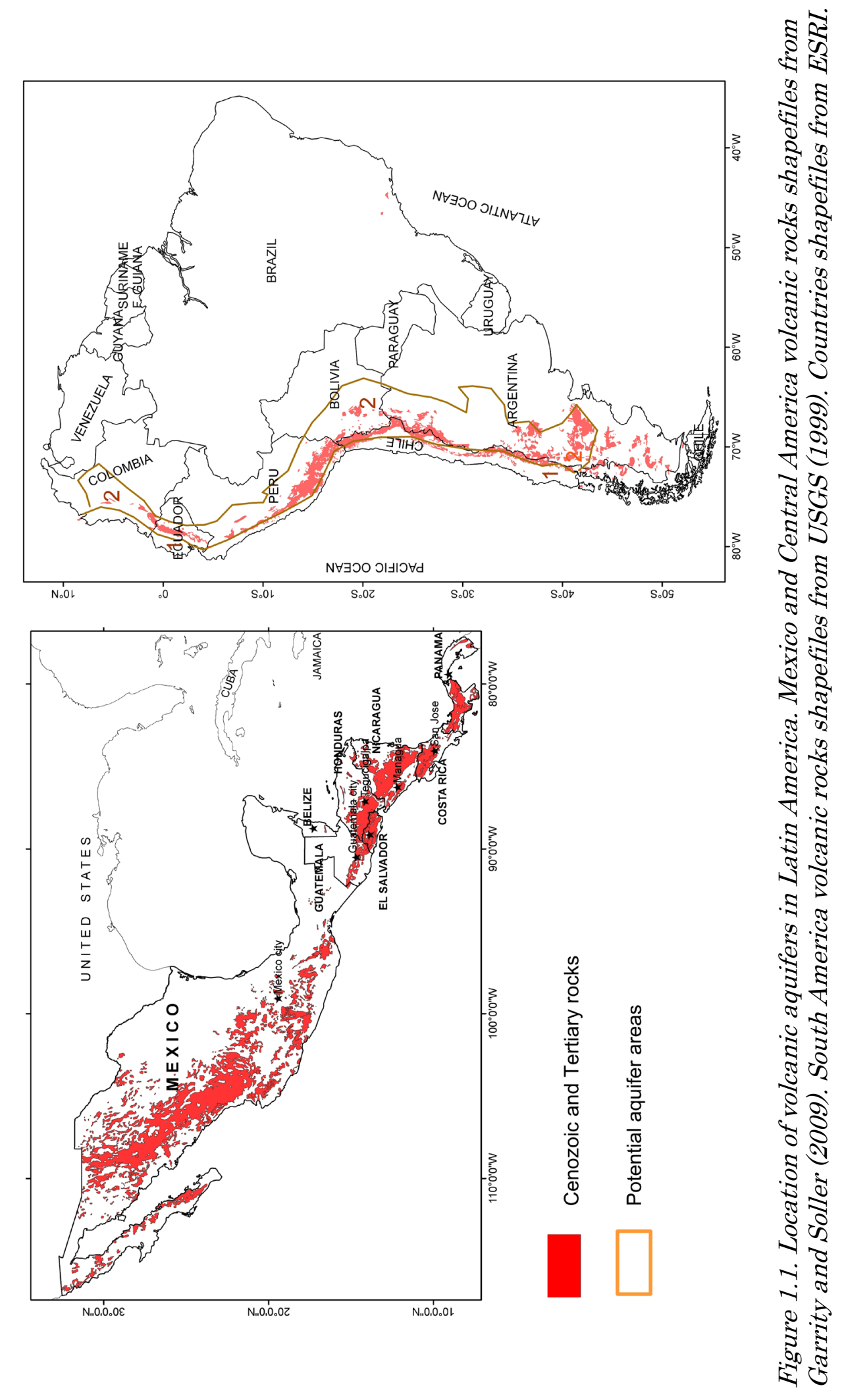




\section{GENERAL OVERVIEW}

\section{Overall goal}

The overall goal of the study was to develop and test remote-sensing-based and digital-terrain analysis protocols for characterizing fracture networks and faults and boundaries in mountainous regional aquifer systems of volcanic origin and to evaluate the control of such structures on natural hydrological behaviour.

These protocols were tested and enhanced using geophysical data, hydrogeochemistry, structural geology and geomorphic observations, and hydrogeological data (water levels and aquifer tests). The study area is the Quito Aquifer System (QAS) in Ecuador, which is located within a complex tectonic basin. Groundwater is mainly used for drinking water for the Quito metropolitan area, as well as for agricultural purposes.

\section{Study framework}

The study was carried out in two phases. In the first phase, two methods were used to create a comprehensive regional lineament map of the QAS. Lineaments were then compared to previously mapped faults and lineaments in order to evaluate the performance of the methods, characterize lineaments as faults and fractures, and analyze the impacts of faults and fractures on the hydrogeology of the region. The second phase entailed detailed mapping a sub-region within the QAS to test and enhance the lineament-mapping protocols using geophysics, hydrochemistry, structural geology, digital geomorphology, and hydrogeological data. The impact of faults and fractures on the hydrogeology of the plateaus was assessed as well. 


\section{BACKGROUND}

As mentioned before, volcanic aquifers on mountainous terrains of Latin America have too little information to manage groundwater resources in a sustainable manner (Zektser and Everett 2004). The tectonic histories of these terrains, especially faulting and fracturing, are expected to exert significant influences on the hydrogeology.

Satellite-based remote sensing techniques and digital elevation models are areas of focus for water system studies because the acquired imagery provides synoptic views of the Earth and its main surficial components (i.e., soil, surface water, vegetation, and land use) at a broad range of wavelengths, different scales, and temporal resolutions (Becker 2006; Brunner et al. 2007; Hoffmann 2005; Meijerink et al. 2007). In recent years, UNESCO and other organizations through programs such as the TIGER initiative (UNESCO-IHP 2010), GEO-AQUIFER (OSS 2008) GRAPHIC(UNESCO-IHP 2008), and IGCP (UNESCO-IGP-IUGS 2012) have been attempting to fill the water-information gap that exists for many developing countries by fostering the use of remote sensing techniques.

The earliest uses of remotely sensed imagery in hydrogeology is lineament analysis in hard-rock terrains (Bruning et al. 2011a; El-Baz 1995; Ricchetti 2002), the objective of which was to pinpoint locations for follow-up detailed geophysical investigations and well drilling. Bruning et al. (2011) found that the majority of successful lineament analyses were applied in "ideal" conditions in which geologic structure was well known and the climate was semi-arid to arid, with minimal effects of vegetation and human development. Recognizing that there was not yet a protocol for mapping lineaments in non-ideal conditions, Bruning et al. (2011) developed a new 
approach for image-processing/synthesis to identify successful satellite imagery types for lineament analysis in non-ideal terrain.

Once the RSA methodology was applied in this study, it was found that one of the most important faults of the area was not properly identified. Moreover, tectonic features that were observed in the field were missed as well. Consequently other methods to map lineaments were considered in this work in order to understand where the shortcomings of the RSA were and to acquire a more robust set of methods for the lineament mapping.

Digital terrain analysis has been used broadly as part of structural mapping, tectonic studies, geomorphologic studies, and hydrogeological assessment of fractured areas (Jordan et al. 2005; MacMillan et al. 2000; Onorati et al. 1992; Saadi et al. 2009; Siart et al. 2009). DEMs also have been used to analyze structural aspects of faults, such as strike, dip, block movement, and the general structural style (Argialas and Mavrantza 2009; Grohmann et al. 2007; Henderson et al. 1996; Onorati et al. 1992). Even in areas in which deformation is not easily recorded, morphotectonic indicators can be apparent on DEMs which can help to identify faults and fractures (Seta et al. 2004b). Considering the lack of consistent methods for the use of DEMs on structural geology and tectonic geomorphology, Jordan et al. (2005) proposed a systematic scheme to carry out morphotectonic terrain analysis, focused on the extraction of lineaments of tectonic origin.

Applications of combined remote sensing (RS) and digital terrain analysis (DTA) for mapping lineaments are common in the literature (Henderson et al. 1996; Siart et al. 2009; Solomon and Quiel 2006; Thurmond et al. 2006). As 
mentioned before for the DEM based studies, none of these studies have included a systematic approach to map lineaments.

The techniques suggested by Jordan et al. (2005), based on the digital process of DEMs, were applied in this study to map lineaments. The addition of digital terrain analysis (DTA) using DEMs is a new advancement on the work of Bruning et al. (2011) for extracting lineaments in another type of complex volcanic terrain (a basin fill) that complements the use of satellite imagery. More lineaments of geologic origin were identified in the DTA in this work. Moreover, a more complete topographic and structural description of the terrain was gained. DEMs offer insights into the vertical dimension for aquifer characterization.

\section{SCOPE OF THE TECHNICAL WORK}

The overall goals of this project were to:

1) Develop and test a combined remote sensing (RSA) and digital terrain analysis (DTA) protocol for characterizing fracture networks in regional aquifer systems, discontinuities and boundaries of local and regional aquifer systems and to evaluate their control on natural hydrological behavior.

2) Test and enhance the protocols for characterizing fracture networks, discontinuities and boundaries of aquifer systems using geophysical data, geochemistry, structural geology, and hydrogeological data.

The primary objectives of the project and how they were achieved are described below. 


\section{a) Develop and test remote sensing techniques and digital terrain analysis techniques to map surface expressions of geological lineaments and discontinuities.}

Two techniques were used to map lineaments in the QAS. The first one was a combined approach of the RS coincidence analysis proposed by Bruning et al. (2011a) with a DTA approach developed in this work and based on the methods proposed by Jordan et al. (2005). This technique was used for mapping lineaments across the entire QAS and could be considered the "regional approach" since most of the features that were mapped can be considered of regional origin. The RSA and DTA techniques are described in more detail in Rios-Sanchez et al. (2012a).

The detailed (or local) approach to map lineaments is described in RiosSanchez et al. (2012c). A detailed lineament map of the Plateaus Region near Quito, Ecuador was created using the regional map as starting point. A new set of more detailed lineaments was found based on the combined use of high-spatial-resolution imagery, such as QuickBird, and the ASTER visible and near-infrared (VNIR) bands and the aspect map derived from the DEM. Field verification and identification of morphotectonic indicators on the imagery were used to aid the characterization of lineaments as faults and fractures. Shallow geophysical methods were used to evaluate the expressions of the tectonic features underground.

b) Identify faults and discontinuities by correlating lineament maps to existing geology and geophysical data and evaluate the interconnections between different components of the hydrogeological basin by integrating datasets. 
The methods used to identify faults and discontinuities, along with their hydrologic connections, for the QAS are described in Rios-Sanchez et al (2012d). The regional lineament map created for the QAS was compared to previously map geological faults and lineaments to analyze the degree of correspondence and identify the major regional features of the QAS. The associations between springs and lineaments and faults were explored to evaluate the influence of the tectonic features on the discharge of the aquifer. Water levels and spring elevations were used to create piezometric maps and analyze the impacts of tectonic features on the development of groundwater flow (i.e., faults acting as barriers, zones of infiltration or exfiltration).

For the Plateaus Region, Rios-Sanchez et al. (2012b) evaluated the impact of fractures and faults on the aquifer behavior, based on the analysis of water levels, well logs, pumping tests, hydrochemistry, and isotopic data. A 3dimensional flow scheme for this region of the QAS is proposed.

c) Foster a collaborative international approach to conduct systematic research in order to improve the understanding of complex aquifer systems and establish a foundation for continued research and monitoring.

This work was the result of an international collaboration that included Michigan Technological University, through its Partnership for International Research and Education (PIRE) project funded by the National Science Foundation (NSF 0503109), the Water and Sanitation Utility Company of Quito (EPMAPS), and Ecuador's National Polytechnic University (EPN). Secondary collaboration took place with the Ecuadorian Remote Sensing Institute (CLIRSEN) and University of Montpellier (France). EPMAPS has been the most important collaborator. 


\title{
MAJOR FINDINGS OF THE TECHNICAL WORK
}

Table 1.1 summarizes the major findings of this dissertation research. The different aspects of the aquifer system are described in terms of what was known before this research and what was added and/or altered as a result of this work. The table also indicates which document best describes the particular findings and indicates the focus of each paper.

The papers listed in Table 1.1 and the methods used to achieve the advancements of this work are summarized below.

\section{PAPER 1. UTILIZING DIGITAL IMAGE PROCESSING TECHNIQUES TO IDENTIFY AND CHARACTERIZE FRACTURE PATTERNS IN THE QUITO, ECUADOR AQUIFER SYSTEM}

\author{
Miriam Rios-Sanchez, John S. Gierke, Ann L. Maclean
}

Rios-Sanchez et al. (2012a) created a lineament map for the QAS by introducing variations of the coincidence analysis methodology developed by Bruning et al. (2011a) in the remote sensing approach and adding digital terrain analysis based on that proposed by Jordan et al. (2005). Both approaches were compared in order to assess how each was able to map the same tectonic features and to identify the limitations and advantages of the approaches. Moreover, lineaments obtained from the RSA and DTA were compared to faults and lineaments identified in other studies. The main findings from this part of the research include:

Major Finding 1. Thermal bands can be included as digital products for mapping lineaments. Moreover, they have potential to indicate exfiltration zones because of the relative differences in temperature that can be observed, especially in nighttime ASTER thermal images. 
Table 1.1 Description of the major findings of the research project, contributing to the knowledge of the aquifer system.

\begin{tabular}{|c|c|c|c|}
\hline $\begin{array}{c}\text { Previous } \\
\text { understanding }\end{array}$ & $\begin{array}{c}\text { Advancements from } \\
\text { this work }\end{array}$ & Methods & Paper \\
\hline \multirow[t]{3}{*}{$\begin{array}{l}\text { Faults and } \\
\text { lineamenys mapped } \\
\text { in detail in the } \\
\text { northern regiobn }\end{array}$} & $\begin{array}{l}\text { Regional faults and } \\
\text { lineaments mapped } \\
\text { for the entire aquifer } \\
\text { system }\end{array}$ & $\begin{array}{l}\text { Regional lineament } \\
\text { mapping using RSA and } \\
\text { DTA approaches }\end{array}$ & $\begin{array}{l}\text { QAS Lineament mapping } \\
\text { (Rios-Sanchez et al., } \\
\text { 2012b) }\end{array}$ \\
\hline & \multirow[t]{2}{*}{$\begin{array}{l}\text { Detailed lineament } \\
\text { mapping of the } \\
\text { plateaus }\end{array}$} & $\begin{array}{l}\text { Detailed lineament } \\
\text { mapping (high spatial } \\
\text { resolution imagery and } \\
\text { DEM derived digital } \\
\text { products) }\end{array}$ & $\mid \begin{array}{l}\text { Plateau lineament } \\
\text { mapping (Rios-Sanchez et } \\
\text { al.2012d) }\end{array}$ \\
\hline & & $\begin{array}{l}\text { Shallow geophysics (VLF- } \\
\text { EM and 2D-ER } \\
\text { geolectrical profiling) }\end{array}$ & $\begin{array}{l}\text { Geophysics methods } \\
\text { applied to identify } \\
\text { fractured zones (Rios- } \\
\text { Sanchez et al. 2012a) }\end{array}$ \\
\hline \multirow{4}{*}{$\begin{array}{l}\text { Assesment of the } \\
\text { influence of faults } \\
\text { and lineaments on } \\
\text { the geomorphology } \\
\text { and hydrology has } \\
\text { not been considered }\end{array}$} & \multirow{4}{*}{\begin{tabular}{|l|} 
Fractures and faults \\
are controlling the \\
topographic \\
development of the \\
area and therefore are \\
controlling rhe \\
development of local \\
and sub-regional \\
groud water flow
\end{tabular}} & $\begin{array}{l}\text { Detailed lineament } \\
\text { mapping }\end{array}$ & \multirow{4}{*}{$\begin{array}{l}\text { Impacts of tectonics on } \\
\text { the hydrogeology of the } \\
\text { Quito Aquifer System } \\
\text { (Rios-Sanchez et al. } \\
\text { 2012e) }\end{array}$} \\
\hline & & $\begin{array}{l}\text { Groundwater level } \\
\text { analysis }\end{array}$ & \\
\hline & & Spring elevation analysis & \\
\hline & & $\begin{array}{l}\text { Drainage network } \\
\text { analysis }\end{array}$ & \\
\hline \multirow{3}{*}{$\begin{array}{l}\text { Regional flows are } \\
\text { characterized } \\
\text { broadly and } \\
\text { qualitatively }\end{array}$} & \multirow{3}{*}{\begin{tabular}{|c|} 
Fracturing is affecting \\
the permeability of the \\
aquifers (Plateaus \\
area)
\end{tabular}} & Pumping test analysis & \multirow{3}{*}{$\begin{array}{l}\text { Developing a conceptual } \\
\text { hydrogeological model for } \\
\text { a mountainous volcanic } \\
\text { aquifer in Ecuador, based } \\
\text { on a multidisciplinary } \\
\text { approach (Rios-Sanchez } \\
\text { et al. 2012c) }\end{array}$} \\
\hline & & $\begin{array}{l}\text { Hydrochemical } \\
\text { classification }\end{array}$ & \\
\hline & & Shallow geophysics & \\
\hline
\end{tabular}

For the coincidence analysis approach, thermal bands of Landsat 7 and ASTER and the panchromatic band of Landsat 7 were incorporated into the digital process to map lineaments. Thermal bands were chosen due to their 
effectiveness for displaying linear features associated with abrupt changes in topography in many parts of the QAS, and the potential to use these bands to assess the potential of faults and fractures to act as discharge or recharge areas.

Major Finding 2: By combining two approaches (satellite images and DEMS) a greater number of lineaments were found. Major features were mapped with more precision compared to the features appearing in the different approaches.

The DTA tools were used to create a lineament map in which different products derived from a DEM were used. This map was combined with that obtained from the RS approach to obtain a final map.

Figure 1.2 illustrates the common and different lineaments mapped by using the two approaches. Major differences were found for the Quito Fault (QF) zone, which was defined from a combination of the two methods. The longitudinal expression of the fault was best defined by the DTA, as well as the scarps associated with the fault. Fractures perpendicular to the fault were mapped by only the RSA.

- The lineament located on the northeastern border of the study area was apparent only in the DTA.

- Lineaments on the southwestern part, around the town of Machachi, were mapped almost exclusively by the RSA. 


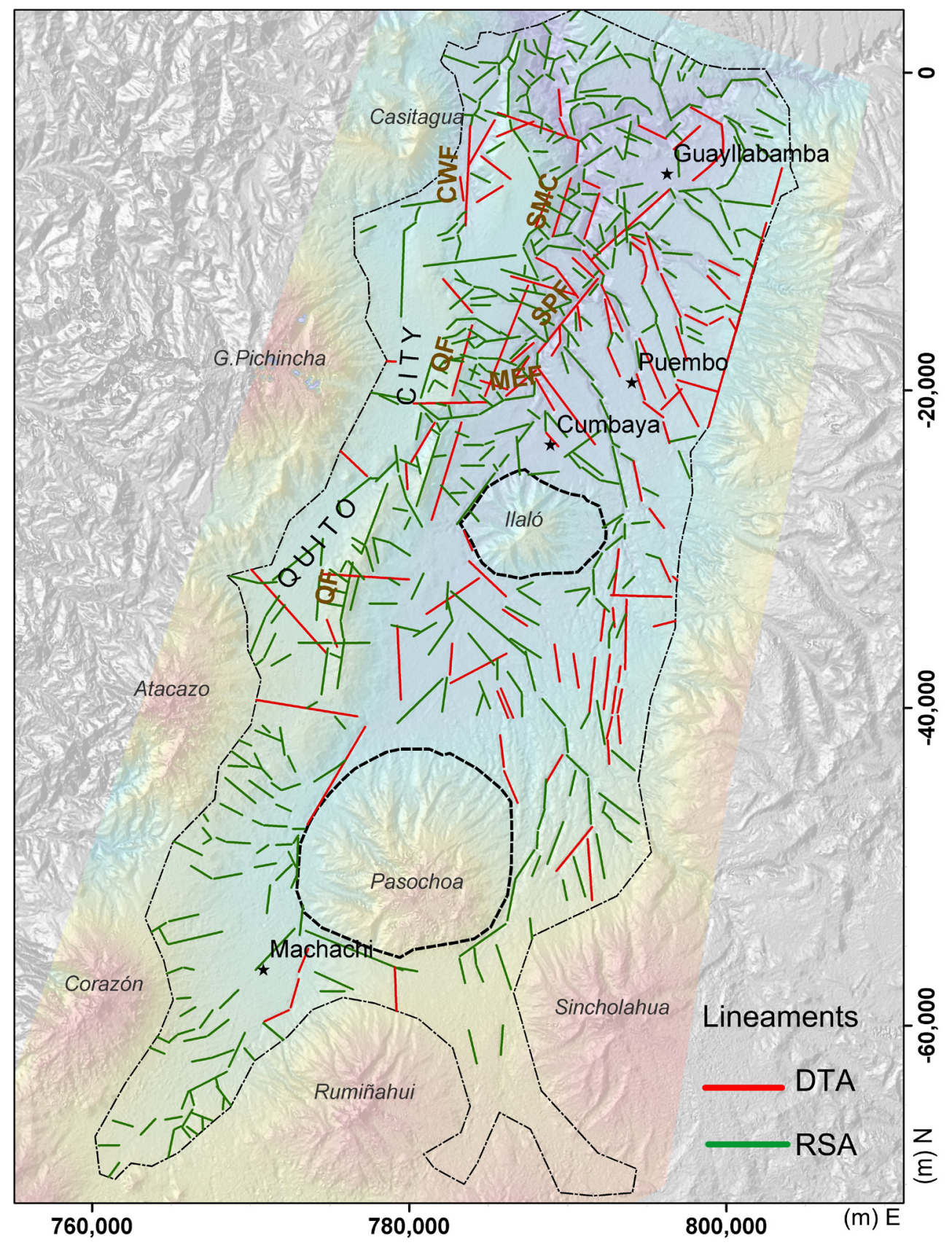

Figure1.2. Comparison between the lineaments mapped with both approaches. Major Faults are indicated: QF: Quito Fault, SMC: San Miguel del Comun .Fault and MEF: Machangara-east Fault. The base layer is a hillshade derived from a $30-\mathrm{m}$ ASTER DEM (product of METI and NASA). Map projection: UTM_WGS84_17N 
Major Finding 3. The combined approach used in this study is an efficient method to map lineaments over large areas, under non-ideal conditions. More lineaments and more detailed tectonic features were mapped using the combined method compared to other studies carried out in the same geographic area.

Figure 1.3 displays the lineament map created in this study compared to previously mapped faults in other studies. The best map to compare the lineaments and faults is the one created by Villagomez (2003) for the northeastern part of the study area. The other two studies were done at small scales.

\section{PROCEEDINGS PAPER 1. HYDROGEOLOGICAL CHARACTERIZATION OF THE PLATEAUS REGION OF THE QUITO AQUIFER SYSTEM USING REMOTE SENSING, DIGITAL GEOMORPHOLOGY, AND GEOPHYSICS ${ }^{1}$.}

Miriam Rios-Sanchez, John S. Gierke, Teresa Muñoz-Martínez

Rios-Sanchez et al. (2012c) created a detailed lineament map for the Plateaus Region of the QAS. Lineaments of regional origin were extracted based on a combined remote sensing and digital terrain analysis approach. To improve the detail of the map, finer spatial-resolution images (ASTER VNIR, QuickBird) and DEMs were used.

${ }^{1}$ Published at the 2012 World Environmental and Water Resources Congress. ASCE. Albuquerque, New Mexico. Paper included in Appendix I 


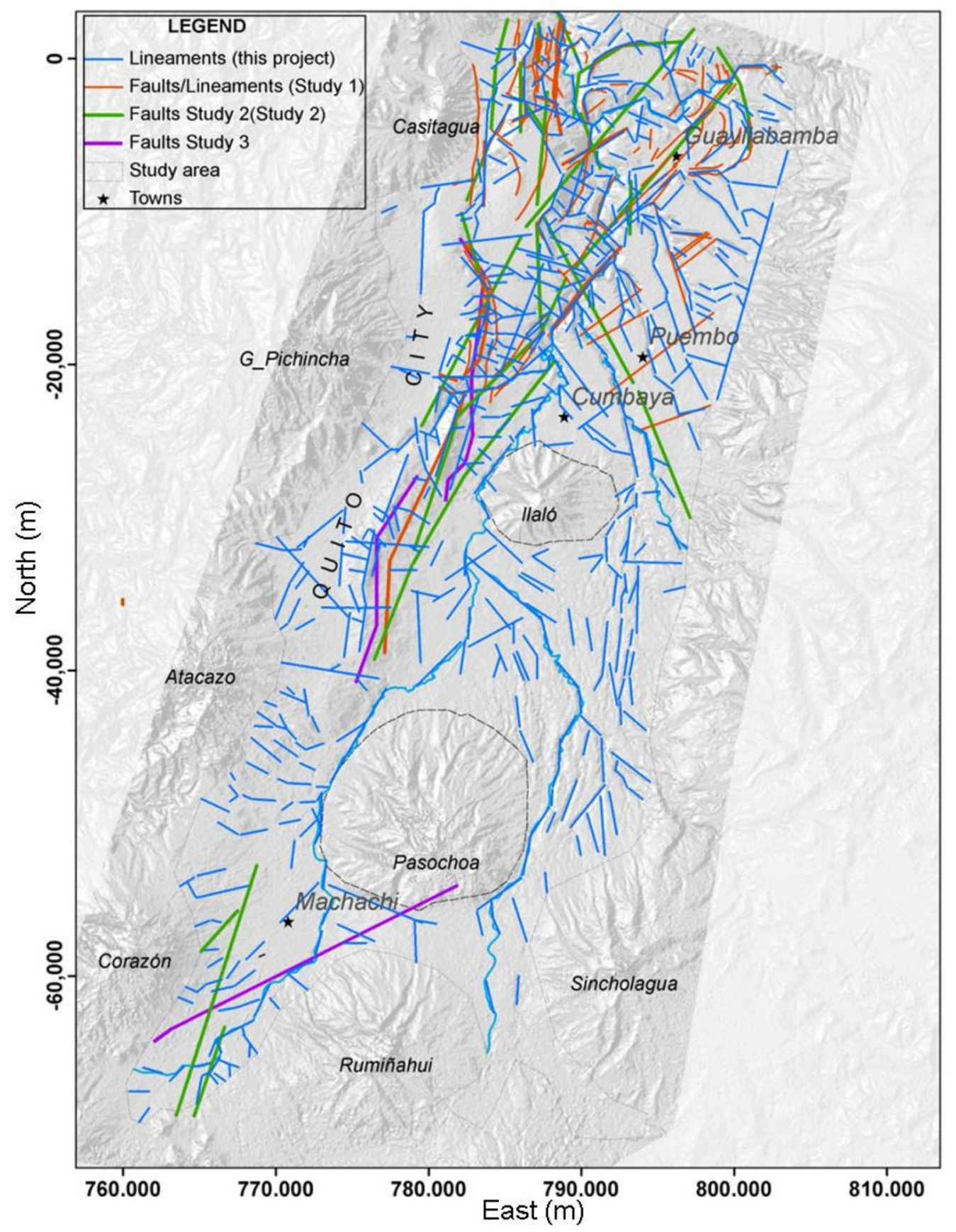

Figure 1.3. Lineament map from this study, compared to lineaments and faults from previous studies. Study 1corresponds to the lineaments mapped by Villagomez (2003); Study 2 refers to the map by Eguez et al (2003); Study 3 is the Geological Map of Ecuador (1982). The map base layer is a hillshade derived from a $30-\mathrm{m}$ ASTER DEM (product of METI and NASA) 
Major Finding 4. Additional tectonic linear features were mapped by using high spatial resolution imagery and the DEM derived aspect map. High spatial resolution provided the detail to identify short length fractures. The aspect map was used to extend the spatial extension of many of those fractures.

Lineaments were extracted by using high-spatial-resolution imagery such as the visible and near-infrared bands of ASTER (ASTER-VNIR), which have $15-\mathrm{m}$ resolution, as well as QuickBird images (0.6-cm resolution). These two images, combined with the aspect map derived from the DEM, provide the elements to map structures that at first appear as locally as short features but actually have a larger extent and were spatially correlated to other fractures in a regional view. Besides these benefits, it is important to recognize that this high-spatial-resolution imagery is not suitable to map regional features because of the large amount of detail that they contain. Figure 1.4 shows the detailed lineament map obtained for the Plateaus Region.

\title{
PAPER 2. GEOPHYSICAL METHODS FOR FRACTURE DETECTION IN MOUNTANOUS VOLCANIC AQUIFERS OF THE PLATEAUS AREA OF QUITO, ECUADOR
}

\author{
Miriam Rios-Sanchez, John S. Gierke
}

In order to identify conductive structures associated with the E-W and SWNE lineaments mapped on the Plateaus Region of the QAS, Rios-Sanchez and Gierke (2012) carried out 2-dimensional electrical resistivity (2D-ER) and Vertical low frequency electromagnetic (VLF-EM) surveys. Surveys for both methods were run orthogonal to the orientation of the lineaments. In order to reduce the bias caused by visual interpretation, digital image processing 


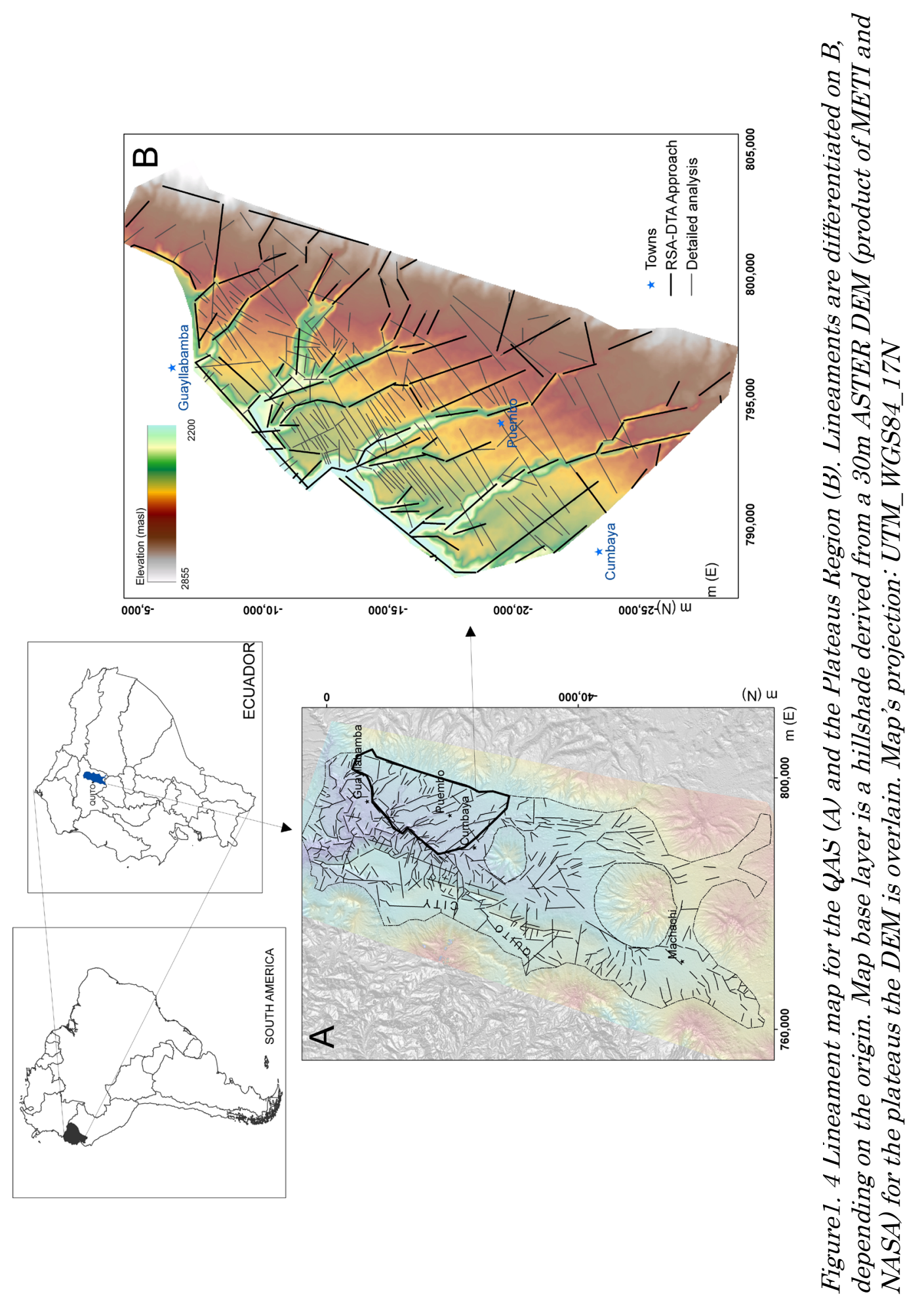


were applied to the inverted sections in order to better define horizontal and vertical boundaries. Gradients, east-filter gradients and local minima extraction were carried out. Based on the outcomes of these processes, three vertical layers were identified for the Plateaus Region. Moreover, lateral boundaries associated to the minimum value of resistivity (local minima) were interpreted as saturated fractured zones (SFZs).

Fraser filtering was applied to the VLF-EM data to identify positive anomalies associated with the existence of "conductors" in the terrain that can be interpreted as water-saturated fractures. Inversion was carried out for the $2 \mathrm{D}$-ER data and for the VLF-EM tipper data in order to characterize the depth and extent of zones interpreted as fractured areas.

SFZ locations interpreted from the 2D-ER and VLF-EM data were overlain on the lineament map to analyze the correlation of the low-resistivity zones mapped from the geophysical data. Moreover, the effectiveness of the 2D-ER compared to the VLF-EM on identifying water bearing fractures was assessed. Detailed description of the surveys, the methods of processing and interpretation are presented in Rios-Sanchez and Gierke (2012).

Major Finding 5. The shallow geophysics methods: 2D-ER and VLF-EM are effective on the subsurface characterization of the fracturing on the volcanic terrains

Rios-Sanchez and Gierke (2012) demonstrated that the lineaments mapped on the plateaus are correlated to the deepest saturated ractured zones (SFZ) extracted from the 2D-ER and VLF-EM Fraser-filtered data. It was observed also that the shallow SFZs are representing a denser network of fractures. This assumption is supported by the existence of short-length fractures 
observed on the walls of the ravines. Their length and the lack of geomorphologic evidence prevented the majority them from being extended to the tops of the plateaus and being included on the lineament map of RiosSanchez et al. (2012c). The outcomes of the geophysical analysis might indicate that that fracturing is affecting a larger portion of the Plateaus Region. Figure 1.5 depicts an example of the 2D-ER section, the SFZ interpreted and the correlation to the lineaments.

Major Finding 6. The very low frequency electromagnetic method (VLF-EM) is a relatively cheap and practical technique that can be used on volcanic terrains to identify water-bearing fractures, even in areas where development is present.

When VLF-EM results were compared to 2D-ER sections, it was observed that inversion of the tipper data provided electrical resistivity profiles similar to those of the 2D-ER method to a depth of $30 \mathrm{~m}$ as depicted in Figure 1.6 Therefore VLF-EM may be used as an alternative to 2D-ER, especially when targeting shallow features and in areas of limited space to run 2D-ER surveys.

Major Finding 7. The 2D-ER S a more suitable method than the VES to analyze the lateral and vertical variations in resistivity in volcanic terrains.

The VES data interpreted in the plateaus did not display a common pattern of vertical layering. Moreover, resistivity values obtained varied significantly among the different VES surveys, even over short distances. On the contrary, 

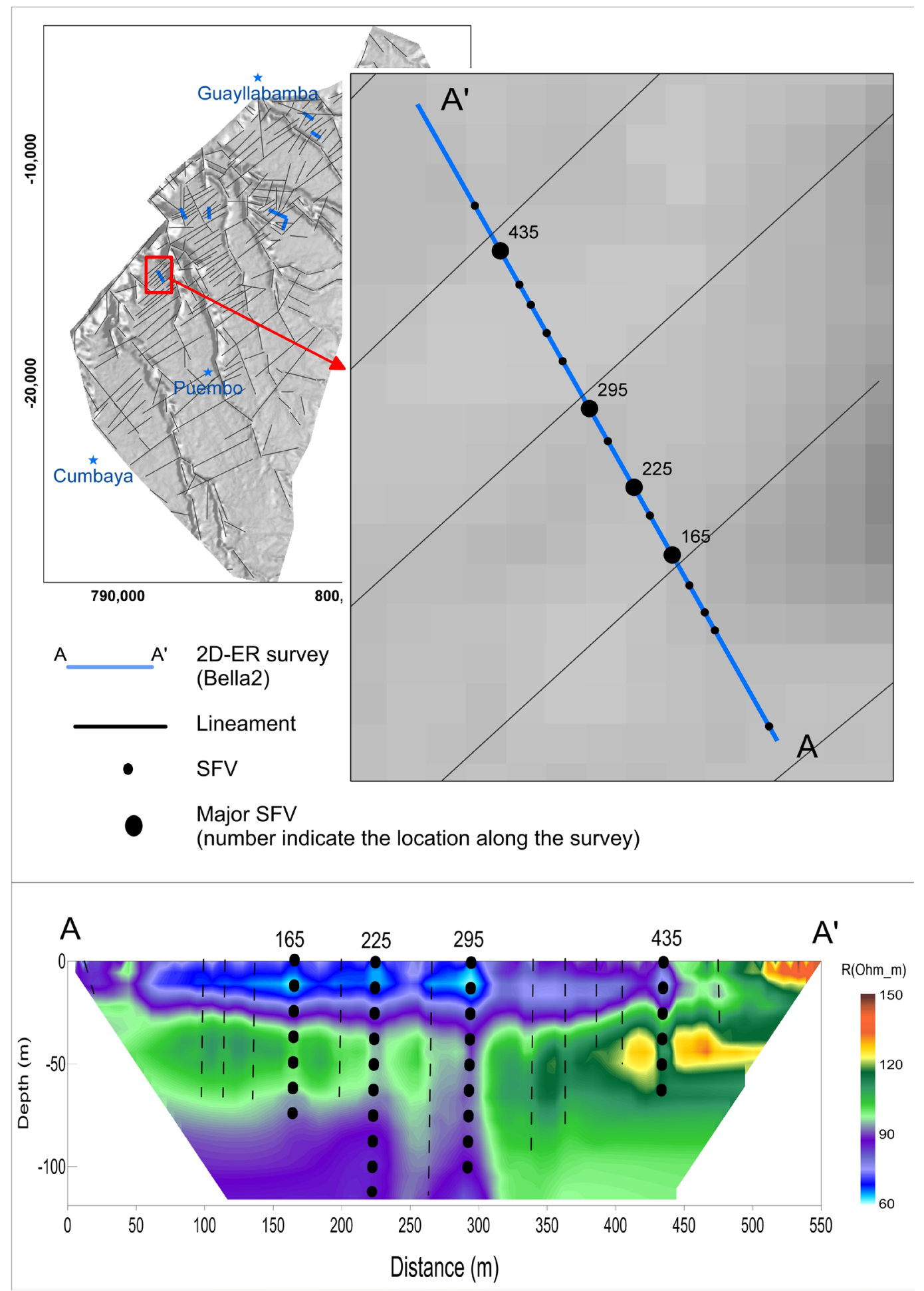

Figure 1.5 Relation between the Lineaments and SFZ identified with the 2D-ER. Major SFZ and the distances are indicated on the map and on the resistivity section. 
2D-ER inverted sections have a common pattern of vertical layering that agrees with the geological information and water-level data of the Plateaus Region.

The conclusion drawn from comparing the two methods is that the VES method is not suitable to characterize vertical or lateral variations in the resistivity for aquifer characterization. The 2D-ER demonstrated better lateral and vertical resolution. The 2D-ER method is a more convenient than the VES method to apply for hydrogeological characterization of parameters associated to electrical resistivity.

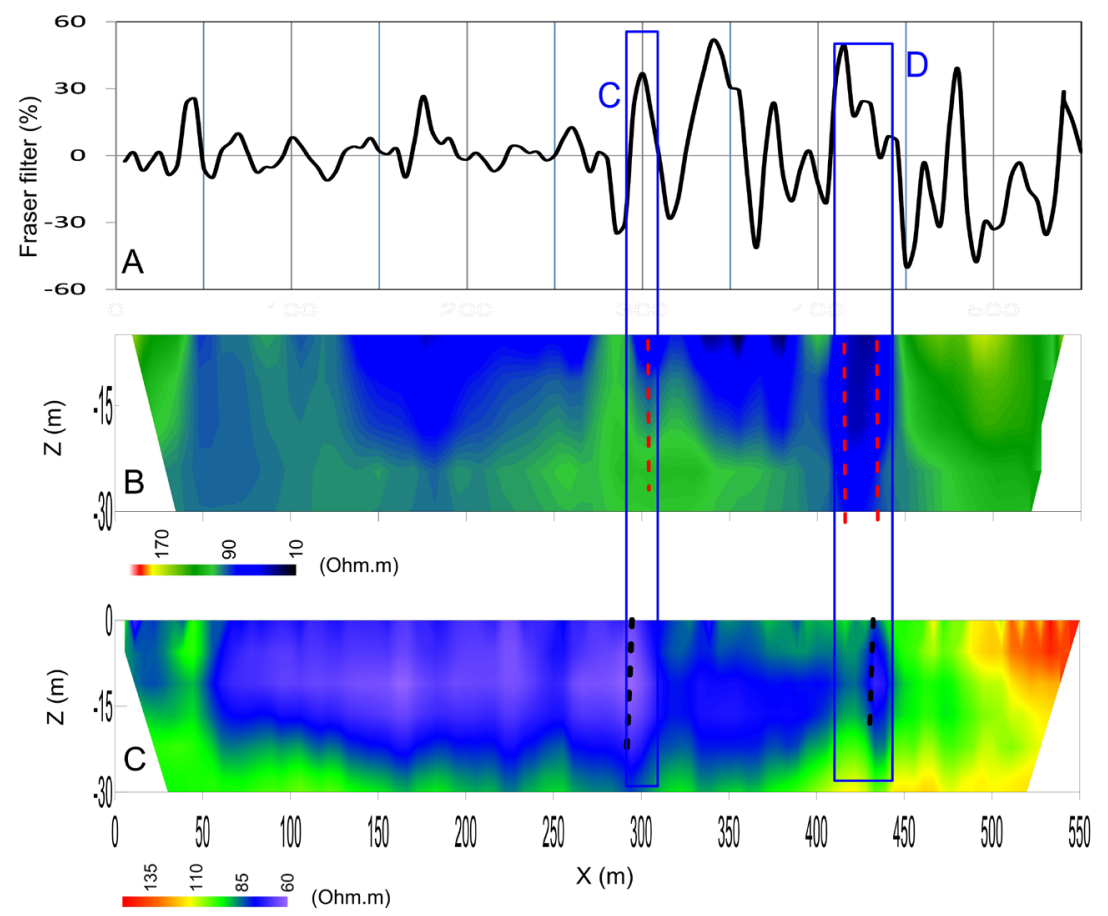

Figure 1.6. Correlation of the VLF Fraser filtered in-phase data (A) to its inverted section (B) and a section of the $2 D$-ER profile (C). Although apparent resistivity values are quite different for both inverted and raw data sections, they are correlated. Boxes labeled $C$ and $D$ in graph $A$ indicated the highest positive anomalies on the Fraser filtered profile and show how they are displayed on the $V L F$-EM inverted and on the $2 D$-ER sections. 


\title{
PAPER 3. DEVELOPING A CONCEPTUAL HYDROGEOLOGICAL MODEL FOR A MOUNTAINOUS VOLCANIC AQUIFER IN ECUADOR, BASED ON A MULTIDISCIPLINARY APPROACH
}

\author{
Miriam Rios-Sanchez, John S. Gierke, Ann L. Maclean, Carla Manciati, \\ Rüdiguer Escobar-Wolf, Remigio Galárraga
}

Rios-Sanchez et al. (2012b) described how the hydrology of the subterranean flow in aquifers of the Plateaus Region are being affected by faulting and fracturing. The effects of faulting and fracturing on groundwater flows were evaluated through pumping-test data evaluation, hydrochemical and isotopedata interpretation, static water levels in wells and spring-discharge elevations, and analysis of tectonic influences on the topography. This work provides additional insight into the groundwater flow arrangement into the local and sub-regional flow systems of the Plateaus Region. It builds on the information derived from the geophysical investigations (Rios-Sanchez and Gierke 2012) and the remote sensing and digital terrain analysis (RiosSanchez et al. 2012c) for lineament mapping.

The use of tectonic indicators (such as observation of fractures on the field, river bends, saddles) and the topological relationships between N-NW and ESW trending lineaments were used as evidence of faulting $\mathrm{n}$ the Plateaus Region. The multifaceted approach applied in this study aimed to build up independent indirect evidence of the impact of tectonism in the plateaus. The evidence was collected, compiled, and synthesized in an attempt to develop a more complete conceptual understanding of flow systems in these complex terrains.

The main findings from the complementary data in this paper include: 
Major Finding 8. Secondary permeability is developed in the aquifers due to faulting and fracturing.

The association of springs and clusters of springs to fractures on the plateaus indicates that these fractures are acting as preferential flow zones. This fact provides evidence of the development of secondary permeability in the aquifer and the effect that that secondary permeability is exerting on the natural discharge of the aquifers. Moreover, qualitative interpretations of timedrawdown and time-drawdown-derivative curves from pumping test data indicate that the curve types reflect a double-porosity aquifer. However, evidence of constant-head boundaries or leaky conditions is observed on short-duration pumping tests. The constant-head boundary might reflect the existence of vertical preferential flow through vertical fractures. Those vertical fractures are indicated on the electrical resistivity profiles (RiosSanchez and Gierke 2012).

Major Finding 9. Faulting and fracturing are controlling the development of sub-regional and local flow systems.

Groundwater flow generally follows the NW regional topographic gradient, which is believed to be influenced by the orientation of the San Pedro Fault (SPF). Due to dissection and the tilting of the plateaus (caused in part by the existence of NW structures), groundwater is partially discharged into the walls of the ravines and forms shallow local flow systems. The groundwater flow following the regional topographic trend is considered to be forming intermediate flow systems consistent with characterizations made in similar work by Toth (2009). 
The general flow system is depicted in Figure 1.7. The flow that continues towards the San Pedro River is a comprised of parts of several local flow systems that form a sub-regional flow system.

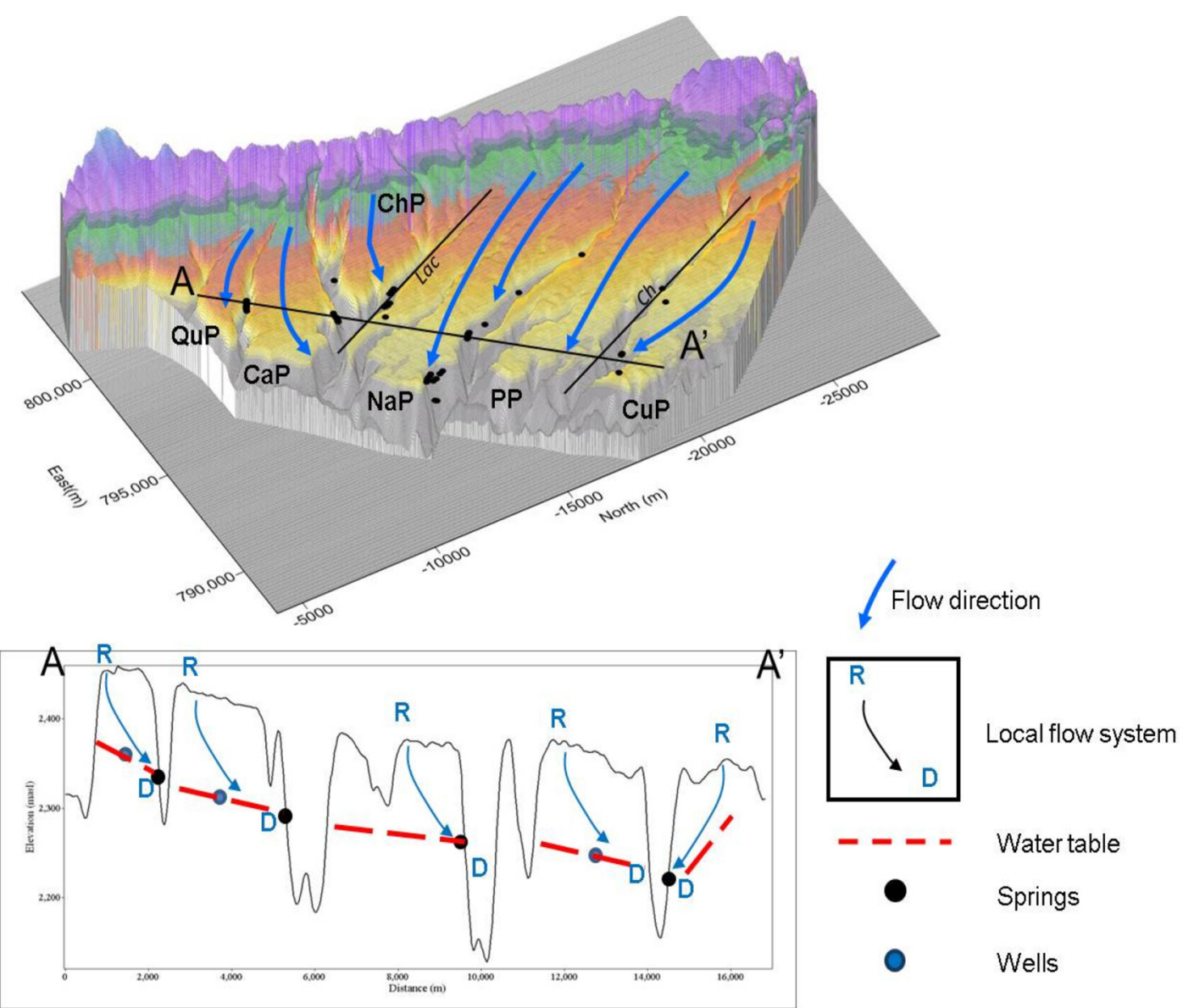

Figure 1.7: Three-dimensional conceptual model of the groundwater flow in the Plateaus Region. Lower graph displays a scheme of flow in two-plateau cross section (Quinche and Caleras), indicating the elevation of the water table (in red), the location of two wells (in orange) and the location of spring clusters. The names of the geological formations are: CF (Cangahua Formation), CHF (Chiche Formation) and GUF (Guayllabamba Formation). 3D relief map created from an ASTER GDEM, a product of METI and NASA 


\title{
PROCEEDINGS PAPER 2. INFLUENCE OF TECTONICS AND TOPOGRAPHY ON THE HYDROGEOLOGY OF THE QUITO AQUIFER SYSTEM $^{2}$
}

\author{
Miriam Rios-Sanchez, John S. Gierke, Teresa Muñoz, Oscar Larrea
}

Rios-Sanchez et al. (2012d) describe the relation between the tectonics and the regional hydrogeological configuration of the QAS. To establish these relationships, the authors explored the occurrence of springs associated with tectonic features. It was found that $54 \%$ of the springs are related to a fracture or fault. Moreover, existing piezometric data was processed and interpreted to generate a flow-direction map. The lineament map was overlain on the flow-direction map order identify tectonic features that were coincident to either a discharge area or groundwater divide.

Major Finding 10. The configuration of groundwater flow within the $Q A S$ is mainly defined by the topography of its perimeter (due to the occurrence of numerous volcanoes) and the existence of faults and lineaments.

Eight flow systems were mapped for the collective QAS, as illustrated in Figure 1.8. On that figure one can observe that most of the boundaries of these flow systems are related to tectonic features. Moreover, surface hydrology is also controlled to a large extent by the drainage network that is seemingly correlated to the tectonic features.

Not the whole QAS area had enough information to characterize the regional flow. Areas lacking piezometric data are located on the southeastern Pita

2 Published as." Influencia de la Tectónica y la Topografía en la Hidrogeología del Sistema Acuífero de Quito (SAQ)". IX Latin American Conference of Hydrogeology, Cartagena -Colombia. 2012. Translation of the whole document found on Appendix II 


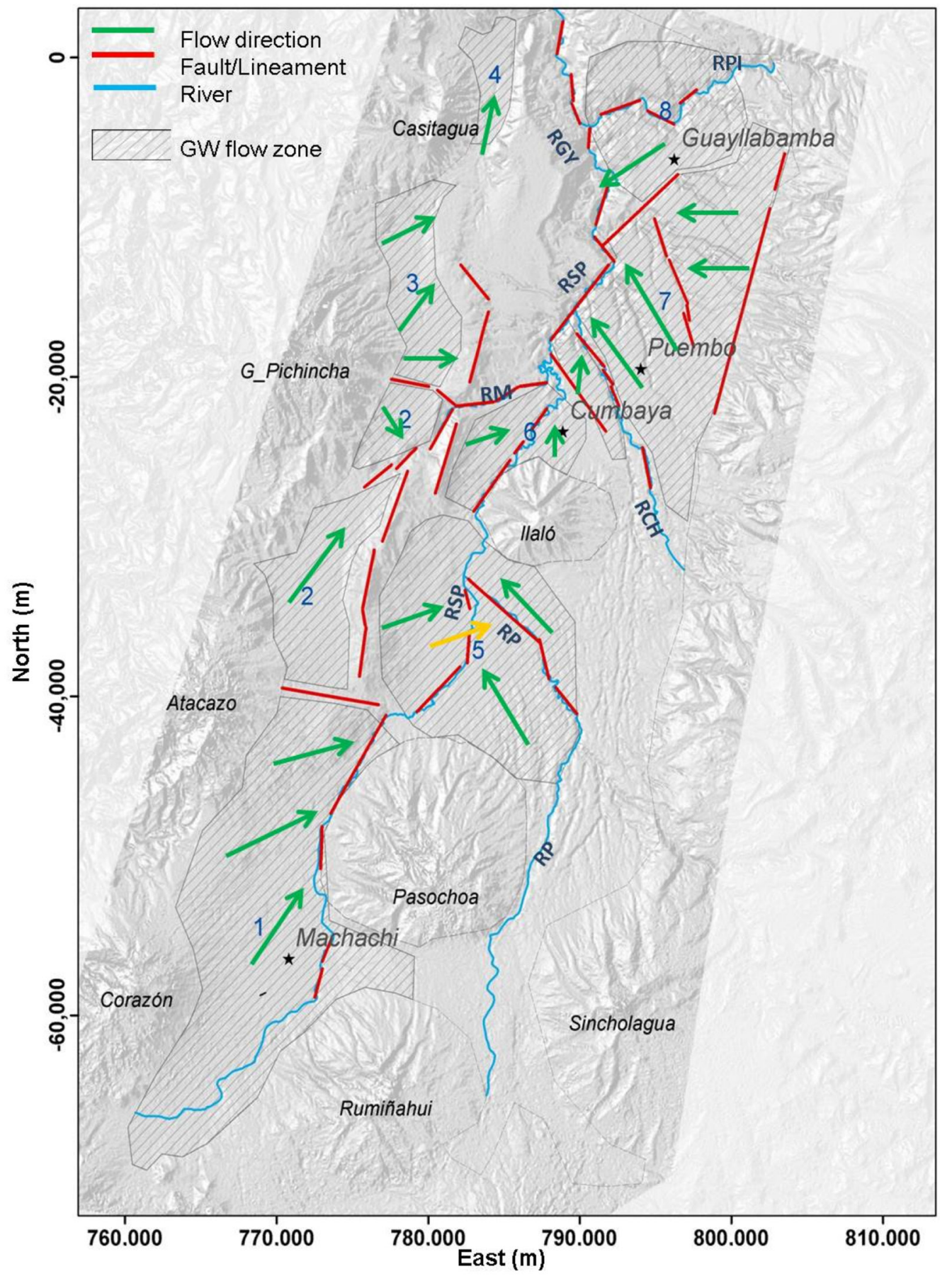

Figure 1.8. Ground water flow systems in the $Q A S$ and their relationship to tectonic features and the main rivers. Map base layer is a hillshade derived from a $30-\mathrm{m}$ ASTER DEM (product of METI and NASA). 
River; the area located east of zone 5; and the Catequila Plateau (between zones 3 and 8). The Guayllabamba Depression (zone 8) needs more information to verify the accuracy of the proposed flow system. The roles of the faults have yet to be verified.

Major Finding 11. Mostly flow systems identified for the $Q A S$ are local flow systems, except for the Plateaus Region, which also has sub-regional flow systems.

The analysis of the groundwater flow-direction map (Figure 1.8) indicates that the flows occurring within the QAS can be considered as local flow systems since the discharge areas immediately follow the recharge areas, meaning there are no other flow systems in the middle.

\section{CONCLUSIONS}

The methodologies used in this research project systematically identify and characterize faults and fractures of the Quito Aquifer System (QAS), Ecuador. At the regional scale, techniques were employed to map regional lineaments of geological origin and classify them as faults or fractures in order to better understand the morphological development of the area. Through the process of assessing the influence of these features, the configuration of the groundwater flow of the QAS was achieved

At the local level for the Plateaus Region of the QAS, additional conventional hydrogeological-characterization and shallow geophysical techniques were applied to create a detailed lineament map, distinguishing lineaments as faults or fractures. A three dimensional characterization of the aquifer layers was developed. These investigations together provide more information to 
support the assertion that the secondary permeability is developed in the aquifers of the Plateaus due to faulting and fracturing. Moreover a more detailed conceptualization of the groundwater flow was achieved.

This project has demonstrated that using both remote sensing and digital terrain techniques in tandem increases the level of detail and number of linear features that can be identified in a tectonically active area. This was achieved not only at the regional scale but also for more detailed mapping at the local scale. Additionally, digital terrain models were able to provide a three-dimensional perspective; thereby increasing the overall understanding of the aquifer system.

Because this aquifer system is positioned in mountainous volcanic terrain, it is important to be cognizant of the interconnected nature of tectonics and topography. Both play important roles in the configuration of the surface and underground hydrology. Any hydrogeological analysis undertaken in these types of terrains should include a thorough characterization of the topography, the tectonic setting, and their impact on existing aquifers.

\section{RECOMMENDATIOS FOR FUTURE WORK}

Based on these research findings, several additional studies are recommended to verify the conceptualization of the aquifer system and some of the boundaries that are considered the most important for the groundwater flow systems in the QAS.

Regional level:

- Investigate the role of the Catequila Plateau on the hydrogeology of the region. The Catequila Plateau is located to the east of Quito city 
and to the north of the Cumbaya and Puembo Plateaus. Flow trends indicate discharge toward the Catequila Plateau, however, there is little information on the physical characteristics of this plateau and the amount of groundwater resources that exist in it and its influence on the recharge of the aquifer in the southern San Antonio valley.

- Investigate the groundwater flow direction and conditions in the Tumbaco-Cumbaya area through a dense water monitoring network. The area represents a convergence of several flow systems. Detailed characterization of the flow in this part of the aquifer is key to understanding the connection between the main flows and the hydrologic role of the main tectonic features, such as the San Pedro Machangara and Quito faults

- Develop research projects to assess the role of the streams and associated faults (or lineaments) that were defined as exfiltration zones. Nighttime thermal ASTER images are excellent candidates to identify the exfiltration zones and narrow the areas for experimental studies.

- Further investigate the role of the Quito fault as a water divide or permeable feature that is acting as a recharge area for flow zones located to the east.

- Create a more detailed water-level monitoring network to improve the detail of flow maps used to define flow systems.

- Broaden the study area in order to identify and characterize hydrologically regional features that extend beyond the QAS boundaries.

- Increase the level of detail of the lineament map, particularly for the Guayllabamba Depression. This zone is one of the most tectonically 
complex parts of the QAS and the detailed mapping approach used for the plateaus may aid in the understanding of the hydrogeology of this important region.

Local level (i.e., the Plateaus Region)

- Carry out further geophysical studies on the plateaus to better define the spatial extension of the "fractured zones" identified through geophysical methods and that were not correlated to lineaments mapped with the RSA/DTA approach.

- Characterize the flow in the unsaturated zone of the plateaus, and the fracture zone affecting the unsaturated and saturated zones. The fractured zones are most likely representations of vertical preferential flow paths and concentrated recharge zones. Verifying the existence and distribution of those flow paths throughout the plateaus region is of paramount importance. The existence of those preferential flow paths has enormous implications on how recharge and contaminants reach the aquifer.

- Evaluate the aquifer characteristics below the plateaus morphology (below river levels). It is postulated that the aquifer layers in this zone are spatially continuous and are a part of the intermediate flow system; a condition more favorable for the development of groundwater resources.

- Investigate the role of the N-NW/S-SE trending fractures and lineaments on the hydrogeology of the plateaus. There is little evidence to illustrate how they are affecting the intermediate flow systems.

- Use VLF-EM or 2D electrical methods as part of hydrogeological investigations of the Plateaus Region. These methods prove more 
effective than VES to determine lateral and vertical changes in the properties of the aquifer related to electrical resistivity.

\section{REFERENCES CITED}

Anton, D. J. (1993). Thirsty Cities, urban environments and water supply in Latin America. IDRC, The International Development Research Centre, Canada.

Argialas, D. P. and O. D. Mavrantza (2009). Comparison of edge detection and Hough transformation techniques for the extraction of geologic features.

Becker, M. W. (2006). "Potential for satellite remote sensing of groundwater." Groundwater 44(2): 12.

Bruning, J. N., Gierke, J. S., Maclean and A. L. (2011). "An approach to lineament analysis for groundwater exploration in Nicaragua." Photogrammetric engineering and remote sensing 77(5): 11.

Brunner, B., H.-J. H. Franssen, L. Kgothlang, P. Bauer-Gottwein and W. Kinzelbach (2007). "How can remote sensing contribute in groundwater modeling." Hydrogeology Journal 15: 13.

Centamore, E., S. Ciccacci, M. Del Monte, P. Fredi and E. Lupia Palmieri (1996). "Morphological and morphometric approach to the study of the structural arrangement of northeastern Abruzzo (central Italy)." Geomorphology 16(2): 127-137.

El-Baz, F. (1995). Utilizing satellite images for groundwater exploration in fractured zones aquifers. Water Resources Management in Arid Countries. Muscat: 9.

Grohmann, C. H., C. Riccomini and F. M. Alves (2007). "SRTM-based morphotectonic analysis of the Poços de Caldas Alkaline Massif, southeastern Brazil." Computers \& Geosciences 33(1): 10-19.

Henderson, D. B., D. A. Ferrill and K. C. Clarke (1996). Mapping geological faults using image processing techniques applied to hill-shaded digital elevation models. Image Analysis and Interpretation, 1996., Proceedings of the IEEE Southwest Symposium

Hoffmann, J. (2005). "The future of satellite remote sensing in hydrogeology." Hydrogeology Journal 13(1): 247-250.

Jordan, G., B. M. L. Meijninger, D. J. J. v. Hinsbergen, J. E. Meulenkamp and P. M. v. Dijk (2005). "Extraction of morphotectonic features from DEMs: Development and applications for study areas in Hungary and NW Greece." International Journal of Applied Earth Observation and Geoinformation 7(3): 163-182.

MacMillan, R. A., D. H. McNabb and R. K. Jones (2000). Automated landform classification using DEMs: a conceptual framework for a multi-level, 
hierarchy of hydrologically and geomorphologicaly oriented physiographic mapping units.

Meijerink, A. M. J., D. Bannert, O. Batelaan, M. W. Lubczynski and T. Pointet (2007). Remote sensing applications to groundwater. Paris, UNESCO.

Onorati, G., R. Ventura, M. Poscolieri, V. Chiarini and U. Crucillà (1992). "The Digital Elevation Model of Italy for geomorphology and structural geology." CATENA 19(2): 147-178.

OSS (2008). GEO-AQUIFER. Monitoring and suistainable management of the transboundary groundwater resources of the North-Western Sahara Aquifer System using satellite imagery. S. a. S. Observatory. Tunis, TIGER AFRICA. 09.

Ricchetti, E. (2002). Structural geological study of Southern Apennine (Italy) using Landsat 7 imagery. Geoscience and Remote Sensing Symposium, 2002. IGARSS '02. 2002 IEEE International.

Rios-Sanchez, M. and J. Gierke (2012). Geophysical methods for fracture detection on mountainous volcanic aquifers of the plateaus area, Quito Ecuador. . Houghton, Michigan Technological University.

Rios-Sanchez, M., J. Gierke and A. L. MacLean (2012a). Utilizing digital image processing techniques to identify and characterize fracture patterns in the Quito, Ecuador aquifer system. Houghton, MI, Michigan Technological University.

Rios-Sanchez, M., J. Gierke, A. L. MacLean, C. Manciati, R. Escobar-Wolf and R. Galárraga (2012b). Developing a conceptual hydrogeological model for a mountainous volcanic aquifer in Ecuador, based on a multidisciplinary approach. Houghton, Michigan Technological University.

Rios-Sanchez, M., J. Gierke and T. Muñoz-Martínez (2012c). Hydrogeological characterization of the Plateaus region of the Quito Aquifer System using remote sensing, digital geomorphology, and geophysics. . 2012 World Environmental and Water Resources Congress, Albuquerque,New Mexico.

Rios-Sanchez, M., J. Gierke, T. Muñoz-Martinez and O. Larrea (2012d). Impactos de la tectónica y la topografía en la hidrogeología del Sistema Acuifero de Quito XI Congreso Latinoamericano de Hidrogeologia, Cartagena ALHSUD.

Saadi, N. M., E. Aboud and K. Watanabe (2009). "Integration of DEM, ETM+, geologic, and magnetic data for geological investigations in the Jifara Plain, Libya." Geoscience and Remote Sensing, IEEE Transactions on 47(10): 33893398.

Seta, M. D., M. D. Monte, P. Fredi and E. L. Palmieri (2004). "Quantitative morphotectonic analysis as a tool for detecting deformation patterns in softrock terrains: a case study from the southern Marches, Italy / Analyse morphotectonique quantitative dans une province lithologique enregistrant 
mal les déformations : les Marches méridionales, Italie." Géomorphologie : relief, processus, environnement: 267-284.

Siart, C., O. Bubenzer and B. Eitel (2009). "Combining digital elevation data (SRTM/ASTER), high resolution satellite imagery (Quickbird) and GIS for geomorphological mapping: A multi-component case study on Mediterranean karst in Central Crete." Geomorphology 112(1-2): 106-121.

Solomon, S. and F. Quiel (2006). "Groundwater study using remote sensing and geographic information systems (GIS) in the central highlands of Eritrea." Hydrogeology Journal 14: 12 .

Thurmond, A. K., M. G. Abdelsalam and J. B. Thurmond (2006). "Optical-radarDEM remote sensing data integration for geological mapping in the Afar Depression, Ethiopia." Journal of African Earth Sciences 44(2): 119-134.

Toth, J. (2009). Gravitational systems of groundwater flow: theory, evaluation, utilization. New York, Cambridge University Press.

UNESCO-IGP-IUGS (2012). International Geoscience Program. Paris

UNESCO-IHP (2008). Groundwater resources assessment under the pressures of humanity and climate changes: GRAPHIC; a framework document. GRAPHIC series; 2 Paris.

UNESCO-IHP (2010). Application of satellite remote sensing to support water resources management in Africa: Results from the TIGER Initiative. Technical Documents in Hydrology. I. H. P. UNESCO, ESA. Paris. IHP-VII.

Villagomez, D. (2003). Evolución geológica Plio-cuaternaria del Valle Interandino Central en Ecuador (Zona de Quito-Guayllabamba-San Antonio). Escuela de Ingeniería. Quito, Escuela Politécnica Nacional. Ing. Geólogo.

Zektser, I. S. and L. G. Everett (2004). Groundwater resources of the world and their use. Paris, UNESCO. 


\title{
PAPER 1. UTILIZING DIGITAL IMAGE PROCESSING TECHNIQUES TO IDENTIFY AND CHARACTERIZE FRACTURE PATTERNS IN THE QUITO, ECUADOR AQUIFER SYSTEM ${ }^{3}$
}

\author{
Miriam Rios-Sanchez ${ }^{1}$, John S. Gierke ${ }^{1}$, Ann L. Maclean² \\ ${ }^{1}$ Department of Geological and Mining Engineering and Sciences, \\ Michigan Technological University, 1400 Townsend Dr., Houghton, MI \\ 499311
}

${ }^{2}$ School of Forest Resources and Environmental Science, Michigan

Technological University, 1400 Townsend Dr., Houghton, MI 499311

\begin{abstract}
Lineament analysis using satellite imagery and digital elevation models (DEMs) are the most common tools to map geological structures including faults, fractures and discontinuities, for different purposes such as hydrogeological studies, geomorphology and oil exploration. However, research has not been completed establishing if one method is superior to the other or if a hybrid approach is needed. This paper evaluates an approach for merging the results of fracture networks delineations from satellite imagery with those from digital terrain data analysis. The study site is the Quito Aquifer System, located in the Central Inter-Andean Valley of Ecuador, an area affected by active volcanism and faulting and characterized by basins filled with series of volcanic deposits and primary and reworked sedimentary rocks. A lineament map utilizing image processing techniques and coincidence analysis was merged with one created from digital terrain analysis tools (DTA). The approach uses satellite imagery (RADARSAT-1, Landsat TM and ETM+, ASTER). The input into DTA analysis was a $30-\mathrm{m}$ spatial resolution DEM. The combined approach used in this study is an efficient method to map lineaments over large areas, under non-ideal conditions. More lineaments and more detailed tectonic features were
\end{abstract}

${ }^{3}$ Paper in process for submitting to the International Journal of Applied Earth Observation and Geoinformation 
mapped using the combined method compared to other studies carried out in the same geographic area.

Keywords: Lineament analysis, digital image processing, digital elevation model, coincidence analysis, Ecuador

\section{INTRODUCTION}

Lineament analysis using satellite imagery and digital elevation models (DEMs) is one of the most common tools to map geological structures including faults, fractures and discontinuities, for hydrogeological studies, geomorphology and oil exploration. Linear features are the surface expression of fractures, faults, or other types of geological discontinuities (Mabee et al. 1994). These discontinuities superimpose secondary effects on the primary properties of rocks by creating zones of preferential infiltration and exfiltration as well as barriers to groundwater flow (Bisson and Lehr 2004; Bruning et al. 2011; Vsevolozhskii et al. 2001). Various approaches have been developed for lineament mapping using satellite images and DEMs; however, there are no systematic assessments of how well the approaches compare.

Lineaments are expressed as surface-feature patterns such as drainage alignments, linear topographic trends, and vegetation anomalies (Bruning et al. 2011b; Vsevolozhskii et al. 2001). In satellite imagery, lineaments are observed as sharp linear changes in tone, color and texture (Bruning et al. 2011). Single or combined bands of Landsat TM (Thematic Mapper) or ETM+ ( Enhanced Thematic Mapper Plus) were used to map geological units and lineaments (Ricchetti 2002; Shaban et al. 2006). Digital image processing procedures, such as intensity-hue-saturation (IHS), and de-correlation stretching (DS) have been used to map geological units or to find subtle differences within units. Moreover, directional filters were applied to singleband combinations to enhance features for mapping lineaments (Solomon and 
Quiel 2006). Advanced Spaceborne Thermal Emission and Reflection Radiometer (ASTER) images were also used by combining different bands and performing basic digital image processes (Peña and Abdelsalam 2006; Saud 2008).

Applications of radar imagery to geological characterization include the identification of geological structures in the tropics by comparing the performance of two different synthetic aperture radar (SAR) beam modes (Paradella et al. 2000). Buried structures were mapped while evaluating the performance of $\mathrm{C}$ and $\mathrm{L}$ bands of Spaceborne Imaging Radar (SIR) (Paillou et al. 2003). Combined Landsat TM and Radar (JERS-1, Japanese Earth Resource Satellite 1 and SAR L-Band, Synthetic Aperture Radar) were used for geological mapping in Madagascar to characterize structural geology features (Inzana et al. 2003) .

Landsat ETM+ and, ASTER were used to map geological structures in Tunisia (Peña and Abdelsalam 2006) by using band combinations of the visible, short, and near-infrared parts of the electromagnetic spectrum. RADARSAT was used to map buried structures and combined with ASTER and LANDSAT ETM+ to improve the delimitation of geological units and structures in southern Tunisia (Peña and Abdelsalam 2006).

Bruning et al. (2011) noted that many lineament analyses using satellite imagery and digital image processing were performed on areas with ideal conditions in which meteorological conditions, vegetation, and human development did not interfere with feature delineation. They demonstrated an integrated approach to map lineaments in non-ideal conditions, where 
extensive vegetation and anthropogenic features were present and frequent cloud cover limited the availability of satellite data.

Bruning et al. (2011) developed an approach named coincidence analysis in order to create an effective and efficient method for lineament mapping for groundwater exploration in volcanic terrains. The coincidence analysis was carried out using several types of remotely sensed imagery (ASTER, QuickBird, LANDSAT ETM+, RADARSAT-1). Various digital image processing techniques were performed on the imagery. The outcomes were evaluated according to their ability to display lineaments. Twelve digital products were selected and lineaments were mapped on each of them. These twelve lineament interpretations were synthesized to create a raster image of lineament-zone coincidence in order to present the level of agreement among the different interpretations. A final map was achieved by restricting mapped lineaments to those that were coincident in at least 4 interpretations.

Digital terrain analysis has been used broadly for lineament analysis, as part of tectonic studies and hydrogeological assessment (Florinsky 1996; Grohmann et al. 2007; Jordan et al. 2005). Lineaments observed in DEMs are morphological features, as result of the intersection of a fault/fracture plane with the land surface. Examples of these features are linear valleys, ridgelines, and slope breaks. Planar features were originated from faults and fractures as well (Arenas 2006; Jordan et al. 2005; Onorati et al. 1992). Faulting can also cause changes in stream courses, such as deflection and offsetting, which indicate the direction of relative fault displacement. Other indicators of tectonic activity observed in DEMs are saddles, scarps, and triangular facets (Keller and Pinter 1996; SETA et al. 2004a). Although most linear features found in a DEM are attributed to faulting and fracturing 
(Sang-Ho and Moon 2001), some can be due instead to bedding and lithological contacts (Way 1973).

Digitally derived products, such as hillshade maps at different illumination angles and shaded relief models, are commonly used to identify lineaments. For morphological analysis, visual interpretations are done by using contour maps, grey-scale maps, and shaded-relief images. For quantitative purposes, the analysis includes numerical differential geometry using slope and aspect maps as well as -derivative maps (Henderson et al. 1996; Jordan et al. 2005). Moreover, analysis of morphotectonic features and other processes in quantitative geomorphic analysis have been done in areas of soft rocks, in which the rocks do not always display tectonic deformations (SETA et al. 2004a). Jordan et al. (2005) proposed a systematic procedure for the mapping of tectonic features (including lineaments) associated with faults based on morphotectonic terrain analysis.

The combination of DEMs and satellite imagery has been used for lineament analysis and morphological classifications. Automatic lineament mapping using the Canny algorithm (Canny 1986) was performed on Landsat TM images (Marghany and Hashim 2010). Lineaments were then compared to those observed in a 3-dimensional (3-D) view of the same area created from a SRTM DEM and Landsat Bands 2-4. Digitally processed images from the Indian Remote Sensing Satellite (IRS) were used to map geomorphological units and lineaments (Dar et al. 2010). Also, DEMs were used to map regional scale lineaments. The final lineament map was obtained by combining both maps and editing duplicates. Combinations of Landsat ETM+ and ASTER bands with DEMs were used to map tectonic structures on parts of the Afar Triangle (Thurmond et al. 2006). Landsat ETM+ and DEMs were 
used to map geological units and faults in the Jifara Plain, Libya (Saadi et al. 2009).

Considering that (1) Bruning et al. (2011) have proposed a new approach for image-processing/synthesis to identify successful satellite imagery types for lineament analysis in non-ideal terrain (2) Jordan et al. (2005) have proposed a systematic procedure for mapping of tectonic features (including lineaments) associated with faults based on morphotectonic terrain analysis and (3) there are no systematic assessments of how well the approaches compare an combined approach of the two methodologies is necessary to assess the performance of each method and establish is they are equivalent or one approach is superior over the other.

This paper discusses the remote sensing and digital terrain analysis approaches used to map the fracture networks existing in the Quito Aquifer System based on the methods proposed by Bruning et al. (2011) and Jordan et al. (2005) A lineament map created from a remote sensing-based protocol (RSA) was combined with one created with digital terrain analysis tools (DTA) to create a composite lineament map that characterizes fracture networks on volcanic terrains. The protocol is tested using satellite imagery (RADARSAT-1, Landsat TM and ETM+, ASTER). The DTA analysis includes digital derived products from a 30-m DEM.

\section{Study Site}

Volcanic aquifers in mountainous areas of Central and South America offer unique opportunities to develop, apply, and validate remote sensing and DEM methods for lineament analysis. This type of terrain is located in tectonically active regions where the morphology is significantly affected by 
faulting and surface and subsurface hydrology are controlled in large part by regional structural features in the bedrock that influence the volume of water stored and transmitted underground. The study area is part of the Quito Aquifer System (QAS), which comprises most of the Quito metropolitan area in Ecuador, South America (Figure 2.1). The QAS is located on the so-called Central Inter-Andean Valley (CIAV), which is a large and complex tectonic basin, situated between the Cordillera Occidental and Cordillera Real in Northern Ecuador.

\section{METHODS}

Imagery was obtained from Landsat (TM and EMT+) and ASTER (day and night). RADARSAT- 1 images were selected with at least one ascending and one descending orbit. The list of images used, dates and data sources are listed in Table 2.1. The DEM was derived from ASTER GMT files, with a 30m spatial resolution (Table 2.1).

\section{IMAGE PREPROCESSING:}

For Landsat images (TM and ETM+) statistics for individual bands were calculated to verify the data follow a normal distribution, since most of the digital processes and analysis are based on that principle. Atmospheric correction was applied to eliminate haze due to scattering caused by the presence of gases in the atmosphere (Hadjimitsis et al. 2004; Liang et al. 2001). The Darkest Pixel Method (Hadjimitsis et al. 2004) was used on bands blue, green and red, which were the bands affected by scattering. 


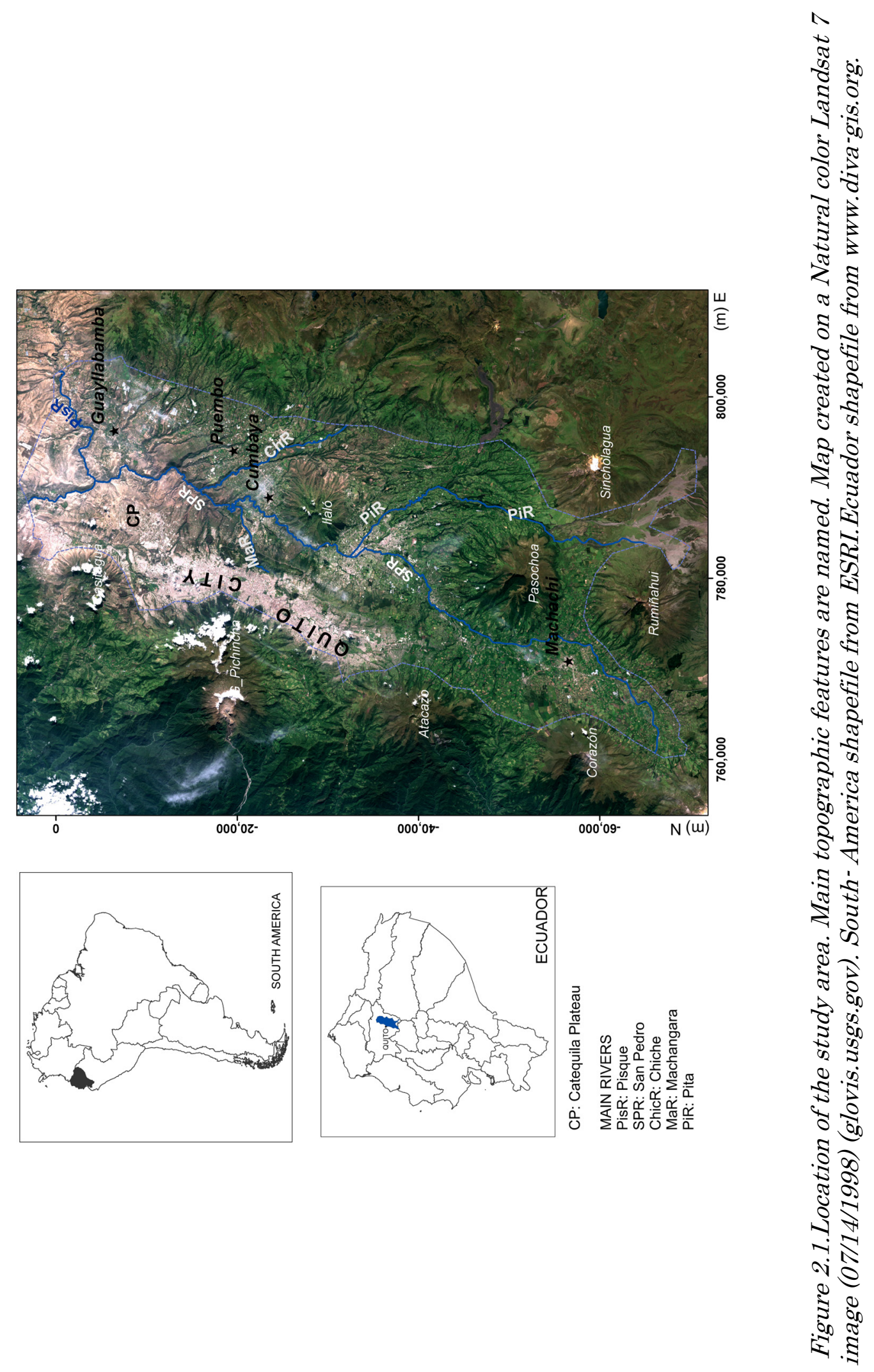


Table 2.1 Satellite images and DEMS used in the study

\begin{tabular}{|c|c|c|c|c|}
\hline TYPE & DATE & ID & SOURCE & $\begin{array}{c}\text { OBSERVATIO } \\
\text { NS }\end{array}$ \\
\hline LANDSAT TM & $7 / 14 / 1998$ & L5_010060 & \multirow[t]{2}{*}{$\begin{array}{l}\text { Global Land } \\
\text { Cover Facility }\end{array}$} & \\
\hline $\begin{array}{l}\text { LANDSAT } \\
\text { ETM+ }\end{array}$ & $6 / 2 / 2002$ & L7_1010060 & & \\
\hline \multirow{6}{*}{ ASTER } & $2 / 2 / 2010$ & $27766 \& 27405$ & \multirow{6}{*}{$\begin{array}{l}\text { LPDAAC- } \\
\text { NASA }\end{array}$} & \multirow{4}{*}{ Night image } \\
\hline & $4 / 23 / 2010$ & $27211 \& 27206$ & & \\
\hline & $1 / 1 / 2010$ & $27393 \& 27398$ & & \\
\hline & $9 / 7 / 2005$ & 18830 & & \\
\hline & $2 / 5 / 2007$ & 27221 & & \multirow{2}{*}{ Day Images } \\
\hline & $10 / 2 / 2001$ & 17760 & & \\
\hline \multirow[t]{3}{*}{ RADARSAT } & $3 / 21 / 2003$ & $\begin{array}{c}\text { R138500451G1S0 } \\
01\end{array}$ & \multirow{3}{*}{$\begin{array}{l}\text { Alaska } \\
\text { Satellite } \\
\text { Facility }\end{array}$} & $\begin{array}{l}\text { Descending } \\
\text { orbit }\end{array}$ \\
\hline & $\begin{array}{c}10 / 14 / 200 \\
0\end{array}$ & $\begin{array}{c}\text { R125816899G1S0 } \\
01\end{array}$ & & Ascending orbit \\
\hline & 4/16/1998 & $\begin{array}{c}\text { R1127882899g1s0 } \\
01\end{array}$ & & Ascending orbit \\
\hline DEM & & $\begin{array}{c}\text { S01W78, S00W79 } \\
\& \text { S01W79 }\end{array}$ & $\begin{array}{l}\text { LPDAAC- } \\
\text { NASA }\end{array}$ & \\
\hline
\end{tabular}

Composite images were created from the corrected bands of blue, green and red plus near-infrared and the two short-wave infrared. Also composite images with the aforementioned bands plus the thermal band were created. Erdas Imagine 2011 ${ }^{\circledR}$ V.11.0.2.(Leica Geosystems Geospatial Imaging, Norcross, GA) was used in the imagery pre-processing. RADARSAT-1 images were orthorectified and geo-referenced using the Alaska Satellite Facility MapReady 2.3.17® Tool (2007). For the orthorectification, the ASTER DEM was used. Despeckling was performed on the RADARSAT images to remove the salt-and-pepper texture. However, no major changes in the quality of the images were achieved, and the original images were used for future processing. 
ASTER daytime-image bands were consolidated into two files: one containing bands green, red, and near-infrared and the second containing those three bands plus the six bands of the short-wave infrared and the five bands of the thermal part of the electromagnetic spectrum. The thermal bands of ASTER nighttime images were clipped and mosaicked to create a cloud-free image of the entire area.

The DEM for the area was created by mosaicking three ASTER Global Digital Elevation Model (AST-GDEM) files, listed in Table 2.1. A fill procedure (ESRI@ ArcMap ${ }^{\mathrm{TM}} 10.0$ ESRI, Redlands, CA) was applied to remove errors, expressed as sinks or peaks on the DEM. errors are caused by incorrect elevation values due to missing data and/or the spatial resolution.

All of the images and the DEM were registered to the UTM 17N, WGS 84, coordinate system. A simple X, Y shift was performed on the DEMs and the RADARSAT- 1 and ASTER images to refine geo-locations using the Landsat7 ETM+ as a base map. Based on a qualitative assessment, the Landsat.ETM+ image was chosen as the reference map, considering the accuracy of location of previously thematic maps of the study area.

\section{LINEAMENT MAPPING USING THE REMOTE SENSING ANALYSIS (RSA)}

A wealth of imagery was available for this study (Table 2.1). To efficiently process the data, the amount of data needed to be reduced while retaining as much of the information as possible that would assist in the lineament mapping. Hence a number of image processing enhancements and transformation were carried out. 
Thermal bands of Landsat and ASTER images were included in the digital image processing. Thermal bands display very well the abrupt changes in the topography of the study area (expressing them as rapid changes in the temperature gradient) so it is expected thermal bands have a lot of potential to display linear features of topographic origin. Figure 2.2 depicts examples of thermal bands from ASTER (night) and Landsat EMT+ for the central area of the QAS. Thermal bands from Landsat ETM+ (C and D on Figure 2.2) display very well the general topographic features and linear associated to them (see for example the valleys of the rivers discharging into San Pedro River). ASTER night thermal bands (A and B on Figure 2.2) show more detailed information around the major topographic features (for example, temperature gradients associated to changes in brightness are observed along the course of San Pedro River). Moreover, thermal images have been used to identify groundwater discharge zones along fractured zones, given the changes in radiance associated due to higher temperatures in the discharge areas (Meijerink 1996; Rosenbom and Jakobsen 2005; Shaban et al. 2005).

The panchromatic band was combined with the thermal band of Landsat ETM+ in order to maximize the use of the high spatial resolution of the panchromatic band with the ability of the thermal band to indicate topographic features that might be associated to lineaments.

The product images were visually evaluated according to their ability to display the major geological faults and lineaments on the northeastern part of the region where lineaments and faults have been previously mapped and published. The assessment was carried out for products derived from each type of imagery, aiming to keep at least one digital product of each one, in 
order to take advantage of the different spectral and spatial resolutions and the enhancements provided by the digital image processing. Twelve derived products were selected for using to visually identify and map lineaments.

These products are listed in Table 2.2

Table 2.2 Images selected for the lineament analysis

\begin{tabular}{|c|c|c|c|}
\hline TYPE & DATES & PRODUCT & OBSERVATIONS \\
\hline \multirow[t]{2}{*}{ LANDSAT TM } & \multirow[t]{2}{*}{$7 / 14 / 1998$} & Color composite (Bands 6,5,4) & \\
\hline & & PCA Color composite (PC3, PC2,PC4) & \\
\hline \multirow[t]{2}{*}{ LANDSAT ETM+ } & \multirow[t]{2}{*}{$6 / 2 / 2002$} & I HS $(6,5,4)$ & \\
\hline & & Stacked layers (Bands 6,8) & \\
\hline ASTER - NIGHT & $\begin{array}{l}\text { 2/2/2010, } \\
4 / 23 / 2010, \\
1 / 1 / 2010,9 / 7 / 2005\end{array}$ & False color image & $\begin{array}{l}\text { Mosaic of cloud } \\
\text { free clipped } \\
\text { areas. }\end{array}$ \\
\hline \multirow[t]{2}{*}{ ASTER-DAY } & \multirow[t]{2}{*}{$2 / 5 / 07 \& 10 / 2 / 01$} & PCA color composite (PC3,PC2, PC1) & \\
\hline & & Color composite (Bands $3 \mathrm{~A}, 2,1$ ) & \\
\hline \multirow[t]{4}{*}{ RADARSAT } & \multirow[t]{2}{*}{$3 / 21 / 2003$} & Gray scale image & \\
\hline & & Edge enhancement & \\
\hline & \multirow[t]{2}{*}{$10 / 14 / 00 \& 4 / 16 / 98$} & Gray scale image & \\
\hline & & Edge enhancement & \\
\hline $\begin{array}{l}\text { RADAR AND } \\
\text { LANDSAT 7- } \\
\text { PCA1 }\end{array}$ & $\begin{array}{l}10 / 14 / 2000 \& \\
06 / 02 / 2002\end{array}$ & $\begin{array}{l}\text { Radarsat } 10 / 14 / 2000 \text { merged with } \\
\text { thePCA1 of the Landsat } 7\end{array}$ & \\
\hline
\end{tabular}




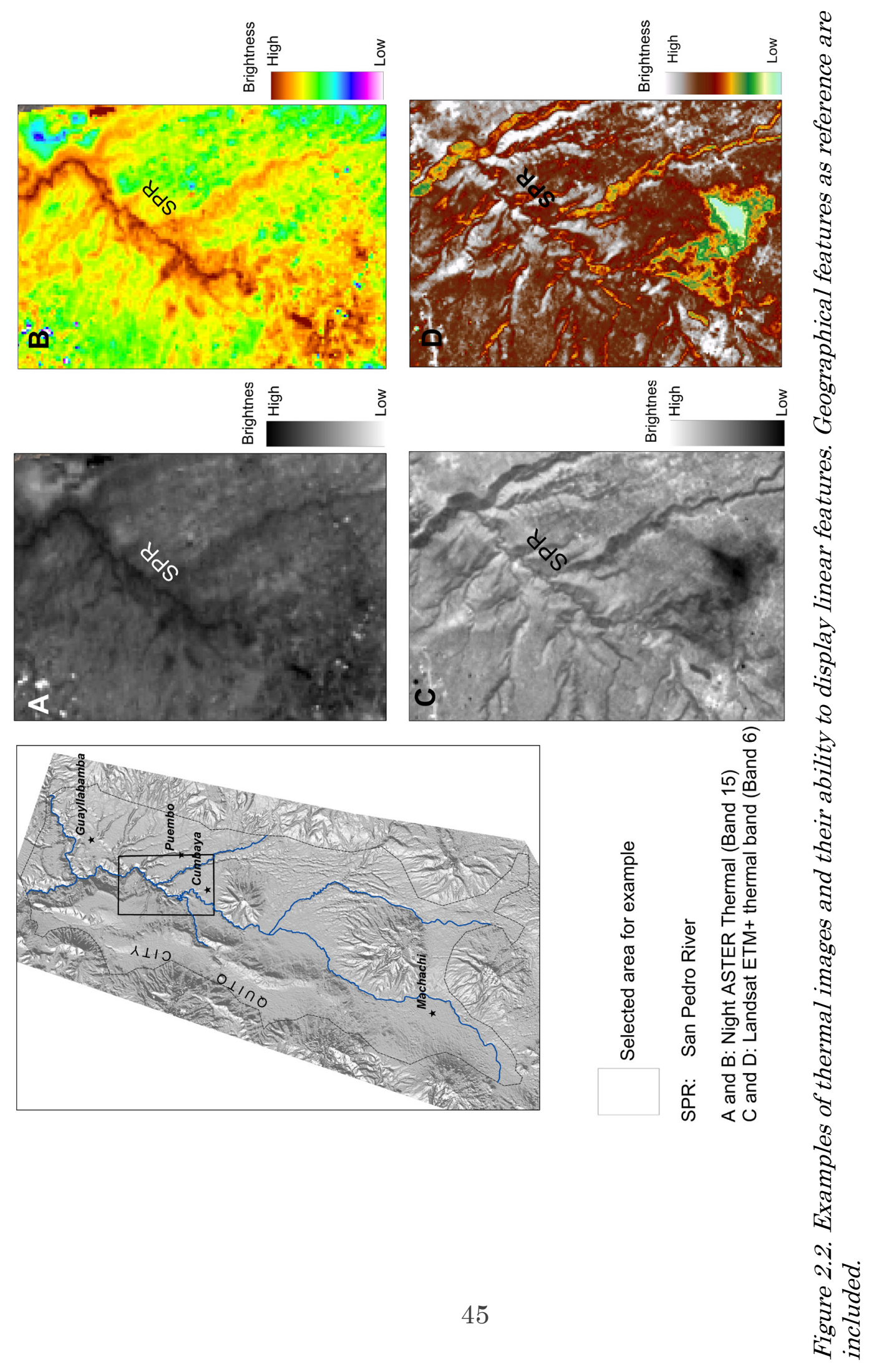




\section{Main characteristics of the images selected for lineament mapping}

The near-infrared and short-wave infrared band of Landsat TM display clearly the relief and the lineaments associated to drainages and changes in lithology. In fact this band combination has been largely used for geological mapping ((NASA/USGS 2012; Peña and Abdelsalam 2006; Ricchetti and Palombella 2005). From the principal component analysis (PCA) carried out for the Landsat 5, bands 3, 2 and 4 (PC3, PC2 and PC4, respectively) were selected for the lineament mapping. Factor loadings for each band on the PCA, listed in Table 2.3, indicate that for PC2 and PC3 the higher contributions come from the short-wave infrared bands (5 and 7). Given that those two bands contain information mainly coming from Bands 5 and 7, they are providing a detailed characterization on features on the image associated to variation to changes in water content, such as soil cover and drainages. PC4 has a large contribution of band 1 and 4, which is helping to characterize changes in water content in the soil and drainages. Despite the fact than the PC1 contains the highest amount of information, the contribution of each band is very similar, so the differentiation of elements that might not help to enhance specific elements that contribute to a better display of linear features.

The Intensity-Hue-Saturation (IHS) color transformation of the short wave and near infrared bands $(6,5,4)$ of Landsat ETM+ provided a very good combination to detect changes in land use and land cover and drainage networks and facilitated the extraction of linear features.

None of vegetation, mineral content, hydrothermal indices calculated for both Landsat images produced satisfactory outputs to map lineaments. 
Table 2.3 Factor loadings for the PCA bands for the Landsat TM analysis

\begin{tabular}{|c|c|c|c|c|c|c|}
\cline { 1 - 6 } PCA band & \multirow{2}{*}{ PC1 } & PC2 & PC3 & PC4 & PC5 & PC6 \\
\cline { 1 - 6 } Landsat band & & & & & & \\
\hline B1 & 0.610 & -0.133 & 0.047 & 0.078 & -0.019 & -0.007 \\
\hline B2 & 0.552 & -0.115 & -0.044 & -0.074 & 0.010 & -0.246 \\
\hline B3 & 0.578 & -0.107 & -0.002 & -0.073 & -0.027 & 0.184 \\
\hline B4 & 0.445 & 0.132 & -0.259 & 0.029 & 0.068 & 0.028 \\
\hline B5 & 0.515 & 0.280 & 0.078 & -0.007 & -0.144 & -0.024 \\
\hline B7 & 0.632 & 0.220 & 0.231 & -0.016 & 0.469 & 0.014 \\
\hline
\end{tabular}

Both RADARSAT images (ascending and descending orbits) efficiently display the topography of the study area so linear features associated to topographic changes can be extracted. Filtering in order to detect edges worked very well for RADARSAT images as well. One of the factors favoring the edge detection might be due to the fact that the topography of the area is characterized by sharp changes along the main river valleys, around the Quito city, and in areas close to the volcanoes that are located within the QAS. Moreover, RADARSAT provided details on linear structures in urbanized areas, an advantage over the digital products derived from both Landsat images.

ASTER night thermal bands provided a unique perspective on lineaments associated to topographic changes and changes in the thermal properties of the ground and the potential to detect groundwater discharge areas.

ASTER visible and near-infrared bands provided a lot of more detailed information due to the high0-spatial resolution $(15 \mathrm{~m})$ and the fact that the 
near-infrared bands provide information about soil water content. The difficulty with the ASTER images was in finding the ones offering a good coverage of the study area. The processed images are from two different dates. Although they are in taken in the rainy seasons, the fact that they are months and years apart might imply that changes in the atmospheric conditions at the moment the image is taken is going to affect the brightness and linear features located similar geological conditions can be observed in one image and missed in the other.

The combination of the single band of the RADARSAT descending image with the PC2 of Landsat ETM+ provided a lot of detail on the linear structures in urban areas, an advantage over the digital products derived from Landsat images alone. Similar to the Landsat TM, the EMT+ PC2 is providing information mainly from bands 5 and 7 .

Lineaments larger than $500 \mathrm{~m}$ were mapped, aiming to create a 1:50,000 maps, suitable for regional analysis (Hung et al. 2005; Manning 2007). Exceptions were considered when shorter lineaments were clearly observed as being fragmented parts of a longer feature. Large areas of high urban and agricultural development were always verified with the visible bands of Landsat 7 ETM+ in order to avoid mapping fences, roads and other anthropogenic features as geologic lineaments. A coincidence analysis (Bruning et al. 2011b) was carried out to produce the final lineament map. Identified lineaments in each product were "buffered" plus and minus $100 \mathrm{~m}$ about the trace to represent the approximate width of the fault or fracture "zone," considering the spatial resolutions of the images, differences in geolocating them, and other unique aspects (e.g., shade dimensions) particular to the different imagery. By spatially overlaying buffered maps, lineaments that were coincident in at least four image products were 
included in the final coincidence raster map in a manner identical to Bruning et al. (2011).

Post processing was carried out for the final coincidence raster map. Slivers and isolated grid cells were removed when the total length was less than 500 $\mathrm{m}$. The edited raster map was vectorized to convert the lineaments into linear features. In Figure 2.3, examples of the coincidence analysis carried out for the RSA is presented. In order to visually make it easier to see the imagery and the lineaments, a small area was chosen and only four digitally derived products. The overall coincidence raster map is presented in Figure 2.4.

\section{LINEAMENT MAPPING USING THE DIGITAL TERRAIN ANALYSIS (DTA) APPROACH}

Following the Jordan et al. (2005) recommendations to digitally process DEMs and extract morphotectonic features (faults) in a systematic fashion, five digital maps derived products were created using the spatial analysis tools of in ESRI ${ }^{\circledR}$ ArcMap $^{\mathrm{TM}} 10.0$ (ESRI, Redlands, CA). The order of the digital maps derived was based on the complexity of the mathematical algorithm involved generating them. The Color Scale Map (CSM), which is the simplest way to visually analyze variations on elevation on a DEM, was the first map generated. The second one was a hillshade, which was based on the Multidirectional Oblique-Weighted (MDOW) method (Mark 1992). The MDOW hillshade consolidates into a single image the four hillshades generated at azimuths of 225,270,315, and 360 degrees and at a 30-degree altitude. This method intends to provide more detailed information since the area of the interest is illuminated from various azimuths and reduces shadows (Mark 1992). 


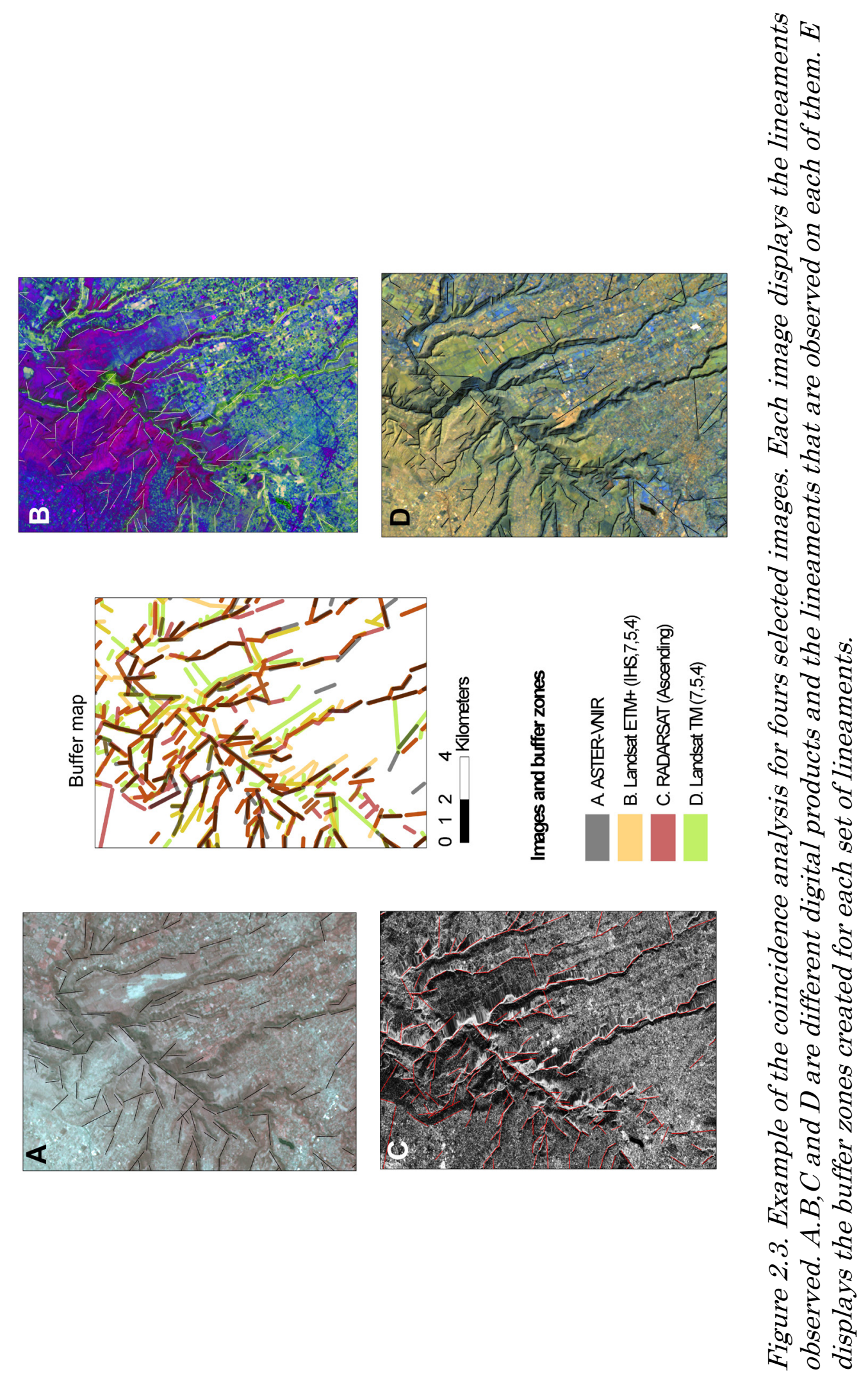




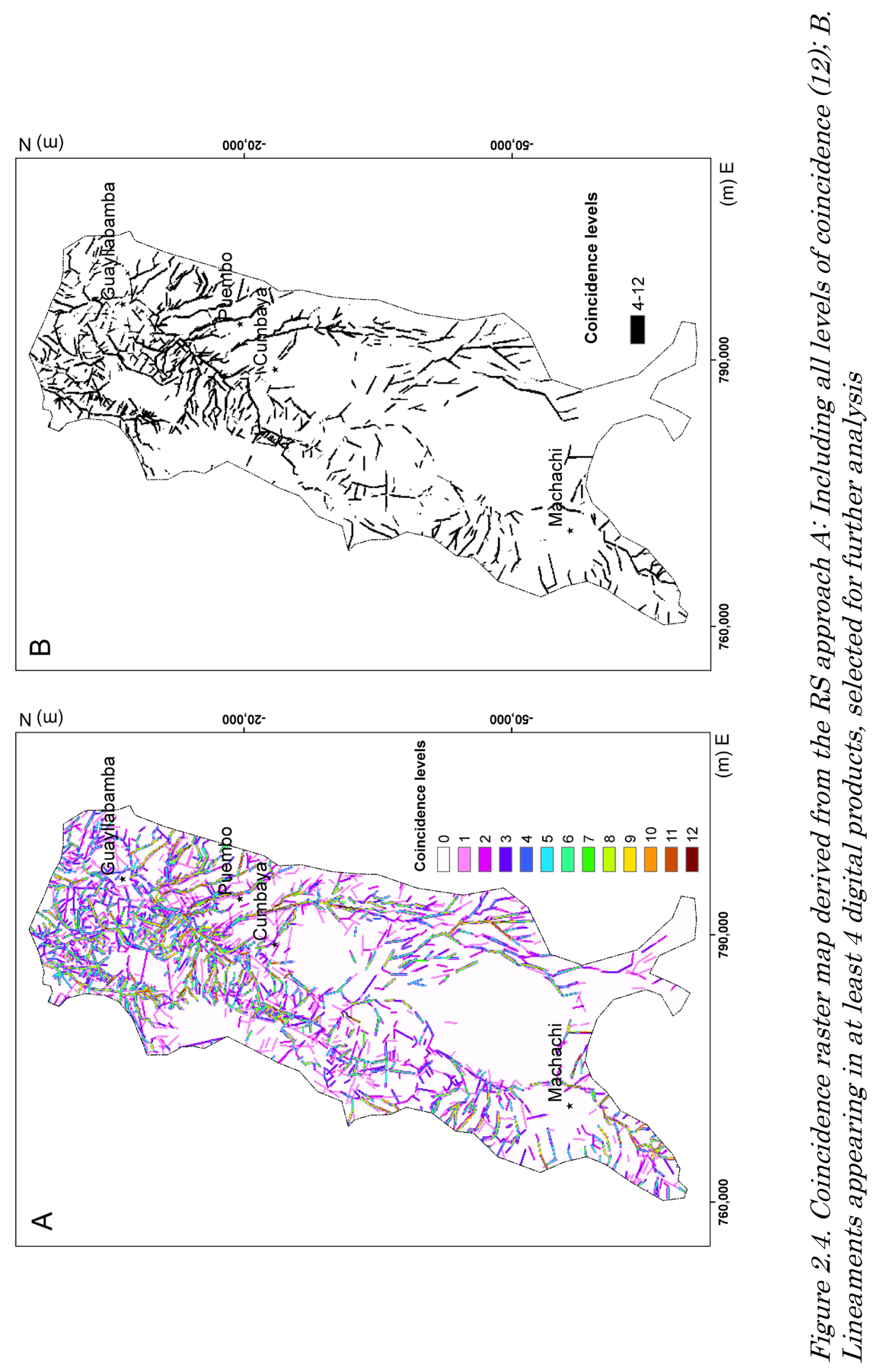


A slope map was created. Lineaments on the slope map are extracted from elongated areas of constant slope value that are considered the expression of fractures and faults (Jordan et al. 2005). The fourth product is the aspect map. The aspect map depicts the spatial orientations of the slopes. As the case with slopes, linear features on the aspect map show up as elongated areas of constant aspect with linear boundaries and can be associated to faulting. Given the amount of information that the aspect map contains and given the regional scale intended for this analysis, a high-pass filter was used to make the map easier to interpret. The high pass filter reduced the detailed on the image, preserving the longest linear features. The second derivative was the final product created. Linear features on the second derivative reflect slope breaks from tectonic origin. Also ridge and valley lines subject to tectonic control can be identified on derivative maps (Jordan 2003).

Lineaments were mapped manually on a successive fashion. It started on the CSM, where the major linear features are expected to be found. The lineament map was then draped over the hillshade map and additional lineaments were added as they were identified in the new digital product. This process was repeated for the slope, high pass filtered aspect, and the second derivative map. As with the image processing analysis, only linear features longer than $500 \mathrm{~m}$ were mapped. Shorter features were mapped if they belonged to a group along the same spatial path, presumably, then, part of the same tectonic feature. Figure 2.5 depicts an example of the visual aspect of each type of product derived from the DEM and the lineaments mapped.

The drainage network was used as part of the interpretation and verification of the existence of linear features and to clarify the influence on the tectonics on the development of the basin. 

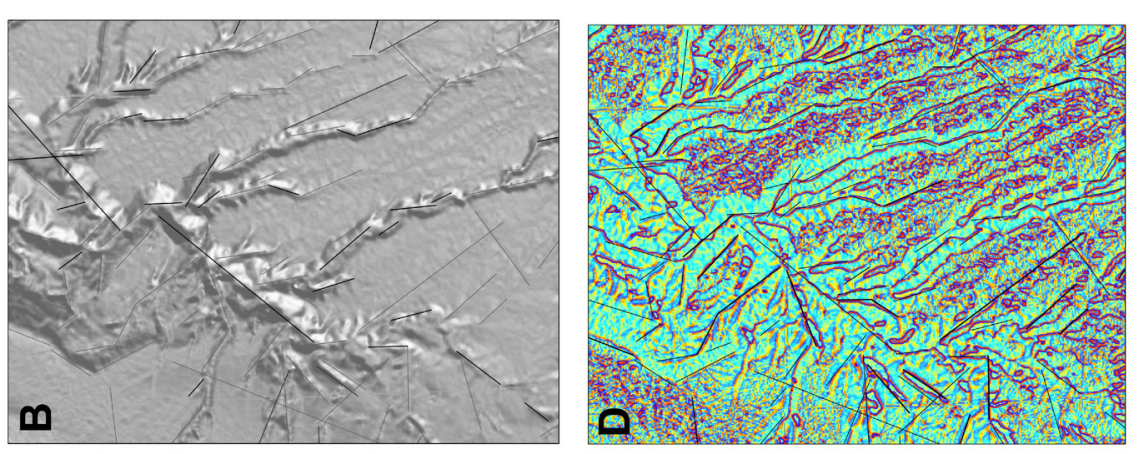

8
0
0
0
0
0
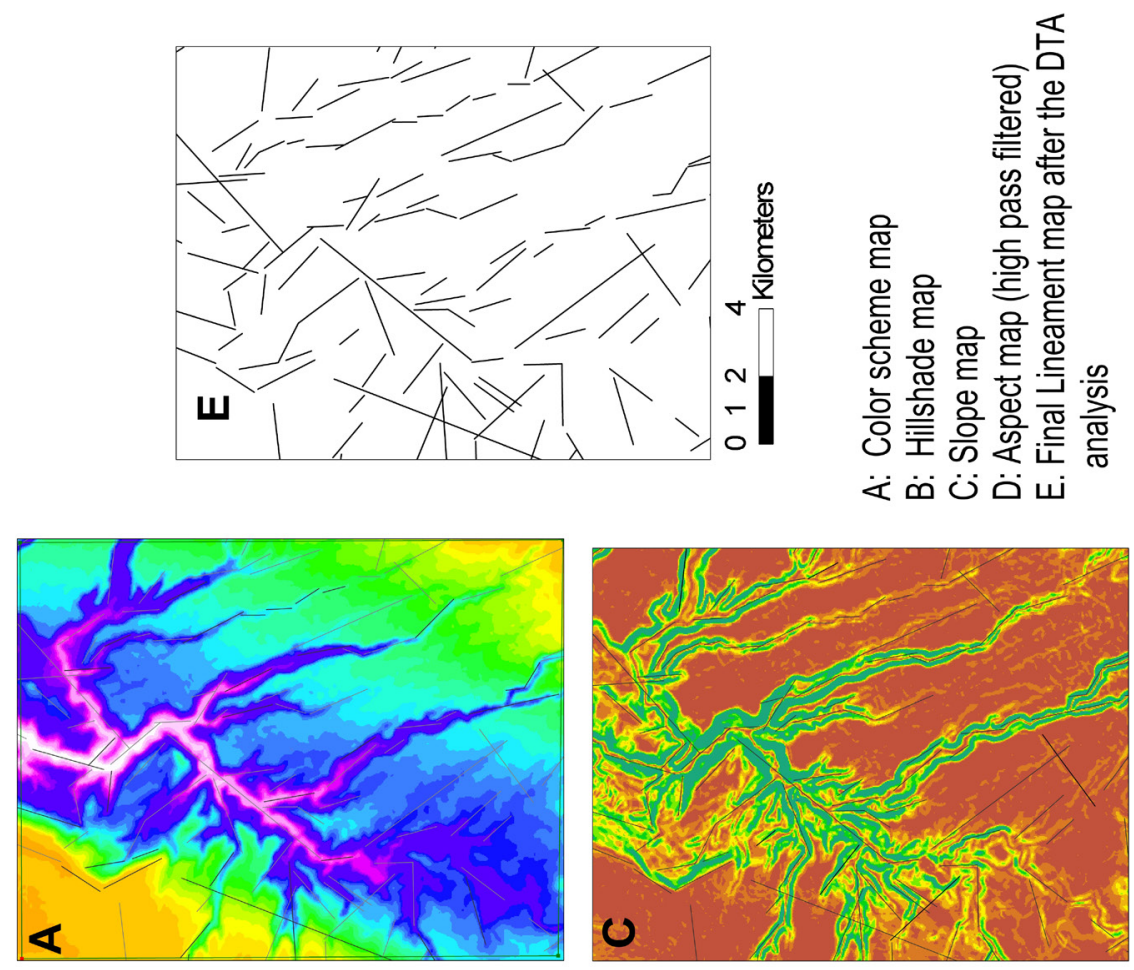

本迹

2

究

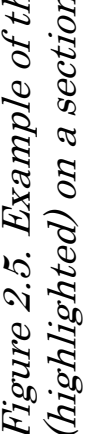


The drainage network was extracted, by using the ESRI@ ArcMap ${ }^{\mathrm{TM}} 10.0$ (ESRI, Redlands, CA) - Hydrological Analysis tool.

\section{IMAGE/PRODUCT INTEGRATION}

In order to obtain the final lineament map, intersection and merge functions were carried out between the previous maps. The intersection function was used to verify whether the two approaches were identifying similar/coincident features. A feature identified in one approach would be considered coincident was intersecting another feature from the other map, within a distance of distance of $100 \mathrm{~m}$ and oriented in the same direction. The 100-m buffer distance encompasses an average width of the fracture zone (as mentioned in the RSA), errors in geographic rectification and location errors of the digitized linear features. Because there were intersected features, after the merging, coincident lineaments were eliminated. When the coincident features had different lengths, the longest one was kept. Merging, intersection, and editing were performed on ESRI@ ArcMap"TM10.0 (ESRI, Redlands, CA).

\section{RESULTS AND DISCUSSION}

After the merging and editing, 612 lineaments were mapped across the entire study area (Figure 2.6). The average lineament length is $1656 \mathrm{~m}$ and $88 \%$ of lineaments have lengths between 500 and $3000 \mathrm{~m}$. The longest lineaments were identified in the north central and north-eastern parts of the study area. The orientation of the lineaments is predominantly NW-SE and NE-SW, as indicated in the rose diagram (Figure 2.7.A). The majority of the longest lineaments, however, have N-S/NE-SW orientations. In order to analyze the spatial distribution of the lineaments over the study area and the differences in the tectonic activity, a density lineament map was created. 


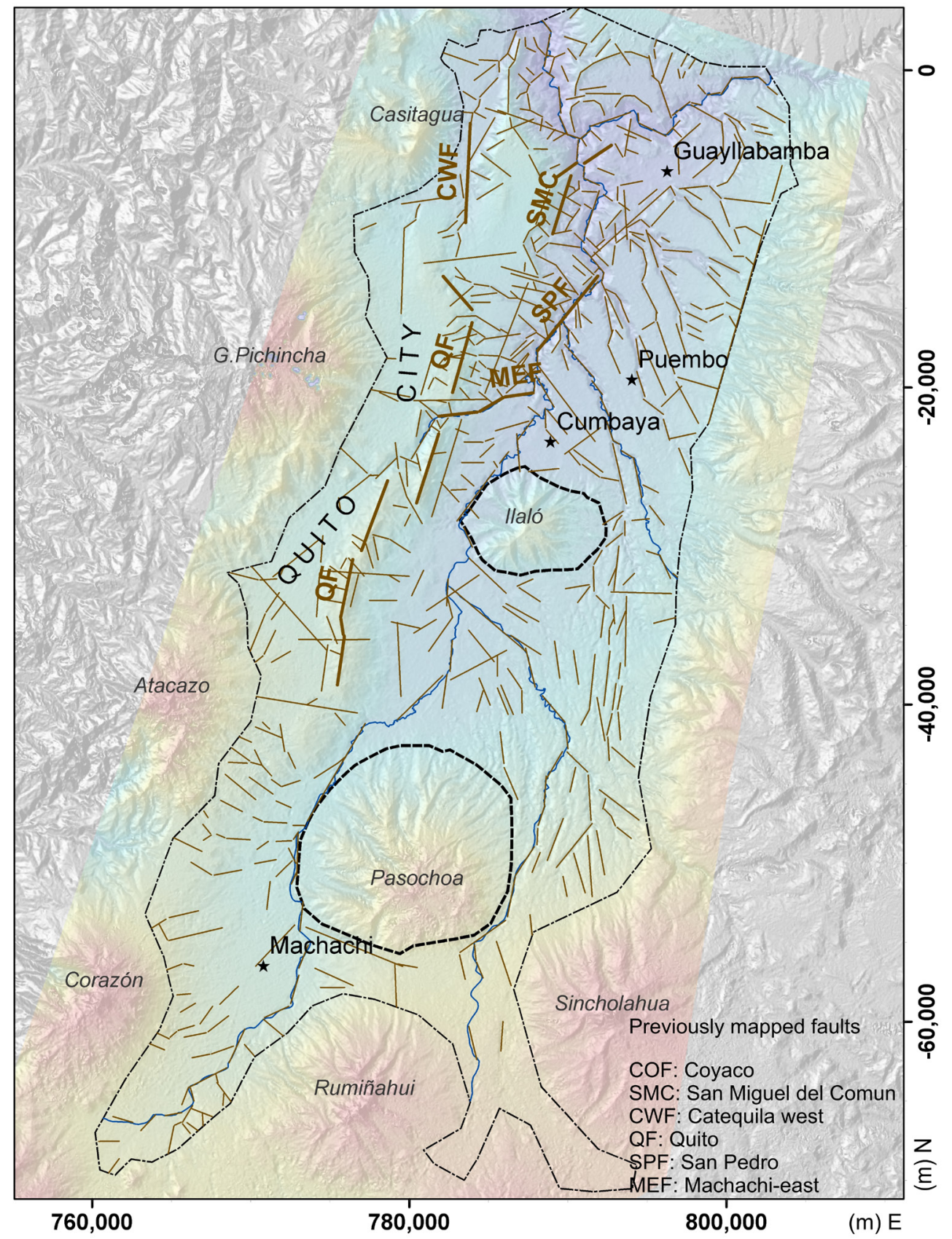

Figure 2.6. Final lineament map obtained for the QAS. Major fault are indicated. The map base layer is a hillshade derived from a 30-m AST-DEM (product of METI and NASA). 

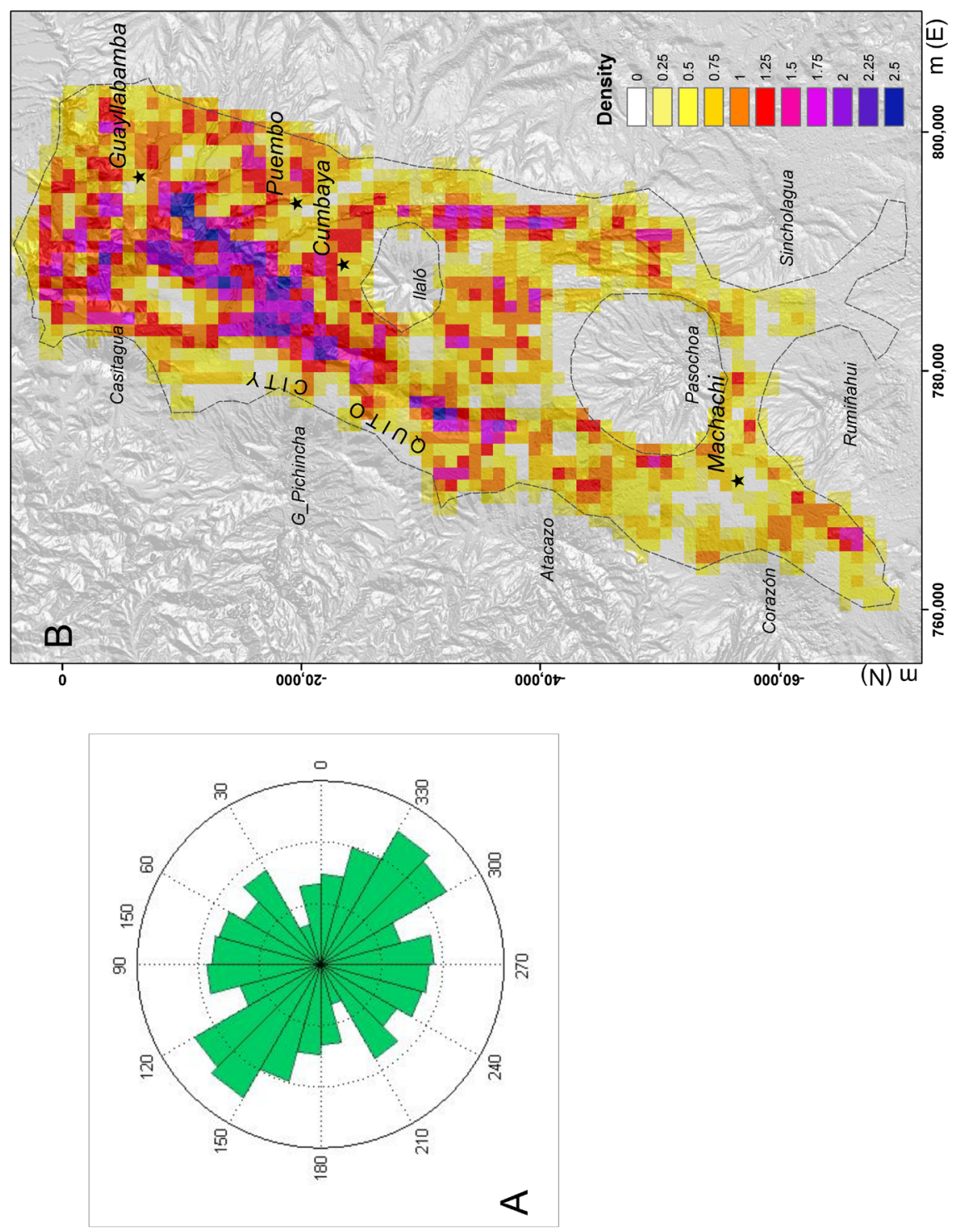
Based on the relationships between the number of lineaments to the area (0.44 lineaments per $\left.\mathrm{km}^{2}\right)$ and the length of lineaments to the area $(0.6 \mathrm{~km}$ of lineaments per $\mathrm{km}^{2}$ ) areas of one $\mathrm{km}^{2}$ were chosen to calculate lineament density on ESRI@ ArcMap ${ }^{\mathrm{TM}} 10.0$ (ESRI, Redlands, CA). The lineamentdensity map obtained is depicted on Figure 2.7.B. A non-uniform distribution of lineaments in the QAS is observed on the map. Density is low in the southern part of the area (west of Pasochoa and Rumiñahui Volcanoes) while increasing northward. The largest concentrations of lineaments are located in the northern central part, along the path of San Pedro and Guayllabamba Rivers and around the Quito Fault. The Quito metropolitan area and Catequila plateaus have very low lineament densities compared to other areas in the basin. The results of this study compare favorably with the faults previously mapped in the 1:100,000 Geological Map of Ecuador (MRNNR 1982), as depicted on Figure 2.8. From a visual analysis it is observed that similar features, at least in terms of orientation and approximate location are found north of Pasochoa Volcano, mostly associated with the Quito Fault (QF), the San Pedro Fault (SPF) and faults parallel to the Guayllabamba River. The number of lineaments recognized in this study is significant larger than the tectonic features mapped in previous studies. Further studies are yet to be developed to categorize them as faults, fractures, or discontinuities. Moreover, more research is necessary to evaluate the extents of these features underground. Based on the number of lineaments mapped and the association of many of them on the drainage network, it is suggested that a strong tectonic control is likely an important part of the development of the basin. The drainage network of the QAS, which is characterized mainly as a trellis pattern, supports this supposition. Moreover, lineaments are controlling $58 \%$ of streams of orders four (Strahler classification) and higher. $\mathrm{N}-\mathrm{NE}$ lineaments south of Machachi are controlling the main drainages 


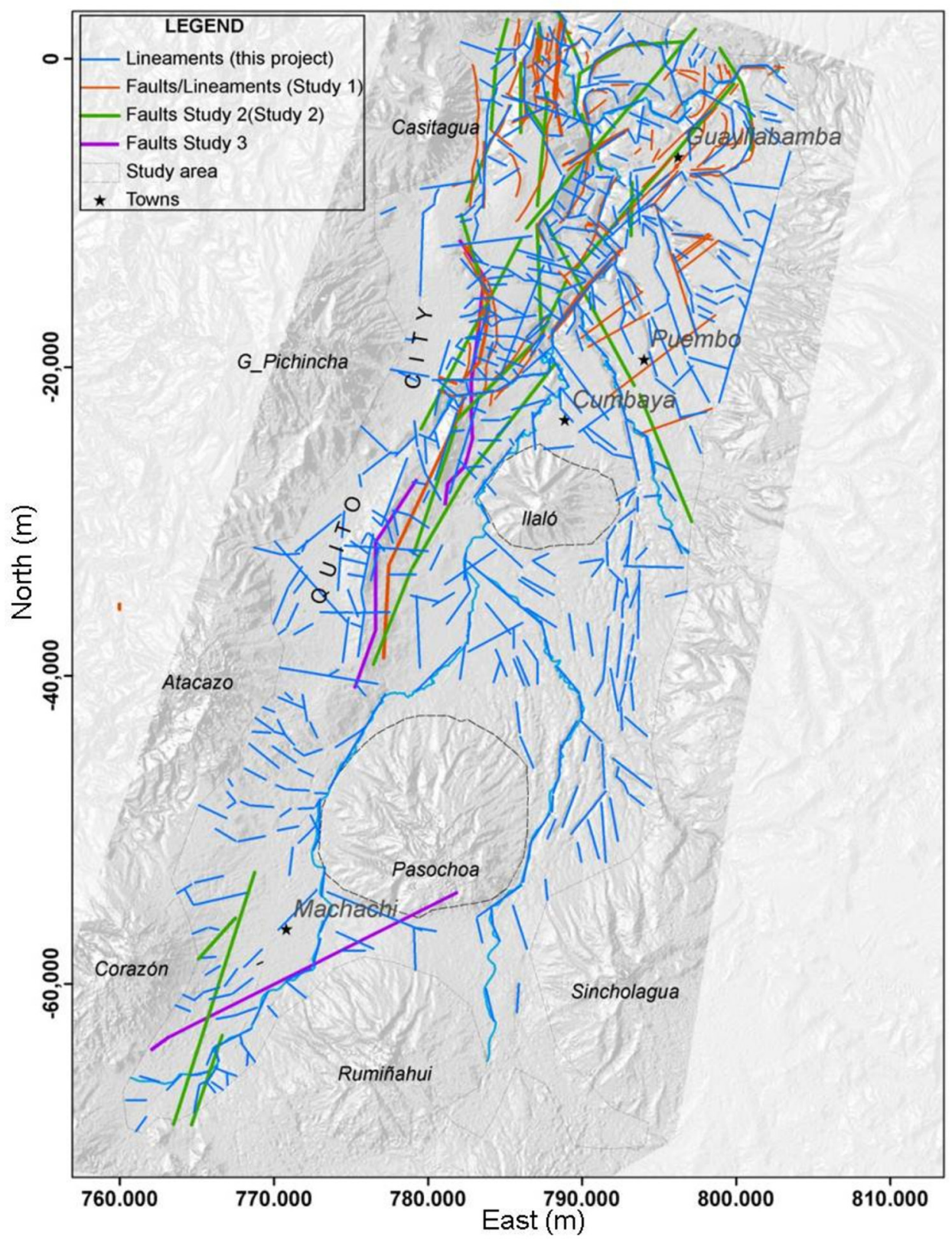

Figure 2.8. Lineament map from this study, compared to lineaments and faults from previous studies. Study 1corresponds to the lineaments mapped by Villagomez (2003); Study 2 refers to the map by Eguez et al. (2003); Study 3 is the Geological Map of Ecuador (1982). The map base layer is a hillshade derived from a $30-\mathrm{m} \mathrm{AST-}$ $D E M$ (product of METI and NASA). 
Also lineaments are controlling the San Pedro River course, which are marking the lowest part in the middle of the basin. NW-SE oriented lineaments are controlling the path of Guayllabamba River (Figure 2.6).About $43 \%$ of the $739 \mathrm{RSA}$-derived lineaments agree with 246 DTAderived lineaments resulting in 612 distinct lineaments for the combined maps (Figure 2.9). Areas near the Rio San Pedro and Guayllabamba River have more coincident lineaments. In the Southern part, east of Machachi, lineaments are mapped exclusively based on the RSA. The absence of DTA lineaments could be due to the fact that the topographic gradient is very low, or these lineaments are not of tectonic origin and they are representing streams dissecting young volcanic materials.

DTA and RSA lineament maps have important differences. Linear features on the DTA digital products are more continuous, tectonic features are represented on the RSA maps by shorter lineaments. The average lineament length from the DTA is $2132 \mathrm{~m}$ and the average length from RSA is $1308 \mathrm{~m}$. This difference in lengths is one of the reasons why the number of lineaments from the DTA is much lower than from the RSA (251 and $819 \mathrm{~m}$, respectively).

Although both approaches applied in this study are intended to map lineaments of geological origin, the maps indicate that the two approaches are mapping different features for a large extension of the study area. The intersected features account for $37 \%$ of the RS approach and $43 \%$ of the DEM approach. As observed in Figure 2.8. On the southwestern part of the region, around the town of Machachi and west of San Pedro River, only four lineaments in this area were derived from DTA. This area could be interpreted as not being affected by tectonics and the linear features are the result of the dissection of river into young volcanic sediments. 


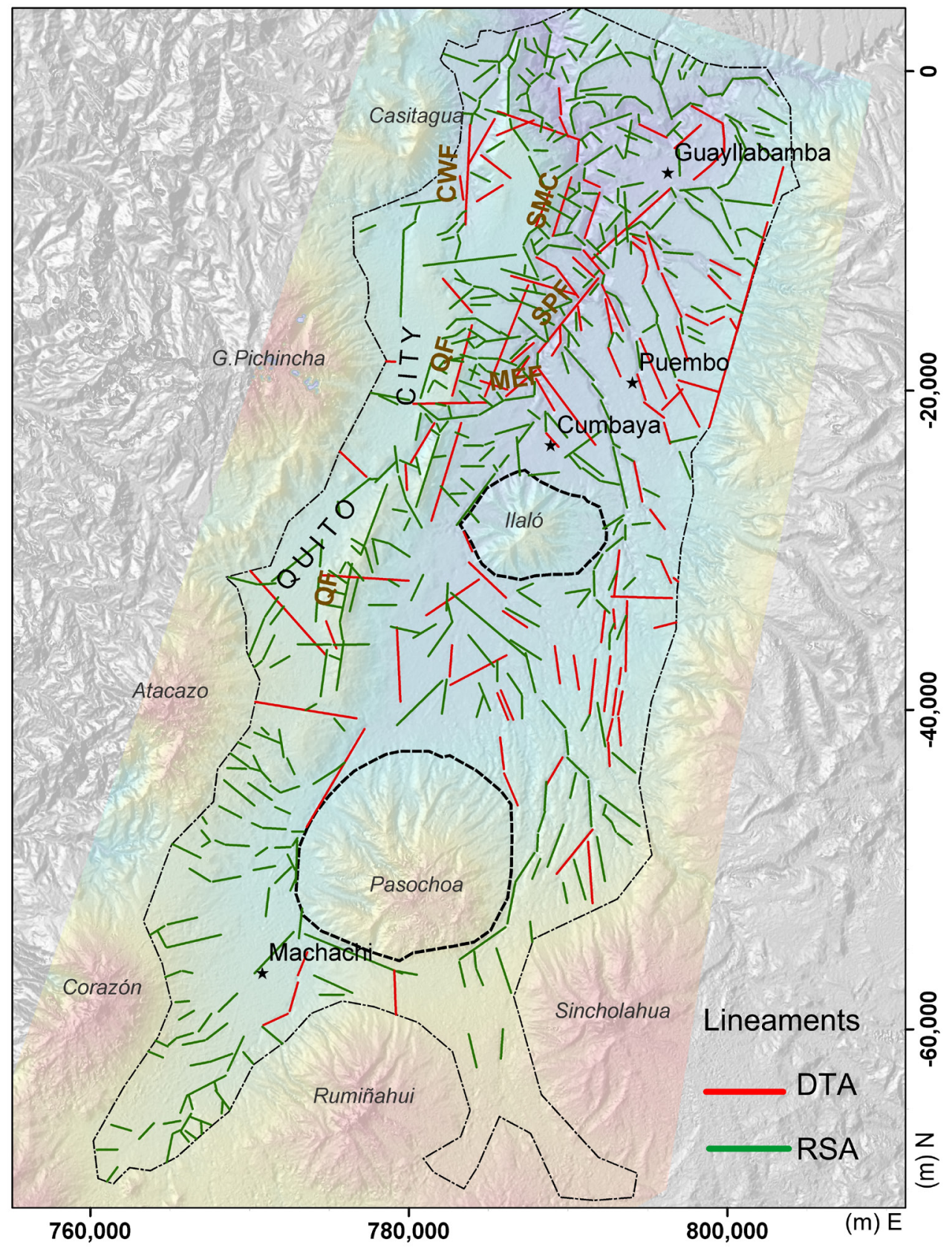

Figure 2.9. Spatial coverage and intersection analysis of lineaments mapped with the two approaches. DTA:Digital Terrain Analysis Approach. RSA: Remote Sensing Approach. The map base layer is a hillshade derived from a $30-\mathrm{m}$ AST-DEM (product of METI and NASA). 
Nonetheless, for regions that are known as affected by tectonism, the DTA approach did display many of the linear tectonic features. For example, the western side of San Pedro River, the northern part of Ilaló Volcano, and even the Quito Fault zone. One explanation could be that the topographic expression of these features (such as changes on elevation or the width of the fault/fracture zone) was not big enough to be reflected in at least one of the DEM derived digital products created with the approach described here. A DEM with a finer spatial resolution most likely will display these short, small or narrow features. The fact that the RSA was able to map many short features that were associated to topographic features suggests that the assumption of the limitations of the DTA due to the spatial resolution of the DEM is correct. Pronounced long, linear features are observed on the eastern border of the study area and on the western part Quito Fault Zone and the Catequila Plateau. These lineaments were derived with the DEM approach only. They are reflecting abrupt changes in elevation or slope but there are no

changes in the physical properties (e.g., vegetation type, rock type, etc.) of the terrain that make them identifiable in the RSA approach. It appears that many of these lineaments are controlling the morphology of the basin.

Lineament mapping was challenging in the area east of Rio San Pedro. This area is characterized by a series of plateaus separated by ravines oriented northwest-southeast. The width of these ravines ranges between 100 to 800 m.

\section{CONCLUSIONS}

A remote sensing approach combined with DIP products derived from DEMs are useful tools to map faults and fractures that are prevalent in the QAS. Combining several types of satellite images with DEM-derived products 
allowed for a more comprehensive mapping of geological lineaments. Combining images and digital products takes advantage of different aspects of the electromagnetic spectrum increase the possibility of observing lineaments of geological origin on non-ideal areas.

RSA lineament analysis is superior for detecting lineaments that are affecting the physical properties of the soil, regardless the topographic expression. So, for many areas it offers more advantages than the DTA approach. DTA is very effective on mapping regional features, not only those due to changes on topographic elevation but also many associated to deformation. DTA provides also a 3D context of the tectonic analysis, making the interpretation of lineament maps easier. When the lineament analysis is intended to contribute to the tectonic analysis of an area, however, both approaches should be applied.

The coincidence analysis offers a very complete way to use the full possibilities of the remotely sensed imagery. With this approach, the different spatial and spectral resolutions can be used and combined to enhance features of different geological origins.

Digital terrain products are valuable tools to delineate faults and lineaments by identifying morphotectonic features or faults that have a spatial extent that is larger than the spatial resolution of the used imagery. The best example is the Quito fault, due to its reverse characteristic and extent. The expression of this fault on the RSA is associated to a series of lineaments, located especially in the highest part of the fault zone. Based on the DTA, however, the $\mathrm{QF}$ is associated to a series of features encompassing more a fault zone than a single fault. 
Although the combined approach proposed in this study is more time consuming than using a single approach or an automatic lineament analysis (Mavrantza and Argialas 2008; Shahid and Nath 2002), it provides a more comprehensive and detailed analysis of lineaments existing in a given region

\section{ACKNOWLEDGEMENTS}

This material is based upon work supported by the National Science Foundation under Grant No. 0530109. We are also grateful to the Water Utility Company of Quito, Ecuador (EPMAPS), especially to Teresa Muñoz and Oscar Larrea, for providing an invaluable technical and logistical support for the development of this study.

\section{REFERENCES CITED}

Arenas, M. A. (2006). Lineament extraction from digital terrain models. Case study San Antonio del Sur Area, South-Eastern Cuba. Enschede, International Institute for Geo-Information Science and Earth Observation. Master of Science.

Bisson, R. A. and J. H. Lehr (2004). Modern groundwater exploration. Discovering new water resources in consolidated rocks using innovative hydrogeologic concepts, exploration, drilling, aquifer testing, and management methods. New Jersey, John Wiley \& Sons.

Bruning, J. N., J. S. Gierke and A. L. MacLean (2011). "An approach to lineament analysis for groundwater exploration in Nicaragua." Photogrammetric engineering and remote sensing 77(5): 11.

Canny, J. (1986). "A computational approach to edge detection." Pattern Analysis and Machine Intelligence, IEEE Transactions on PAMI-8(6): 679-698.

Dar, I. A., K. Sankar and M. A. Dar (2010). "Remote sensing technology and geographic information system modeling: An integrated approach towards the mapping of groundwater potential zones in Hardrock terrain, Mamundiyar basin." Journal of Hydrology 394(3-4): 285-295.

Florinsky, I. V. (1996). "Quantitative topographic method of fault morphology recognition." Geomorphology 16(2): 103-119.

Grohmann, C. H., C. Riccomini and F. M. Alves (2007). "SRTM-based morphotectonic analysis of the Poços de Caldas Alkaline Massif, southeastern Brazil." Computers \& Geosciences 33(1): 10-19.

Hadjimitsis, D. G., C. R. I. Clayton and V. S. Hope (2004). "An assessment of the effectiveness of atmospheric correction algorithms through the remote 
sensing of some reservoirs." International Journal of Remote Sensing 25(18): 3651-3674.

Henderson, D. B., D. A. Ferrill and K. C. Clarke (1996). Mapping geological faults using image processing techniques applied to hill-shaded digital elevation models. Image Analysis and Interpretation, 1996., Proceedings of the IEEE Southwest Symposium

Hung, L. Q., O. Batelaan and F. D. Smedt (2005). Lineament extraction and analysis, comparison of LANDSAT ETM and ASTER imagery. Case study: Suoimuoi tropical Karst catchment, Vietnam. Remote Sensing For Environmental Monitoring, GIS Applications, and Geology, SPIE.

Inzana, J., T. Kusky, G. Higgs and R. Tucker (2003). "Supervised classifications of Landsat TM band ratio images and Landsat TM band ratio image with radar for geological interpretations of central Madagascar." Journal of African Earth Sciences 37: 59-72.

Jordan, G. (2003). "Morphometric analysis and tectonic interpretation of digital terrain data: a case study." Earth Surface Processes and Landforms 28(8): 807-822.

Jordan, G., B. M. L. Meijninger, D. J. J. v. Hinsbergen, J. E. Meulenkamp and P. M. v. Dijk (2005). "Extraction of morphotectonic features from DEMs: Development and applications for study areas in Hungary and NW Greece." International Journal of Applied Earth Observation and Geoinformation 7(3): 163-182.

Keller, E. A. and N. Pinter (1996). Active tectonics: Earthquakes, uplift, and landscape, Prentice Hall (Upper Saddle River N.J).

Liang, S., H. Fang and M. Chen (2001). "Atmospheric correction of Landsat ETM+ land surface imagery. I. Methods." Geoscience and Remote Sensing, IEEE Transactions on 39(11): 2490-2498.

Mabee, S. B., K. C. Hardcastle and Donald U. Wise (1994). "A method of collecting and analyzing lineaments for regional-scale fractured-bedrock aquifer studies." Ground Water 32(6): 884-894.

Manning, J. (2007). "Remote sensing for terrain analysis of linear infrastructure projects." Geological Society Special Publications 283: 135-142.

Marghany, M. and M. Hashim (2010). "Lineament mapping using multispectral remote sensing satellite data." Research Journal of Applied Sciences 5: 126130.

Mark, R. (1992). Multidirectional, oblique-weighted, shaded-relief image of the Island of Hawaii". Menlo Park, CA, U.S Geological Survey. 92-422.

Mavrantza, O. and D. Argialas (2008). An object-oriented image analysis approach for the identification of geologic lineaments in a sedimentary geotectonic environment. Object-based image analysis. Spatial concepts for knowledgedriven remote sensing applications. T. Blaschke, S. Lang and G. J. Hay. Berlin, Springer Berlin Heidelberg: 383-398.

Meijerink, A. M. J. (1996). "Remote Sensing Applications to hydrology: groundwater." Hydrological Sciences Journal 41(4): 549-561.

MRNNR (1982). Mapa gologico nacional de la Republica del Ecuador. M. d. R. N. y. E. d. Ecuador. Quito, Instituto Geográfico Militar. 
NASA/USGS (2012). Landsat Science Data Users Handbook. U. G. Survey. Maryland, Landsat Project Science Office.

Onorati, G., R. Ventura, M. Poscolieri, V. Chiarini and U. Crucillà (1992). "The Digital Elevation Model of Italy for geomorphology and structural geology." CATENA 19(2): 147-178.

Paillou, P., G. Grandjean, N. Baghdadi, E. Heggy, T. August-Bernex and J. Achache (2003). "Subsurface imaging in south-central Egypt using low-frequency radar: Bir Safsaf revisited." Geoscience and Remote Sensing, IEEE Transactions on 41(7): 1672-1684.

Paradella, W. R., A. R. D. Santos, P. Veneziani and M. C. d. Morais (2000). "Synthetic aperture radar for geological applications in the moist tropics." Revista Brasileira de Geociencias 30(3): 538-542.

Peña, S. A. and M. G. Abdelsalam (2006). "Orbital remote sensing for geological mapping in southern Tunisia: Implication for oil and gas exploration." Journal of African Earth Sciences 44(2): 203-219.

Ricchetti, E. (2002). Structural geological study of Southern Apennine (Italy) using Landsat 7 imagery. Geoscience and Remote Sensing Symposium, 2002. IGARSS '02. 2002 IEEE International.

Ricchetti, E. and M. Palombella (2005). Application of Landsat 7 ETM+ imagery for geological lineament analysis of Southern Italy. Geoscience and Remote Sensing Symposium, 2005. IGARSS '05. Proceedings. 2005 IEEE International.

Rosenbom, A. E. and P. R. Jakobsen (2005). "Infrared thermography and fracture analysis of preferential flow in chalk." Vadose Zone Journal 4: 271-280.

Saadi, N. M., E. Aboud and K. Watanabe (2009). "Integration of DEM, ETM+, geologic, and magnetic data for geological investigations in the Jifara Plain, Libya." Geoscience and Remote Sensing, IEEE Transactions on 47(10): 33893398.

Sang-Ho, Y. and W. M. Moon (2001). Lineament extraction from DEM using drainage network. Geoscience and Remote Sensing Symposium, 2001. IGARSS '01. IEEE 2001 International.

Saud, M. A. (2008). "Using ASTER images to analyze geologic linear features in Wadi Aurnah basin, Western Saudis Arabia." The Open Remote Sensing Journal 1: 17-25.

SETA, D., \#160, Marta, D. MONTE, Maurizio, FREDI, Paola, L. PALMIERI and Elvidio (2004). Quantitative morphotectonic analysis as a tool for detecting deformation patterns in soft-rock terrains: a case study from the southern Marches, Italy. Paris, FRANCE, SEDES.

Shaban, A., M. Khawlie and C. Abdallah (2006). "Use of remote sensing and GIS to determine recharge potential zones: the case of Occidental Lebanon." Hydrogeology Journal 14(4): 433-443.

Shaban, A., M. Khawlie, C. Abdallah and G. Faour (2005). "Geologic controls of submarine groundwater discharge: application of remote sensing to north Lebanon." Environmental Geology 47(4): 512-522. 
Shahid, S. and S. K. Nath (2002). "GIS Integration of remote sensing and electrical sounding data for hydrogeological exploration." Journal of spatial hydrology [1530-4736] Shahid yr:2002 vol:2 iss:1 pg:1 2(Spring 2002): 1-12.

Solomon, S. and F. Quiel (2006). "Groundwater study using remote sensing and geographic information systems (GIS) in the central highlands of Eritrea." Hydrogeology Journal 14: 12.

Thurmond, A. K., M. G. Abdelsalam and J. B. Thurmond (2006). "Optical-radarDEM remote sensing data integration for geological mapping in the Afar Depression, Ethiopia." Journal of African Earth Sciences 44(2): 119-134.

Vsevolozhskii, V. A., R. P. Kochetkova and F. Fidelli (2001). "Principles of hydrogeological zoning by the conditions of formation and the distribution of the natural resources of fresh ground water." Water Resources 30(3): 233-245.

Way, D. S. (1973). Terrain analysis: a guide to site selection using aerial photographic interpretation. Stroudsburg, PA. , Dowden, Hutchinson \& Ross. 


\title{
PAPER 2: GEOPHYSICAL METHODS FOR FRACTURE DETECTION IN MONTAINOUS VOLCANIC AQUIFERS OF THE PLATEAUS AREA, QUITO, ECUADOR ${ }^{4}$
}

\author{
Miriam Rios-Sanchez ${ }^{1}$, John S. Gierke ${ }^{1}$ \\ ${ }^{1}$ Department of Geological and Mining Engineering and Sciences, Michigan \\ Technological University, 1400 Townsend Dr., Houghton, MI 49931
}

\begin{abstract}
The Quito Aquifer System (QAS) of Ecuador is critical for providing potable water to Quito, the capitol of Ecuador, and its metropolitan area. The QAS is a complex basin of sedimentary volcanic deposits. However, local and regional groundwater flows are at least significantly affected by the occurrence of faulting and fracturing in this tectonically active area. The plateaus area is a very important source for water supplies. Springs and wells provide $100 \%$ of the drinking water needed for the population centers settled on the plateaus region. As an initial step to evaluate the faulting and fracturing on the plateaus, a lineament mapping of the plateaus of the QAS was created using remote sensing and digital terrain analysis. Shallow geophysical methods were used as an independent approach of confirming the presence of fractures. Shallow geophysical methods are especially appropriate for confirming the presence, extent, and orientation of geological lineaments, as well as for detecting the presence of water in the fractures. Vertical electrical sounding (VES), two-dimensional electrical resistivity profiling (2DER), and very low frequency electromagnetic method (VLF-EM) were applied to define the extent and depth of the tectonic features mapped based on the lineament analysis. Results indicate that lineaments are represented underground by fractures with an average depth of about $60 \mathrm{~m}$. VLF-EM worked well to depths of approximately 40-60 m. Up to those depths inverted sections followed the same spatial resistivity distribution as the 2D-ER sections and similar fractured zones were mapped. The VLF-EM method works well to detect fractures to shallow depths but cannot be used to obtain
\end{abstract}

\footnotetext{
${ }^{4}$ Paper in process of submission to the Journal of Environmental \& Engineering Geophysics
} 
real resistivity values of the terrain. The VES method was not effective in mapping tectonic features on this terrain.

\section{INTRODUCTION}

The formations comprising the Quito Aquifer System (QAS) are critical for providing potable water to the metropolitan area of Ecuador's capitol city, Quito. The QAS is a complex basin of sedimentary volcanic deposits. Local and regional groundwater flows are at least significantly affected by the occurrences of faulting and fracturing in this tectonically active area (RiosSanchez et al. 2012a). Although generally the QAS is a basin fill of volcanic sediments, the tectonic history has resulted in alterations of the landscape, forming depressions, valleys, and highly dissected areas like the plateaus area. The plateaus area is very important for water supplies. Springs and wells provide all of the drinking water needed for the population centers settled on the Plateaus Region. Wells are also used to extract water for agriculture. The original conceptualization of the Plateaus Region hydrology was a combination of primary porosity aquifers. Analyses of pumping tests and geochemistry suggest the hydrogeology is more complex than originally thought (Rios-Sanchez et al. 2012b) and that groundwater flows are controlled by post-deposition tectonic features that potentially act, in some cases, as barriers and in others as preferential flow zones (Rios-Sanchez et al. 2012a; Rios-Sanchez et al. 2012b). As an initial step to evaluate the faulting and fracturing on the plateaus, lineament mapping of the plateaus of the QAS was created using remote sensing and digital terrain analysis (RiosSanchez et al. 2012c). The results of this mapping indicated two main orientation trends for the lineaments. The NNW-SSE trending features are primarily associated with regional features and are expressed as deep ravines. The SE-NW trends are primarily associated with fracture exposures 
that are observed on the ravine walls and geomorphic features corresponding to the deflections of the drainages.

While the interpretations of the remotely sensed imagery and digital terrain data strongly suggest the presence of faulting/fracturing significantly affects groundwater hydrology in the area (Rios-Sanchez et al. 2012a), independent confirmation is needed to enhance the confidence in these interpretations. Ground-truth data is necessary to delineate the subsurface character and extent of the lineaments mapped on top of the plateaus and to understand the impact of the fracturing on the hydrogeology. Shallow geophysical methods are especially appropriate for delineating the extent and orientation of geological lineaments, as well as for detecting the presence of water in the fractures. Electrical and electromagnetic geophysical methods have been widely used to map fractures by identifying the changes in resistivity that happen between the fractures and the solid rock, due to the variation in properties such as permeability and saturation. Twodimensional electrical resistivity profiling (2D-ER) and very-low frequency electromagnetic method (VLF-EM) are among the most commonly methods used to map fractures (Adepelumi et al. 2006; Ganerød et al. 2006; Mitchell 2001; Ramesh Babu et al. 2007; Sharma and Baranwal 2005). Location of faults and fractures are commonly visually identified at areas/lines of contrast in graphs of physical properties obtained through these methods. For the direct current method, this contrast are reflected as changes in electrical resistivity((Ernston and Kirsch 2006). Physical properties and hence changes in electrical resistivity of metamorphic and igneous rocks contrast often in a very obvious manner. However, volcanic and sedimentary deposit changes in resistivity between fractured and non-fractured areas are more subtle and delineating the exact location of those boundaries can be 
subjective (Demanet et al. 2001; Nguyen et al. 2005). Among the factors that contribute to the subjectivity of the interpretation are the quality of the acquired data, different options used during the inversion process, and nonlinearity of resistivity inversion (Nguyen et al. 2005). Moreover, subjectivity in the visual interpretation is influenced by the color scale that is used and criteria selected by the interpreter (Demanet et al. 2001; Nguyen et al. 2005).

Digital image processing algorithms have been used in processing geophysical data to reduce the bias of the interpretations that typically rely only on visual analysis (Carter and Lines 2001; Demanet et al. 2001; Nguyen et al. 2005; Piro et al. 2007). For 2D electrical resistivity data, omnidirectional and directional gradient filters (Pitas 2000; Wiggin 2001) have been applied in order to enhance boundaries. Moreover, the location of low resistivity zones (potentially interpreted as fault zones) has been calculated by applying algorithms used on the extraction of drainage networks (Demanet et al. 2001; Nguyen et al. 2005).

Qualitative interpretation of VLF-EM data rely on filtering the data. Fraser and Hjelt filters are regularly used to locate anomalies associated with faults and fractures (Ganerød et al. 2006; Jeng et al. 2004; Kaikkonen and Sharma 2001; Karaman 2002). Quantitative interpretations are achieved by inverting the tipper data, creating $2 \mathrm{D}$ sections of apparent electrical resistivity (Beamish 2000; Becken and Pedersen 2003; Monteiro Santos et al. 2006; Ramesh Babu et al. 2007).

The lack of areas of easy access on mountainous terrains limits the use of the $2 \mathrm{D}$-ER profiling method. in developing countries, additional limitations include the expense of the surveys (equipment, personnel, etc.), the 
complexity of the methods for the data interpretation, and lack of access to computer programs to perform the analyses (Loke 2012). The VLF-EM method is considered as a faster and cheaper method compared to the $2 \mathrm{D}^{-}$ ER method to detect underground structures (Monteiro Santos et al. 2006; Ramesh Babu et al. 2007; Sharma and Baranwal 2005), but there is less experience and certainty in VLF-EM profiling, especially in these type of volcanic terrains.

The main of goal of this study is to apply the 2D-ER profiling and VLF-EM to define the extent and depth of the tectonic features mapped in the lineament analysis carried out by Rios-Sanchez et al. (2012c). Digital image processing techniques were applied to the $2 \mathrm{D}$-ER profiles to better describe variations in the resistivity, considering the heterogeneity of the terrain. The other goal was to evaluate the VLF-EM method as a cheaper and more convenient alternative to $2 \mathrm{D}$-ER profiling for mapping lateral variations in resistivity on mountainous volcanic terrains.

\section{STUDY AREA}

The plateaus region is located in the eastern part of the Quito Aquifer System (QAS). It belongs to a complex tectonic basin located in the central part of Ecuador adjacent to the Quito metropolitan area. The study area is characterized by a group of NW/SE-oriented low relief areas, separated by wide valleys (Figure 3.1).

Spring water coming from the sides of the plateaus supplies around $500 \mathrm{l} / \mathrm{s}$ for rural parts of the Quito Metropolitan Area. Tectonic structures such as the San Pedro Faults and the Guayllabamba lineaments serve as the northern and western boundaries of the plateaus, as depicted in Figure 3.1. 


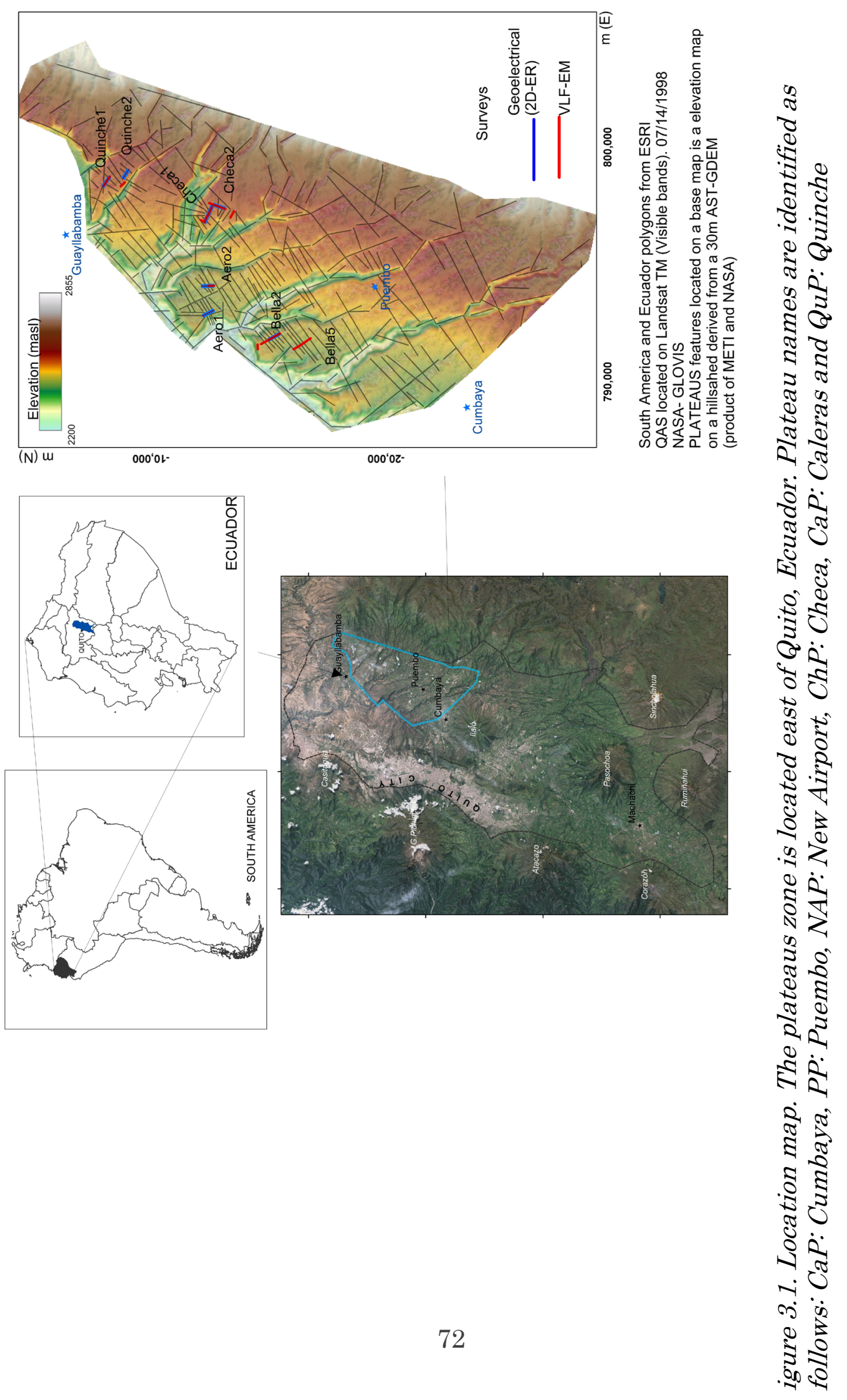


The foothills of Cordillera Real is the geologic boundary to the east, and the Ilaló Volcano and Cumbayá Valley form the southwest boundary. Subhorizontal layers of lava flows, lahar deposits, pyroclastic flows, and fluvial and alluvial deposits are part of the geological formations that exist in the Plateaus (Figure 3.2). The basement of the plateaus is reported to be formed by undifferentiated volcanic rocks of the Pallatanga Unit (Cretaceous) or the Pisque Formation of Pleistocene age. The basal part of the Pisque Formation is composed of andesitic and basaltic lavas.

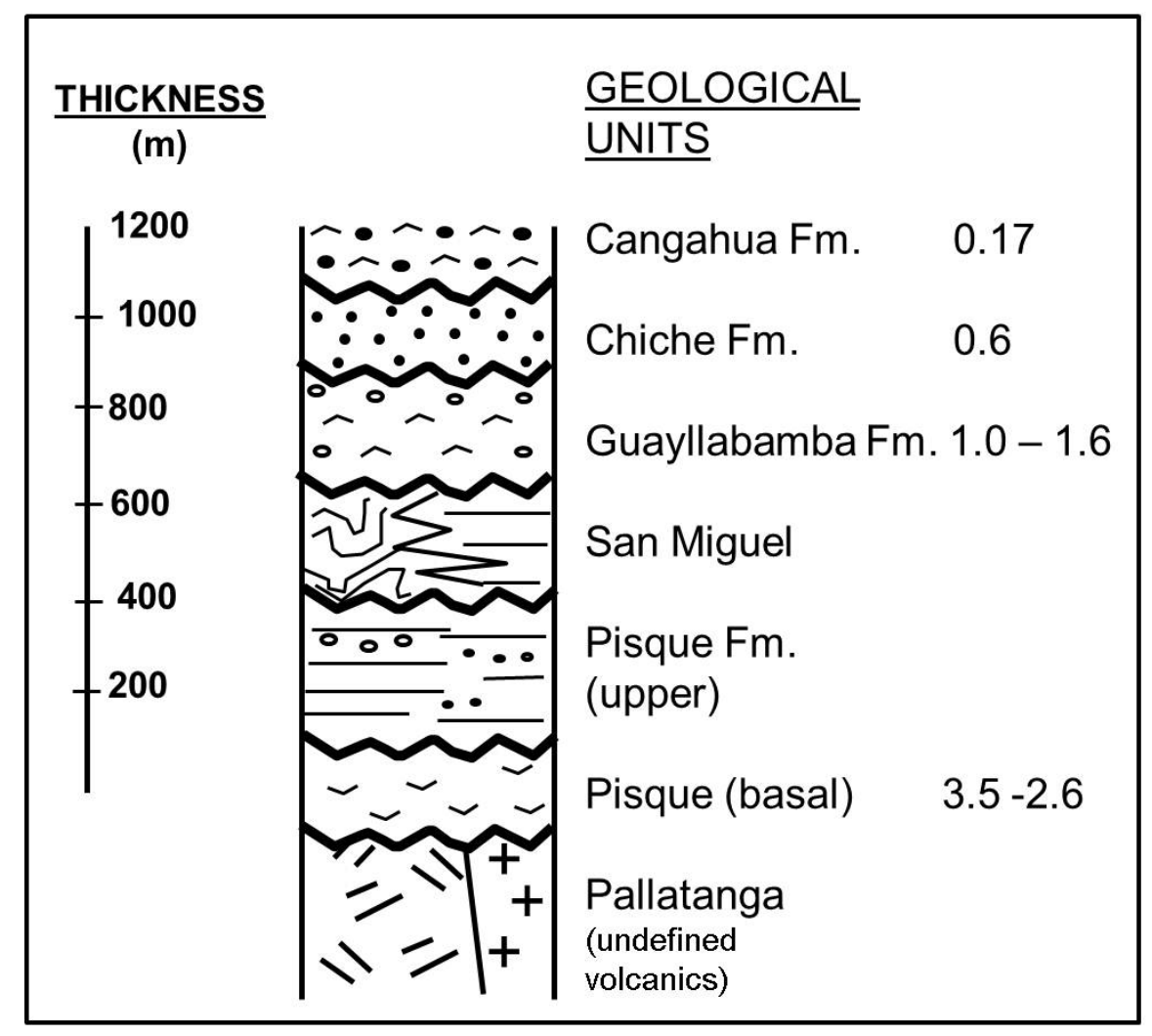

Figure 3.2. Geological units of the Plateaus region (After Winkler et al. (2005) 


\section{TWO-DIMENSIONAL ELECTRICAL PROFILING (2D -ER) METHOD:}

Geo-electrical methods are the most widely applied geophysical techniques for groundwater exploration. An electrical current is induced into the earth by means of two "current" electrodes. The potential differences created between these electrodes are measured at pairs of measuring (called "potential") electrodes. Readings of current strengths at the current electrodes and potential differences at the potential electrodes enable calculation of subsurface resistivities. The most common arrays for groundwater exploration are the 1D or vertical electrical soundings (VES), and the 2-dimensional profiling. VES is a very useful method for evaluating horizontally layered aquifers. $2 \mathrm{D}$-ER is designed to also detect lateral changes in resistivity such as water-bearing fractures (Ernston and Kirsch 2006; Loke 2012). Inversion methods are used to calculate apparent resistivities into subsurface resistivities that approximate the true subsurface resistivity distribution.

Two-dimensional electrical resistivity data was collected using the Advanced Geosciences, Inc. SuperSting R8/IP eight channels and the SuperSting R1/IP single-channel Memory Earth Resistivity and IP Meter (Advanced Geosciences, Austin, TX) For each survey with this system, 56 electrodes were set up along each profile using a uniform spacing that varied from 6 to $15 \mathrm{~m}$ depending on the desired depth and available space connected to the control box via addressed multi-channel cables. The control box followed a sequence of steps from a user-defined control file to operate the appropriate combinations of current and potential electrodes to complete the desired array (e.g., Schlumberger, Pole-dipole, Dipole-dipole or Wenner).

Fourteen profiles were carried out in the study area. The orientation of the surveys was mainly NNW so as to identify conductive structures associated 
with the E-W/SW-NE lineaments. Details regarding the azimuth, length and array used are listed in Table 3.1. Locations are indicated on Figure 3.1

Table 3.1. Description of the 2D-ER profiles carried out on the plateaus region. Coordinates on UTM_WGS84_17M

\begin{tabular}{|c|l|c|c|c|c|l|}
\hline \multirow{2}{*}{ ID } & \multirow{2}{*}{ NAME } & \multicolumn{2}{|c|}{ ORIGIN } & \multirow{2}{*}{ ORIENTATION } & \multirow{2}{*}{ LENGTH $(\mathbf{m})$} & \multirow{2}{*}{ ARRAY } \\
\cline { 3 - 4 } & & $\mathbf{X}(\mathbf{m})$ & $\mathbf{Y}(\mathbf{m})$ & & & \\
\hline SS-01 & Quinche1 & 799043.8 & -9108.5 & N50W & 504 & Schlumberger \\
\hline SS-02 & Quinche2 & 798735.2 & -8253.7 & N55W & 550 & Schlumberger \\
\hline SS-03 & Checa1 & 797553.3 & -12663.3 & N50W & 855 & Schlumberger \\
\hline SS-04 & Checa2 & 797415.6 & -13105.3 & N35E & 550 & Schlumberger \\
\hline SS-05 & Bella1 & 792050.0 & -15475.2 & N22W & 550 & Schlumberger \\
\hline SS-06 & Aero1 & 793053.5 & -12682.9 & N30W & 550 & Wenner \\
\hline SS-07 & Aero2 & 794089.7 & -12681.5 & NS & 550 & Wenner \\
\hline
\end{tabular}

Resistivity inversion was carried out using the Earth Imager (Advance Geosciences Inc, Austin, TX) software using a finite element method solver for the spatial approximations and a Cholesky decomposition method to solve the resulting system of equations. Figure 3.3 depicts the inverted sections that were obtained.

\section{Digital Image Processing}

Gradient calculation, directional gradient filtering, and extraction of local minima (by using watershed modeling algorithms) were performed on each of the 2D-ER sections to improve the characterization of the horizontal and vertical variations on electrical resistivity. Based on the outcomes, edges and boundaries on the sections were related to geological features. 

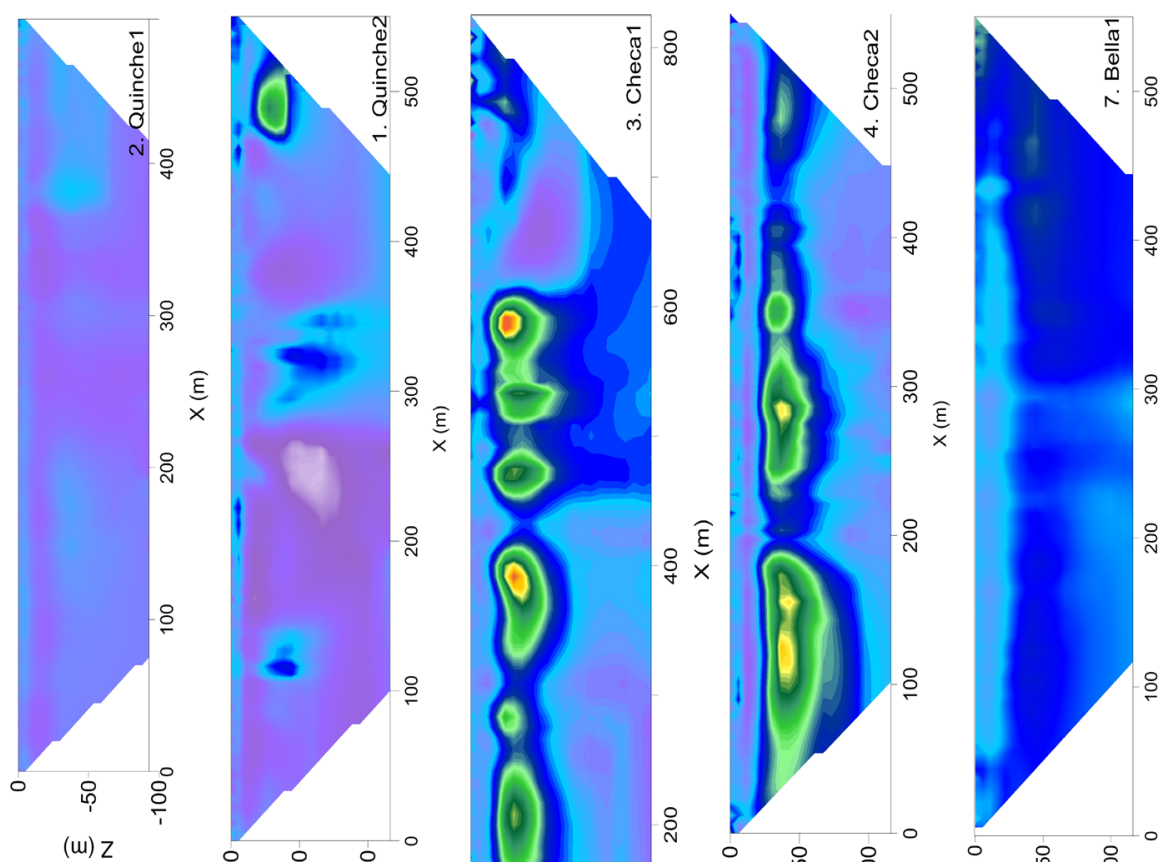

$\frac{8}{x}$

(u) Z
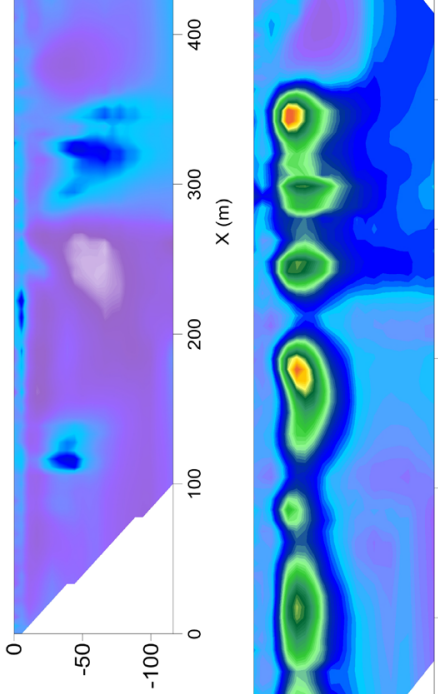

$\div$

8

(0) $\stackrel{\substack{\underline{\varepsilon} \\ x}}{0}$

(u) Z
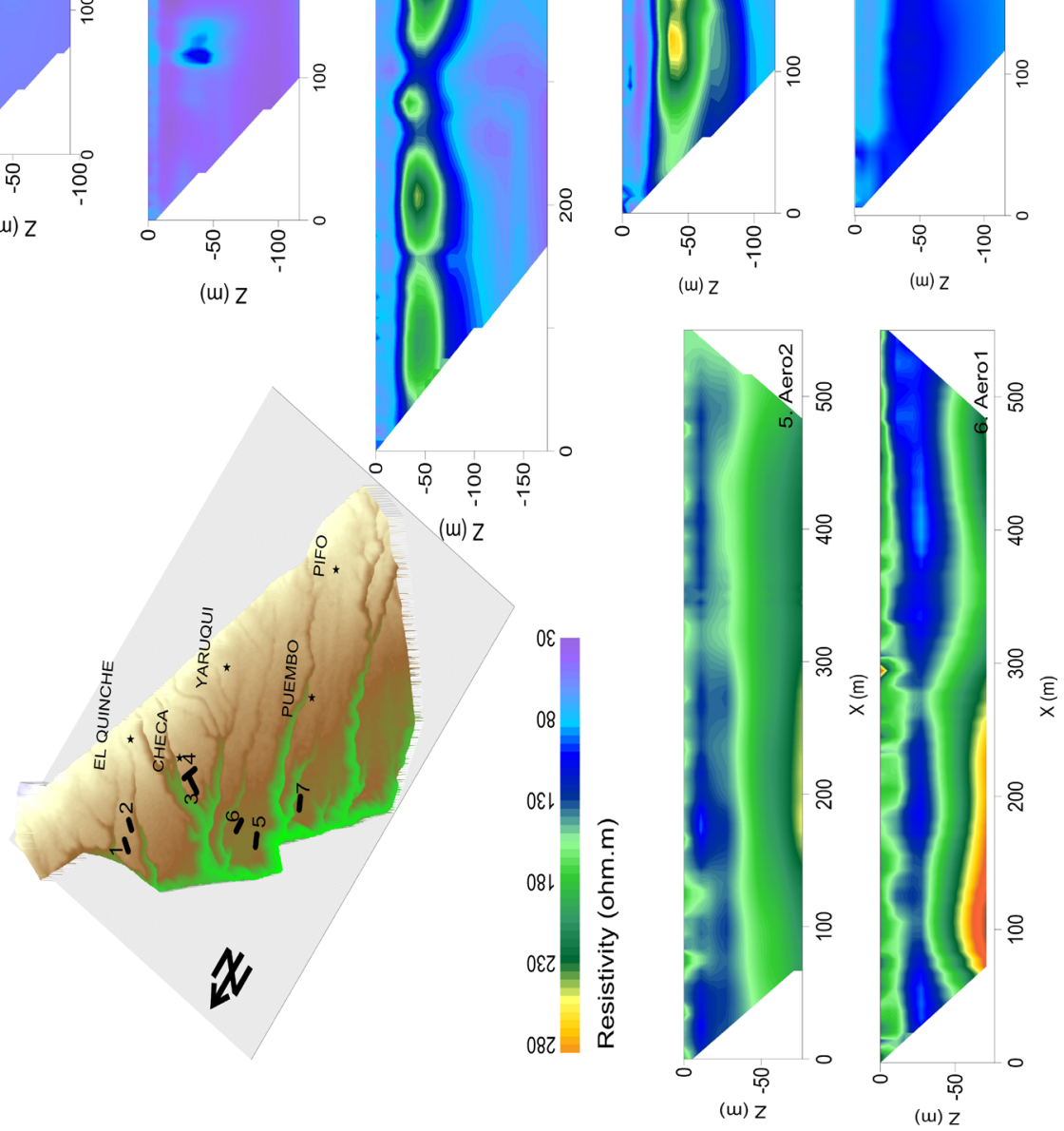
Gradient calculations and filtering were carried out using Surfer V.9.3 (Golden Software Inc, Golden, CO). Local minima maps were generated using the flow direction and flow accumulation algorithms in ESRI ${ }^{\circledR}$ ArcMapTM 10.0 (ESRI, Redlands, CA). Gradient sections were used to calculate horizontal boundaries. Lines of maximum gradient were used to identify the boundaries between layers. Saturated fractured zones (SFZ) were identified where vertical linear features (boundaries between east-gradient filtered zones), associated to a local resistivity minimum, indicating the lowest resistivity point, as illustrated on Figure 3.4.
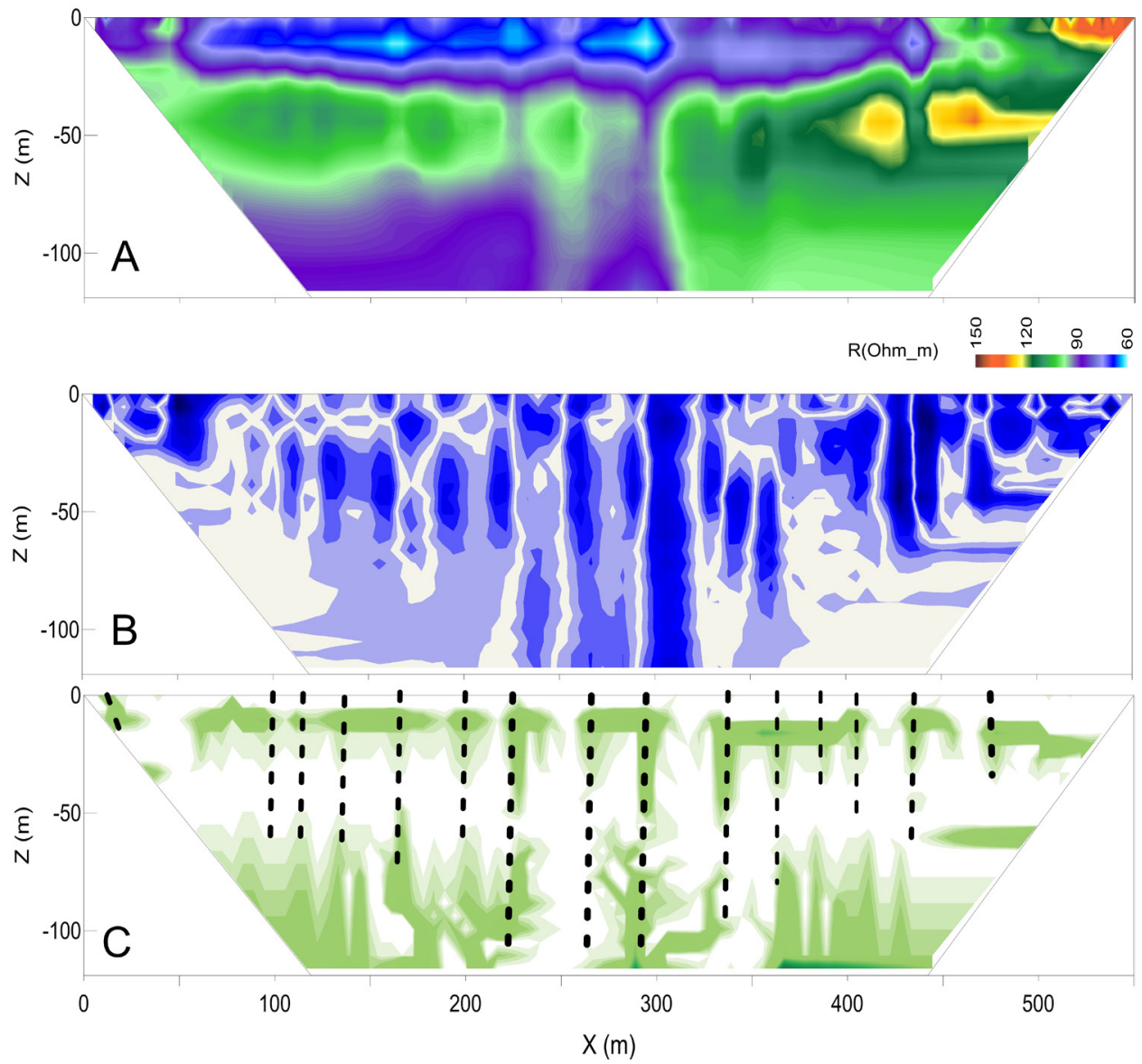

Figure 3.4. Example of the extraction of SFZ on the survey Bella 2. A. Inverted section. B: East gradient filtered section and $C$. section with the local lowest resistivity values (local minima). Dashed lines are the interpreted $S F Z$ 
Given the complex distribution of the electrical resistivity in the first $10 \mathrm{~m}$ of depth, many of the features were interpreted from continuous vertical features below the 10-m depth.

Gradient filtered sections are depicted on Figure 3.5. East-gradient filtered and the location of the SFZ for all the surveys is depicted in Figures 3.6.

Figures 3.3 and 3.5 suggest that despite the similarities of the geological layers and their subhorizontal nature, there are large variations in resistivity values from plateau to plateau. Resistivity varies from $20 \mathrm{ohm}^{-m}$ to $358 \mathrm{ohm}^{-}$ $\mathrm{m}$. The areas with the lowest-resistivity layers were found in QUP (Quinche 1 and 2) and PP (Bella1). The highest resistivity values were observed in the surveys carried out on the NAP (Aero 1 and 2). Lateral variations on resistivity are also observed in all the surveyed areas (Figure 3.6). Surveys on the CHP (Checa 1 and 2) had the largest variability in resistivity.

On the gradient sections (Figure 3.5) the existence of horizontal layers is evident, except for the survey Quinche2. Two common horizontal geoelectrical layers were identified. The first geoelectrical layer has an average thickness of $30 \mathrm{~m}$ and is interpreted as the upper part of the Cangahua Formation.The top of the second layer is observed at an average depth of $70 \mathrm{~m}$. This layer is interpreted as the lower part of the Cangahua formation. A third layer is observed on the Checa 1 and Checa 2 surveys. The top of this layer is observed at an average depth of $100 \mathrm{~m}$. This layer corresponds to the unsaturated part of the Chiche formation. The top of the third layer is also indicating the location of the water table. It is noteworthy to mention that these layers are spatially discontinuous. Changes in the thickness of these layers are also observed along the profiles. These lateral changes are due probably to the existence of vertical fracturing. 


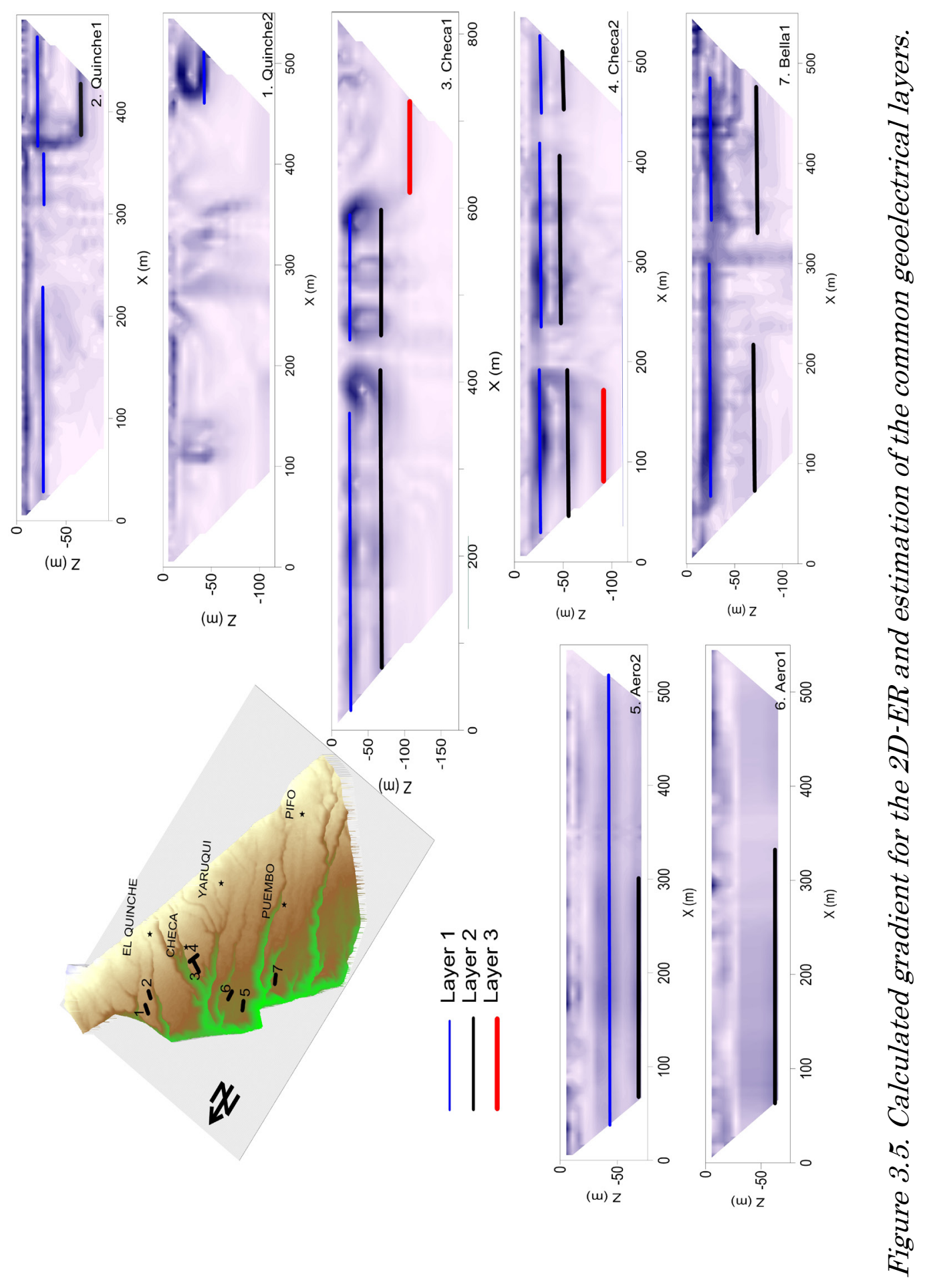




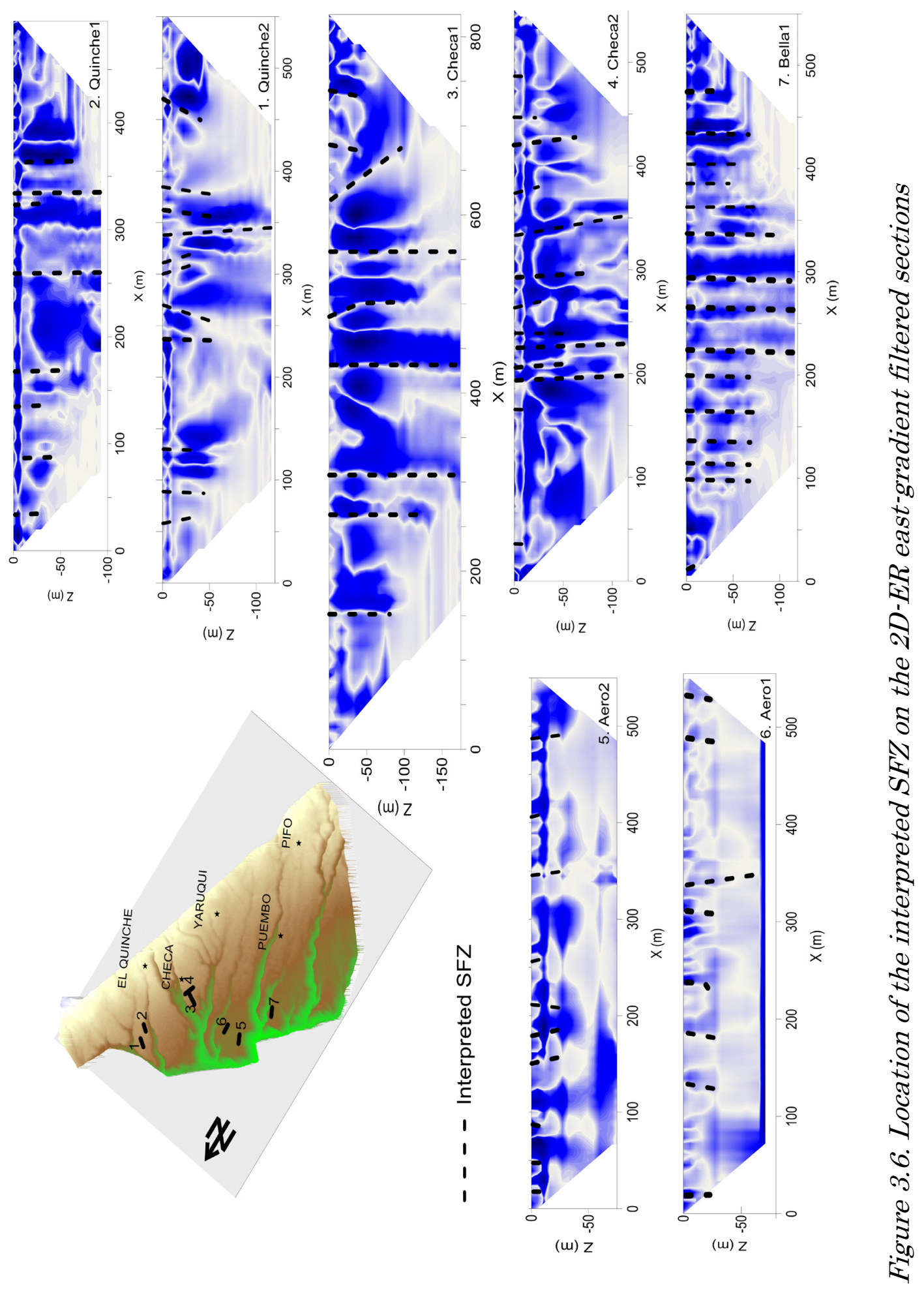


A total of 75 SFZs were extracted for the surveyed areas (Figure 3.6). The highest number of SFZs is found on Bella1 survey and the lowest on the Checa 1 and Checa 2 surveys. The average depth of the SFZ is $59 \mathrm{~m}( \pm 40 \mathrm{~m})$, The shallowest SFZ's are found on the surveys Aero 1 and Aero 2. For these surveys, the SFZ are found mostly at depths less than $\sim 30 \mathrm{~m}$. This could indicate that fracturing is affecting the upper part of the NAP Plateau. Figure 3.6 also indicates that there is an increasing depth of the features toward the center of the surveys. This effect might be due to the data acquisition method.

\section{Vertical Electrical Sounding (VES)}

Vertical electrical sounding (VES) is a traditional geophysical method for groundwater exploration. The method started in the 1920s and it continues to be used commonly in groundwater investigations (Loke 2012). In this method, the current electrodes of the array remain fixed. The separation between the potential electrodes is increased to obtain more information about the deeper layers of the aquifers. To interpret the data from such a survey, it is normally assumed that vertical changes in resistivity are due to the existence of horizontal layers. Changes in the resistivity in the horizontal direction are not considered (Ernston and Kirsch 2006; Loke 2012). VES data was acquired from the groundwater database of the Quito water utility company EPMAPS (2012). VES data sets were selected to be compared to 2DER inverted sections. The criteria for VES selection were (1) located near to a 2D-ER survey. (2), AB/2 lengths are enough that could provide depths of investigation comparable to those of the 2D-ER inverted sections. Selected VES were interpreted using the program IPI2WINv.7.01.03 (Moscow State University, Moscow, Russia). Interpreted data included the calculation of 
number of layers, thickness, and resistivity values. Those interpretations were then compared to the outcomes of the $2 \mathrm{E}$-ER inverted section.

The spatial correlation of the resistivity layers obtained from interpreted VES is challenging. Despite their close location, VES results do not display a common pattern of vertical layering or resistivity values. On the contrary, 2DER inverted sections have a common pattern of vertical layering that agrees with the geological information and water-level data of the plateaus.

Figure 3.7 depicts an example of two interpreted VES data sets located nearby the Bella $12 \mathrm{D}$-ER survey. The layers and resistivity values identified on the VES2 and VES4 have practically no correspondence between them or with the $2 \mathrm{D}$-ER section. An interpolation of apparent resistivity between the two VES was carried out, that is depicted in Figure 3.7 as well. This profile also has no similarity to the 2D-ER section.

\section{VERY-LOW FREQUENCY ELECTROMAGNETIC METHOD (VLF-EM) METHOD}

Electromagnetic methods for groundwater are based on the interaction of electromagnetic fields with subsurface electrical conductors. Primary electromagnetic fields that are generated by radio transmitters made for navigation purposes can induce currents at subsurface conductors as they pass through the crust. The induced currents produce a secondary electromagnetic field that differs in magnitude, orientation, and phase from the primary field. A receiver measures the resulting total field. The very-low frequency electromagnetic method (VLF-EM) uses radio signals in the bandwidth of $15-30 \mathrm{KHz}$. 

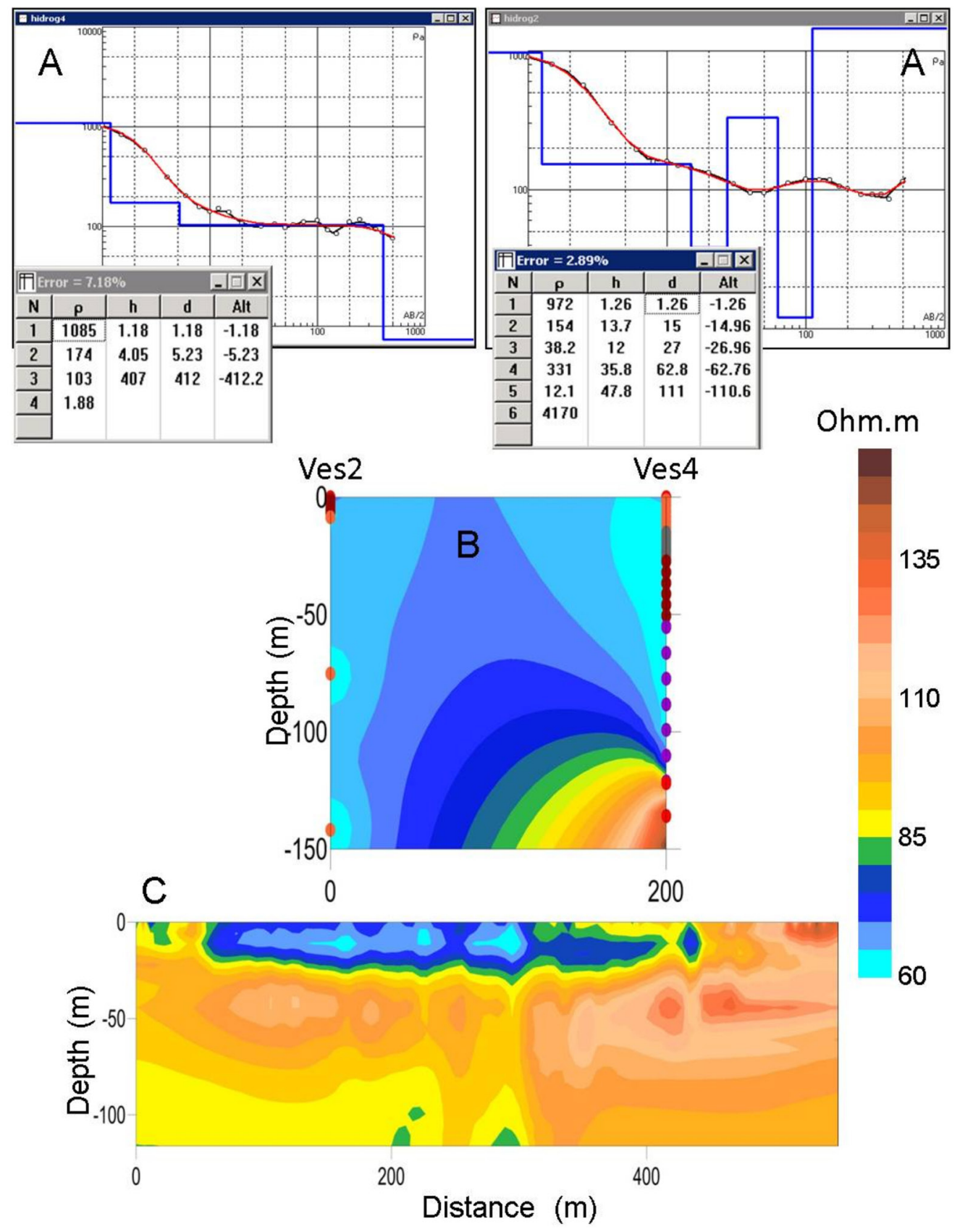

Figure 3.7. Interpreted VESS compared to the 2D-ER inverted section (Bella 2). A: VES log- log curves and layer models. B: Resistivity contour maps derived from VES interpretation. $C$ : Interpreted $2 D-E R$ (SST) section. 
In this method the vertical and one horizontal component of the elliptically polarized magnetic field are measured. The vertical component $\left(H_{Z}\right)$ is called the real part or in-phase; the horizontal component $\left(H_{y}\right)$ is called the imaginary part or quadrature. The relationship between these two components area is described by a scalar tipper, $B$, defined as $H_{z}=B \cdot H_{y}$.

VLF-EM data is acquired by doing traverses as perpendicular as possible to the suspected water-bearing fracture and almost parallel to the direction of the radio signal. Variations are permitted up to 30 degrees on either side of the direction of the signal (Mitchell 2001). Along the traverse, a VLF reading is taken at the same intervals. Significant subsurface structures are indicated by distinct positive and negative peaks in profiles from the VLF-EM data. The zero-crossing points in the in-phase and quadrature profiles determine the location of a fault or linear structure. Compared to the inphase data, the quadrature responses are usually smaller but are important in distinguishing the electrical conductivity of these faults/structures. A positive inflection (peaks going from positive to negative) indicates a poor conductor (i.e., dry fracture), whereas a negative inflection represents a good conductor (more likely a water bearing fracture).

For qualitative analysis VLF-EM data, Fraser and Karous-Hjelt filters are applied to the in-phase and quadrature data. The purpose of the filters is to differentiate between the different fractures/anomalies that could be present in one traverse. Fraser filtering improves the signal of conductive structures by transforming the zero-crossing points into peaks. Karous-Hjelt filtering is used to obtain relative current density pseudo-sections in which lower values of relative current density correspond to higher values of electrical resistivity. VLF-EM quantitative interpretation is performed by inverting the tipper data. When lateral changes in resistivity are expected in the terrain, the 
tipper along the traverse is expected to vary, showing the strongest gradients at electrical conductivity contrasts. Through inversion, a surface distribution of the electrical resistivity of the ground can be obtained. One of the major advantages of the inversion method is the information obtained about the depth and width of the conductors identified in the filtered data.

For this study, VLF-EM data were collected using the WADI (ABEM Instruments, Sundbyberg, Sweden),along thirteen traverses oriented mainly NNW and with a traverse oriented NNE. Readings were taken every 5, 10 or $20 \mathrm{~m}$. Frequencies between 20 to $24 \mathrm{kHz}$ were used for the measurements. Several of the surveys were run parallel to the 2D-ER surveys to evaluate the performance of the VLF-EM method in detecting water-bearing fractures. Information about the surveys is presented on Table 3.2.

Fraser and Karous-Hjelt filtering were applied to the VLF-EM data, using the IXVLF V.1.04 (Interpex Ltd., Golden, CO). In this study the current density pseudo-sections derived from the Karous-Hjelt filter did not show satisfactory results when compared to the $2 \mathrm{D}$-ER data and were not considered in the interpretations. The Inv2DVLF-V1 (Monteiro Santos et al. 2006) was used to invert the VLF-EM tipper data. The program is based on a $2 \mathrm{D}$ regularized approach, using the smoothness-constrained least-squares method. One of the input parameters for the inversion is a starting resistivity value. Values entered for each profile were based on the average resistivity found, based on the 2D-ER surveys or existing vertical electrical soundings.

Locations and depths of conductive structures were identified on the 2D-ER and VLF-EM inverted sections and Fraser-filtered profiles. In order to assess the performance of the VLF-EM method, sections were compared to the $2 \mathrm{D}^{-}$ ER profiles where possible. 
Table 4.2. Information about the VLF-EM traverses carried out on the plateaus (Coordinates in UTM_WGS_17N)

\begin{tabular}{|c|c|c|c|c|c|c|c|}
\hline \multirow{2}{*}{ ID } & \multicolumn{2}{|c|}{ ORIGIN } & \multirow{2}{*}{ NAME } & \multirow{2}{*}{ FILE } & \multirow{2}{*}{$\begin{array}{c}\text { ORIE } \\
\text { NTATI } \\
\text { ON } \\
\end{array}$} & \multirow{2}{*}{$\begin{array}{l}\text { LEN } \\
\text { GTH } \\
(\mathrm{m}) \\
\end{array}$} & \multirow{2}{*}{$\begin{array}{c}\text { Station } \\
\text { distance }(\mathrm{m})\end{array}$} \\
\hline & $\mathrm{X}(\mathrm{m})$ & $\mathrm{Y}(\mathrm{m})$ & & & & & \\
\hline W-01 & 792050.0 & -15475.2 & Bella1 & 0114 & $\mathrm{NS}$ & 545 & 5 \\
\hline W-02 & 791768.2 & -14976.0 & BellaNS & 0116 & $\mathrm{NS}$ & 350 & 10 \\
\hline W-03 & 791580.7 & -14531.6 & Bella_EW & 0115 & EW & 210 & 10 \\
\hline W-04 & 791845.9 & -16784.5 & Bella5 & 0117 & $\mathrm{~N} 25 \mathrm{~W}$ & 380 & 10 \\
\hline W-05 & 791598.5 & -16424.9 & Bella6 & 0118 & N39W & 250 & 10 \\
\hline W-06 & 794089.7 & -12681.5 & Aero2 & 0090 & $\mathrm{NS}$ & 310 & 5 \\
\hline W-07 & 797044.8 & -12435.9 & Checa1 & 0100 & NW & 270 & 5 \\
\hline W-08 & 796811.5 & -12333.2 & Checa11 & 0101 & $\mathrm{~N} 40 \mathrm{E}$ & 160 & 5 \\
\hline W-09 & 797415.6 & -13105.3 & Checa13 & 0102 & $\mathrm{~N} 25 \mathrm{E}$ & 750 & 10 \\
\hline W-10 & 797252.0 & -13551.7 & Checa3 & 0103 & N50W & 300 & 5 \\
\hline W-11 & 797041.1 & -12422.4 & Checa 4 & 0106 & $\mathrm{~S} 56 \mathrm{E}$ & 420 & 20 \\
\hline $\mathrm{W}-12$ & 798517.4 & -8913.0 & Quinche12 & 0108 & N50W & 240 & 5 \\
\hline W-13 & 798735.2 & -8253.7 & Quinche2 & 0110 & N55W & 480 & 10 \\
\hline
\end{tabular}

\section{VLF-EM RESULTS}

A total of 94 positive anomalies were identified on the FFD of the surveyed areas. Positive anomalies were observed on average every $48 \mathrm{~m}( \pm 38 \mathrm{~m})$. The average width of the anomalies is $23 \mathrm{~m}( \pm 14 \mathrm{~m})$. Inverted sections provided information on the variations of the apparent resistivity up to depths of $60 \mathrm{~m}$, Figure 3.8 shows some examples of the FFD and the inverted sections obtained. When comparing the FFD and the resistivity sections it is observed that some positive anomalies were represented as vertical conductors (A, on Figure 3.8). Other anomalies were represented as linear features indicating sharp changes in resistivity (B, on Figure 3.8). Moreover, there were groups of anomalies that were modeled as zones of low resistivity (C, on Figure 3.8) 


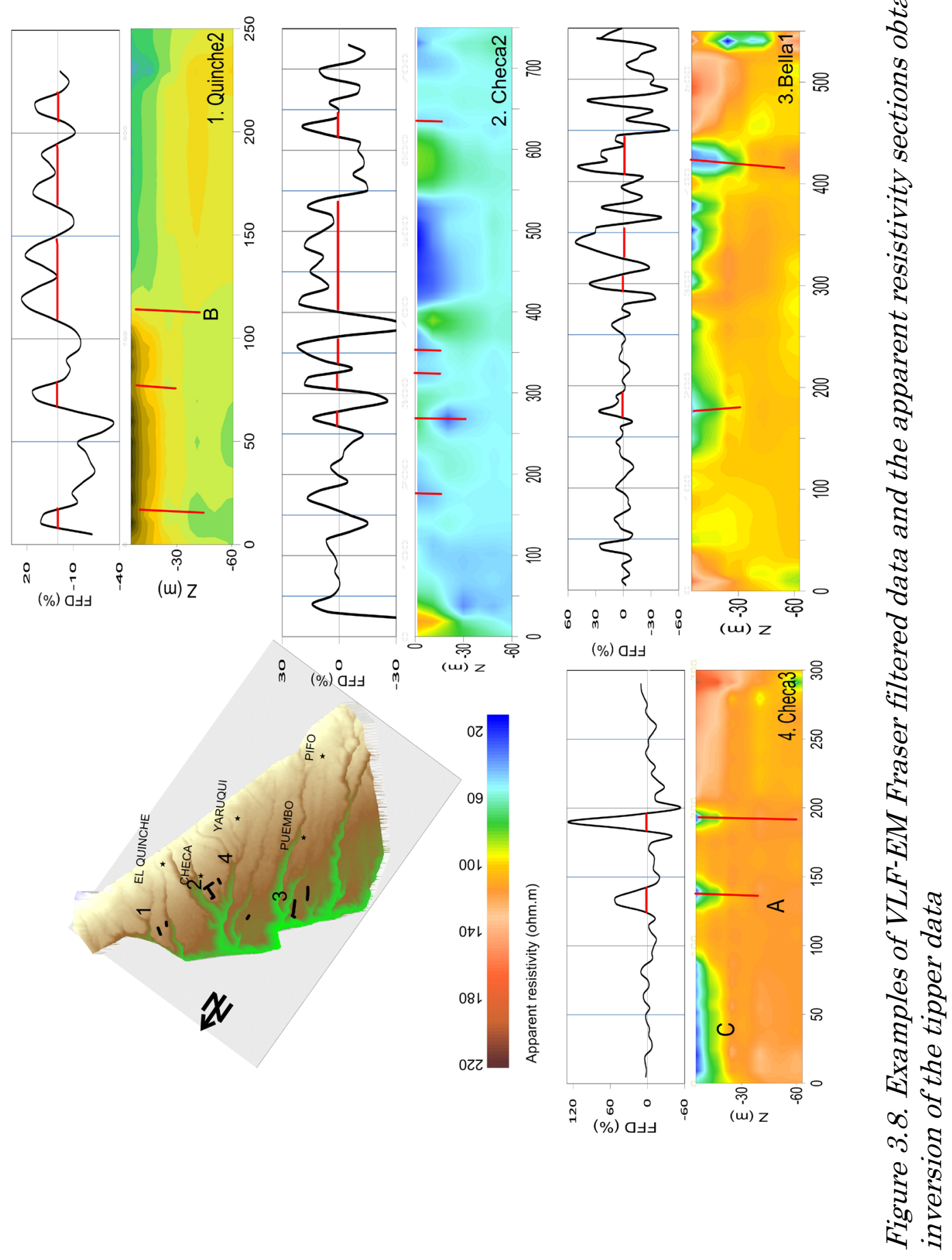


On the inverted data $73 \%$ of the positive anomalies identified on the FFD were represented as vertical features (either as a conductor or a line of sharp change in resistivity). The average depth of features interpreted on the inverted data is $33 \mathrm{~m}( \pm 16 \mathrm{~m})$.

\section{Comparison between the 2D-ER and the VLF-EM}

Fraser-filtered data (FFD) and inverted sections from the VLF-EM and 2DER inverted and east-gradient filtered sections were used to analyze the performance of the VLF-EM methods in mapping fractured zones. Apparent resistivity sections of the tipper inverted data were also compared to the $2 \mathrm{D}^{-}$ ER resistivity profiles. This analysis was carried out for four VLF-EM surveys, which were done at the same location and spatial orientation to $2 \mathrm{D}$ ER sections.

Comparative analysis was performed on Surfer V.9.3 (Golden Software Inc, Golden, CO). The comparisons focused on the analysis of the distribution of the positive anomalies over the surveyed area (locations of the peak and widths of the anomalies) in relation to the location of the VFZ extracted from the 2D-ER sections and the filtered zones as well, as depicted on Figure 3.9. On that figure is observed the location of the positive anomalies on the FFD corresponds to low resistivity zones in the 2D-ER profiles. Moreover, the widths and spatial distribution of positive anomalies follow the same "trend" in terms of location and extent of the 2D-ER filtered (examples are indicated using boxes labeled A and B on Figure 3.9). This correspondence might indicate that the VLF-EM method is representing the variations in the lateral electrical resistivity in the ground. Out of 46 positive anomalies, 54\% of them correspond to a VFZ extracted from the 2D-ER sections. 


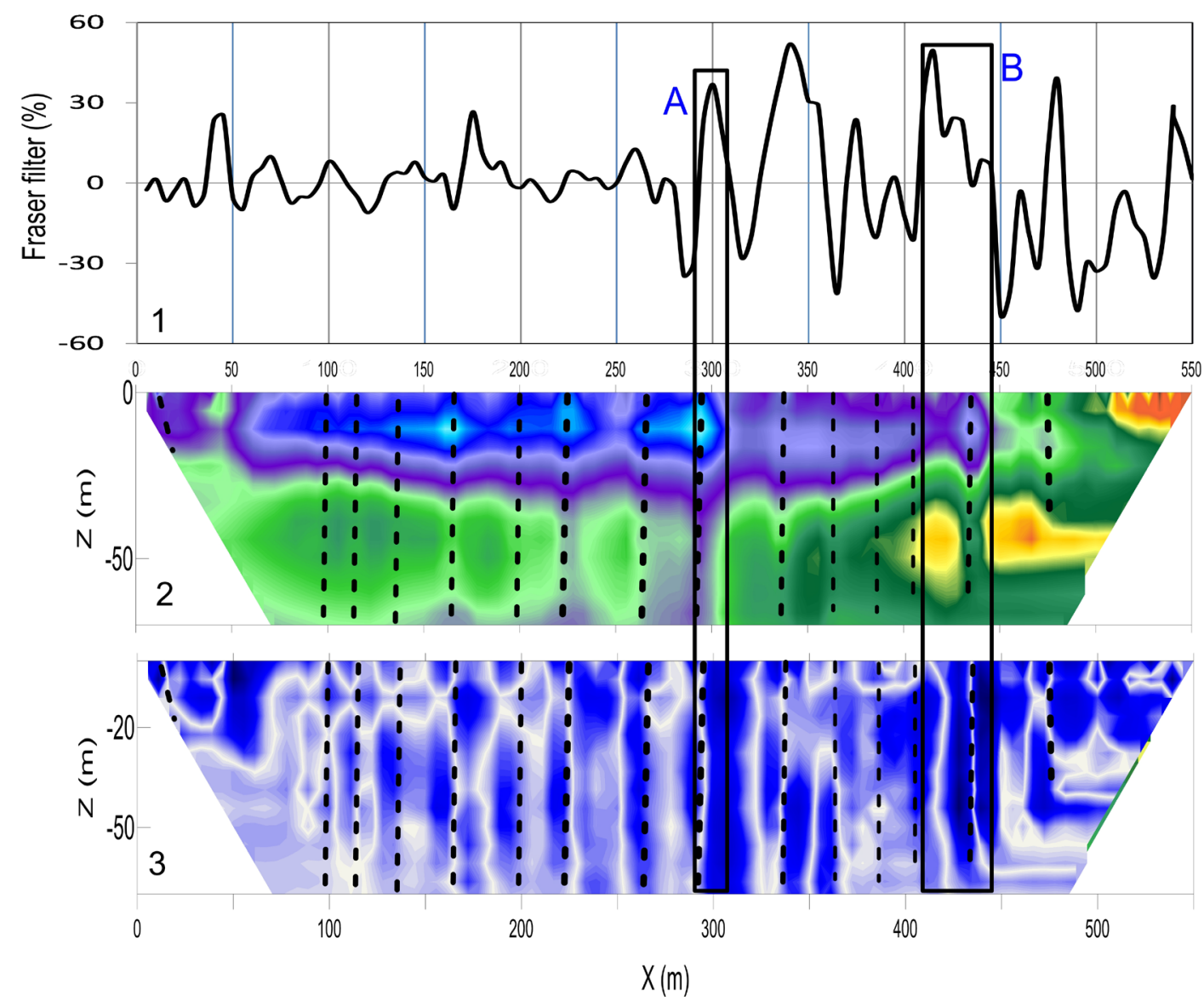

Figure 3.9. Example of the correlation between VLF-EM Fraser filtered data and the 2D-ER (Survey Bella 1). 1. VLF-EM Fraser filtered data. 2. 2D-ER resistivity section. 3.2D-ER east-gradient filtered section. Dashed lines indicate the SFZs interpreted in the $2 D$-ER method.

A comparison of VLF-EM and 2D-ER resistivity sections indicate that the VLF-EM profiles follow the general trends on resistivity patterns observed on the first $30 \mathrm{~m}$ of the 2D-ER inverted sections of the Bella2, Checa2 and Aero2 surveys and for the first $10 \mathrm{~m}$ of the Checa2 section. This might indicate that the depths of the conductors are being overestimated when VLF-EM inversion is performed. Moreover, resistivity pattern distribution on the VLFEM section is less detailed and hence fewer vertical conductors were identified than those observed on the 2D-ER method. The percentage of SFZ's identified on the VFL-EM resistivity sections is: Quinche 2: 27.3\% Checa2: 31.3\%, Bella2: 42.9\% and Aero2: 57.1\%). In summary, based on the 
comparative analysis, the VLF-EM (especially the FFD) reflects very well the changes in lateral resistivity of the shallow part of the ground (down to $30 \mathrm{~m}$ depth). Inversion of the tipper data produced the general character of the lateral variations in resistivity but is not detailed enough to identify all the anomalies seen in the FFD. Based on these findings, VLF-EM positive anomalies indicated on the FFD were used to identify locations of potential fractured areas that were compared to the lineament map created by RiosSanchez et al (2012c), regardless of their representation on the inverted data.

\section{GEOPHYSICALLY IDENTIFIED FRACTURED AREAS VERSUS LINEAMENT MAP}

Relationships between lineaments and the interpreted fractured areas from the VLF-EM and 2D-ER methods (geophysically features) were explored by overlying the locations of those potential fractured areas from both methods to the lineament map created by Rios-Sanchez et al. (2012c).

The methodology used for the map was a combined remote sensing and digital terrain analysis approach, lineaments of regional origin were located. To improve the detail of the map, finer spatial-resolution images (ASTER VNIR, Quickbird) and DEMS were used.

Lineaments were extracted by using high-spatial-resolution imagery combined with the aspect map derived from the DEM, provide the elements to map structures that at first appear as locally as short features (on the walls of the ravines) but actually have a larger extent and were spatially correlated to other fractures in a regional view. The detailed analysis revealed a new set of SW-NE lineaments that were not observed before. However, not all the short fractures observed were correlated to a lineament. 

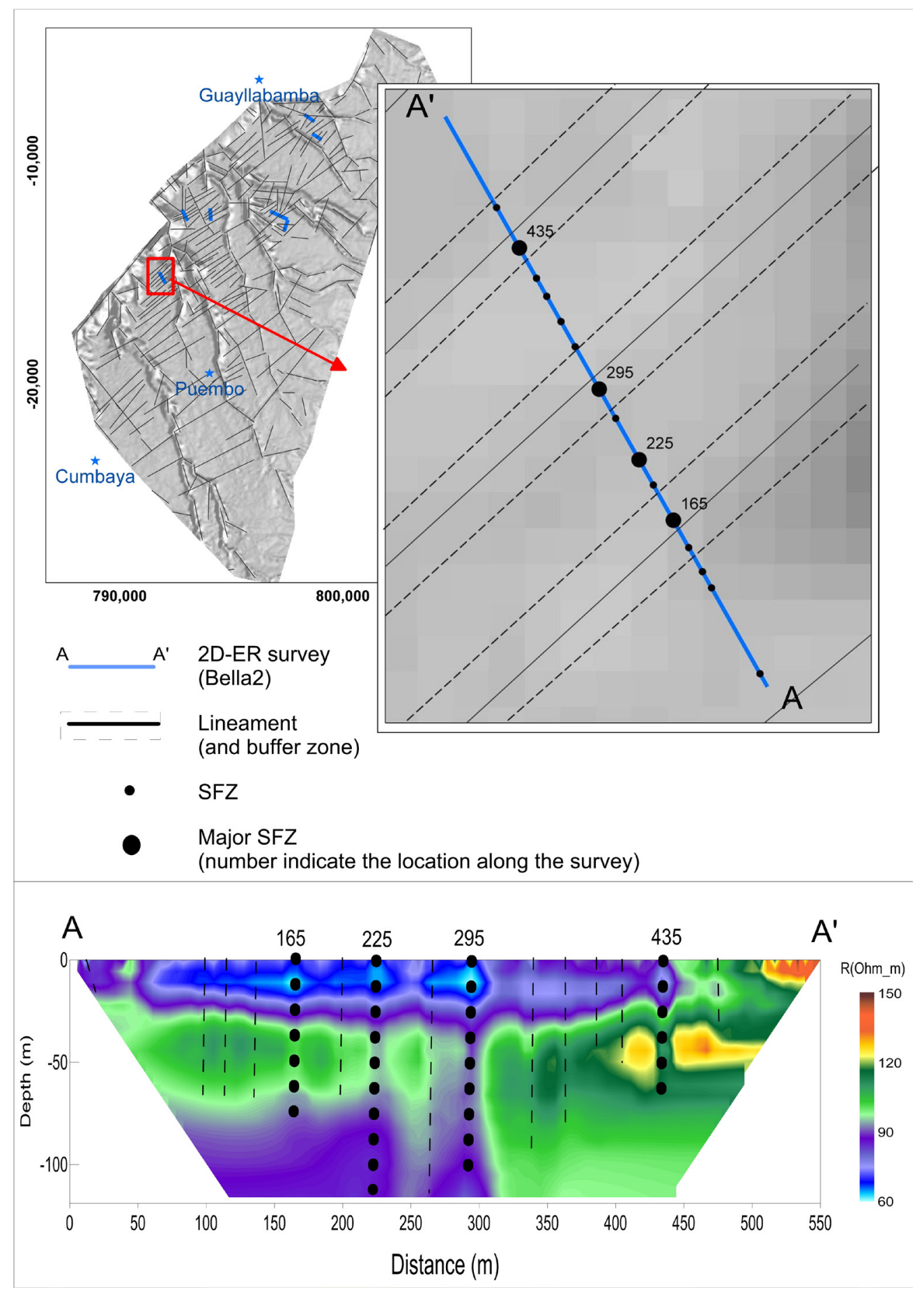

Figure 3.10. Example of the relationship between lineaments and the SFZ'S extracted on the 2D-ER. Upper part indicates the geographic location of the SFZ and on the section. Lower part displays the location of the SFZ on the section (dotted lines) 
During the analysis Buffer areas of $\sim 30 \mathrm{~m}$ width were calculated for lineaments to analyze the coincidence between the lineament and the geophysically detected features, as depicted on Figure 3.10. The width of the buffer area was calculated based on the aspect map. From the superposition it was observed that lineaments were correlated to more than one geophysically detected feature. This happens due to the fact that the spacing of geophysical features is smaller than the distance between lineaments.

Lineaments coincide generally with the deepest SFZ's from the 2D-ER and those indicating the highest resistivity contrast (Figure 3.10). No specific pattern was observed for the VLF-EM positive anomalies coinciding with lineaments.

Geophysically interpreted fracture zones outnumber the number of lineaments mapped using remote sensing images by Rios-Sanchez et al. (2012c). One of the reasons for the difference between the number of anomalies and lineaments can be due to the fact that the geophysical surveys are reflecting more fracturing than is represented by the lineament map. Geophysically detected features can be interpreted such as expression on top of the plateaus of the fracturing observed on the walls of the ravines. As mentioned before, not all of these fractures were extrapolated as lineaments. The intense agricultural activity on the plateaus and the lack of geomorphologic evidence prevented the majority of the short fractures from being recognized on top of the plateaus and being extrapolated and included on the lineament map (Rios-Sanchez et al. (2012c).

The distance between nearby short fractures agrees with the distance between geophysically detected features. Lateral variations on electrical 
resistivity might be indicating the expression on top of plateaus of fractures that initially were considered to be affecting mainly the walls of the ravines. An example of the relationship between these short fractures and the geophysically detected features is depicted on Figure 3.11. The QuickBird imagery from the figure was acquired from the EPMAPS database ((EPMAPS 2012).

Lateral variation in resistivity on the surveyed areas can also be due to the fact that the surveyed zones are mainly located at the unsaturated zone which it is located at depths of $\sim 100 \mathrm{~m}$. In this zone, higher variation in resistivity is expected, given the different degrees of water content that can occur and its influence, when compared to the saturated zone. In order to verify the fracturing on the plateaus, other geophysical methods should be applied.

\section{CONCLUSIONS}

Based on the outcomes of this study, it is possible to conclude that the Plateaus Region is highly affected by faulting and fracturing. The impacts of this fracturing are expressed as lateral variations inthe properties of the rocks and sediments. Moreover, changes in the thicknesses of the geological layers that form the aquifers can also be attributed to the existence of faults and fractures.

This research demonstrates that the 2D-ER and VLF-EM methods are effective for subsurface characterization of fracturing in the volcanic terrains. Lineaments mapped by Rios-Sanchez et al. (2012c) were correlated to saturated vertical fractures (SFZ) extracted from the 2D-ER and VLF-EM 
Fraser filtered data. Moreover, this detailed geophysics study likely indicates that more intense fracturing is happening in the plateaus.

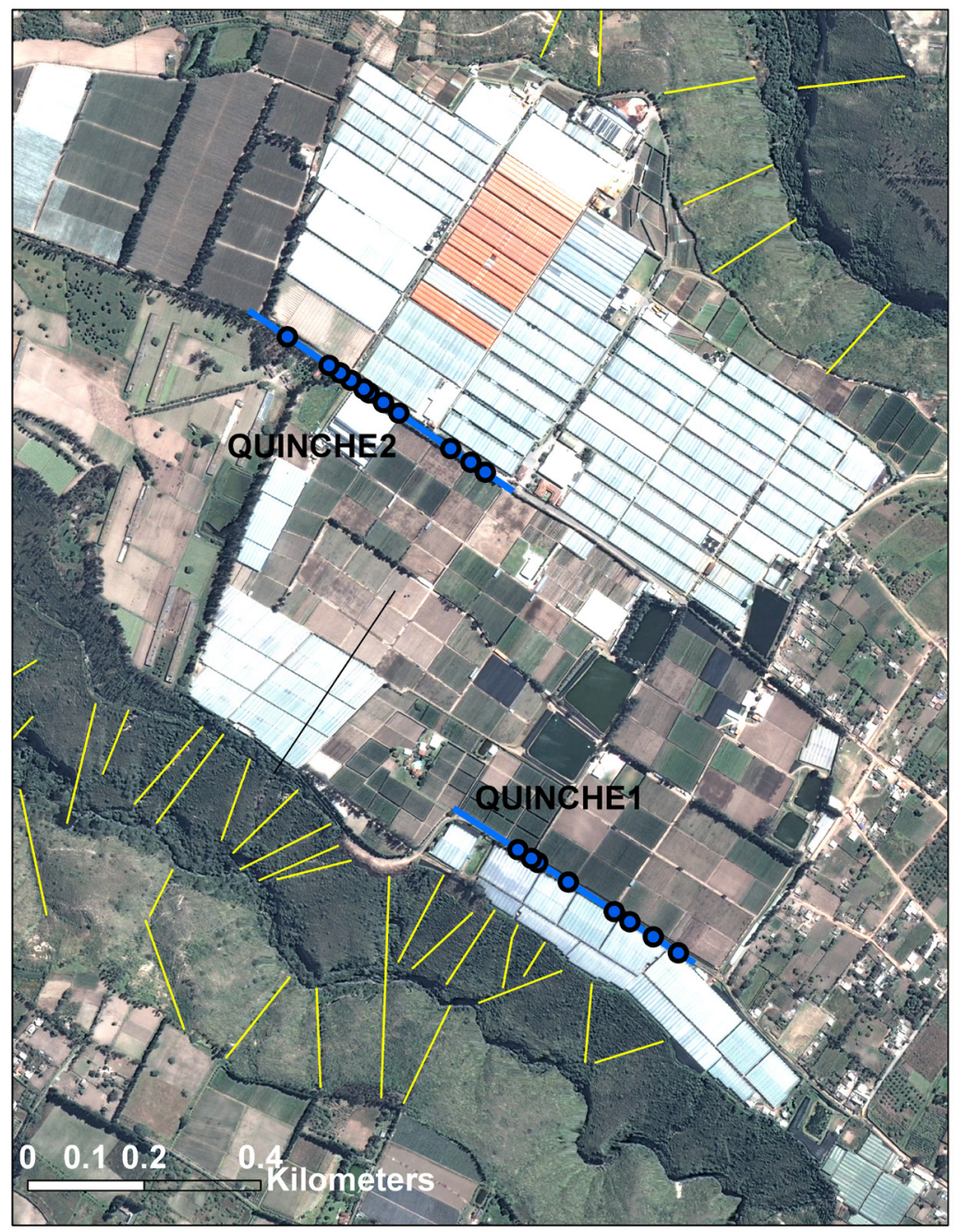

Figure 3.11. Locations of the 2D-ER surveys (blue lines) and their VFZ's (black circles) in relationship to the fractures (yellow lines) on the ravines. Fracture lines and VFZ located on a QuickBird image (from EPMAPS database).

Digital image processing techniques are a very useful tool to apply to resistivity sections in order to minimize the uncertainty when extracting vertical and horizontal boundaries. 
The VLF-EM method proved to be effective to identify conductors associated with water-bearing fractures in volcanic terrains with depths less than $30 \mathrm{~m}$. The combined interpretation of Fraser filtered profiles and an inverted section was necessary since the Fraser filtered profiles give not information of depth. Inverted data provided information on the depth and lateral extension of the anomalies. However, not all the anomalies were represented as vertical conductors, which is a limitation of the method.

When analyzing the profiles laterally it was observed that areas of high resistivity were often separated by zones of significantly lower resistivities. These variations may indicate the presence of zones of fracturing that are acting as preferential flow areas for rainfall and irrigation coming from plantations. These areas would have lower resistivities and were more frequently identified on the first layer and less frequently on the second layer and third layer. Also, the lateral variations were more easily observed on the raw data profiles than in the inverted ones.

The comparison of 2D-ER and VLF-EM inverted sections allowed for assessing the effectiveness of the VLF-EM method for mapping subsurface fractures. By analyzing 2D-ER and VLF-EM inverted sections from the same locations it was observed that for the first $30 \mathrm{~m}$ the VLF-EM inversion produces a generally similar resistivity horizontal distribution pattern to the one obtained with the $2 \mathrm{D}$-ER method. The range of resistivity values though is not comparable between the two methods. Below the practical depth range of $30 \mathrm{~m}$, VLF-EM sections have little to no correlation with the 2D-ER sections. 


\section{ACKNOWLEDGMENTS}

This material is based upon work supported by the National Science Foundation under Grant No. 0530109. We are also grateful to the Water Utility Company of Quito, Ecuador (EPMAPS), especially to Teresa Muñoz and Oscar Larrea, for providing invaluable technical and logistical support for the development of this study. We are also grateful to Vinicio Naranjo, Guillermo Mendoza, and Marco Morales (EPMAPS); students of Michigan Technological University's Aqua Terra Tech Enterprise; Peace Corps Masters International students Daniel Smith and Jacqueline Houston; Geology students Fernanda Naranjo and Andrea Cordoba at Escuela Politecnica Nacional, EPN, Ecuador; and Carla Manciati (PhD Student at University of Montpellier) for their participation in the field work.

\section{REFERENCES CITED}

Adepelumi, A., M. Yi, J. Kim, B. Ako and J. Son (2006). "Integration of surface geophysical methods for fracture detection in crystalline bedrocks of southwestern Nigeria." Hydrogeology Journal 14(7): 1284-1306.

Beamish, D. (2000). "Quantitative 2D VLF data interpretation." Journal of Applied Geophysics 45(1): 33-47.

Becken, M. and L. B. Pedersen (2003). "Transformation of VLF anomaly maps into apparent resistivity and phase." Geophysics 68(2): 497-505.

Carter, N. and L. Lines (2001). "Fault imaging using edge detection and coherency measures on Hibernia 3-D seismic data." The Leading Edge 20(1): 64-69.

Demanet, D., E. Pirard, F. Renardy and D. Jongmans (2001). "Application and processing of geophysical images for mapping faults." Computers \& Geosciences 27(9): 1031-1037.

EPMAPS (2012). Groundwater Database. Q. A. D. Quito Water Utility Company. Quito, Ecuador.

Ernston, K. and R. Kirsch (2006). Groundwater Geophysics - A Tool for Hydrogeology. Berlin Heidelberg, Springer-Verlag.

Ganerød, G. V., J. S. Rønning, E. Dalsegg, H. Elvebakk, K. Holmøy, B. Nilsen and A. Braathen (2006). "Comparison of geophysical methods for sub-surface mapping of faults and fracture zones in a section of the Viggja road tunnel, Norway " Bulletin of Engineering Geology and the Environment 65: 12. 
Jeng, Y., M.-J. Lin and C.-S. Chen (2004). "A very low frequency-electromagnetic study of the geo-environmental hazardous areas in Taiwan." Environmental Geology 46(6): 784-795.

Kaikkonen, P. and S. P. Sharma (2001). "A comparison of performances of linearized and global nonlinear 2-D inversions of VLF and VLF-R electromagnetic data." Geophysics 66(2): 462-475.

Karaman, G. Ö. A. (2002). "Characterizing water-level changes due to fracturing generated by the strike-slip fault of the 12 November 1999, Düzce, Turkey, earthquake using the VLF method." Environmental Geology 42(1): 61-64.

Loke, M. H. (2012). "Tutorial : 2-D and 3-D electrical imaging surveys." from http://www.geotomosoft.com/downloads.php.

Mitchell, H. L. (2001). Exploring for groundwater and fracture systems with the WADI in the South Carolina piedmont. South Carolina Geology, S.C Department of Natural Resources. 43: 49-56.

Monteiro Santos, F. A., A. Mateus, J. Figueiras and M. A. Gonçalves (2006). "Mapping groundwater contamination around a landfill facility using the VLF-EM method -- A case study." Journal of Applied Geophysics 60(2): 115125.

Nguyen, F., S. Garambois, D. Jongmans, E. Pirard and M. H. Loke (2005). "Image processing of $2 \mathrm{D}$ resistivity data for imaging faults." Journal of Applied Geophysics 57(4): 260-277.

Piro, S., A. Sambuelli, A. Godio and R. Taormina (2007). "Beyond image analysis in processing archaeomagnetic geophysical data: case studies of chamber tombs with dromos." Near surface geophysics 5(6): 405-414.

Pitas, I. (2000). Digital Image Processing Algorithms and Applications. New York, John Wiley and Sons.

Ramesh Babu, V., S. Ram and N. Sundararajan (2007). "Modeling and inversion of magnetic and VLF-EM data with an application to basement fractures: A case study from Raigarh, India." Geophysics 72(5): B133-B140.

Rios-Sanchez, M., J. Gierke and A. L. MacLean (2012a). Utilizing digital image processing techniques to identify and characterize fracture patterns in the Quito, Ecuador aquifer system. Houghton, MI, Michigan Technological University.

Rios-Sanchez, M., J. Gierke, A. L. Maclean, C. Manciati, R. Escobar-Wolf and R. Galárraga (2012b). Developing a conceptual hydrogeological model for a mountainous volcanic aquifer in Ecuador, based on a multidisciplinary approach. Houghton, Michigan Technological University.

Rios-Sanchez, M., J. Gierke and T. Muñoz-Martínez (2012c). Hydrogeological characterization of the Plateaus region of the Quito Aquifer System using remote sensing, digital geomorphology, and geophysics. . 2012 World Environmental and Water Resources Congress, Albuquerque,New Mexico.

Sharma, S. P. and V. C. Baranwal (2005). "Delineation of groundwater-bearing fracture zones in a hard rock area integrating very low frequency electromagnetic and resistivity data." Journal of Applied Geophysics 57(2): 11. 
Wiggin, E. (2001) " Elementary Digital Filtering.". http:// www.gamedev.net/reference/articles/article1068.asp, (09/20/2001 


\title{
PAPER 3: DEVELOPING A CONCEPTUAL HYDROGEOLOGICAL MODEL FOR A MOUNTAINOUS VOLCANIC AQUIFER IN ECUADOR BASED ON A MULTIDISCIPLINARY APPROACH ${ }^{5}$
}

\author{
Miriam Rios-Sanchez ${ }^{1}$, John S. Gierke1, Ann Mclean², Carla Manciati², \\ Rüdiguer Escobar-Wolf ${ }^{1,}$ Remigio Galárraga ${ }^{4}$ \\ ${ }^{1}$ Department of Geological and Mining Engineering and Sciences, Michigan \\ Technological University, 1400 Townsend Dr., Houghton, MI 499311
}

${ }^{2}$ School of Forest Resources and Environmental Science, Michigan Technological University, 1400 Townsend Dr., Houghton, MI 499311

${ }^{2}$ Master Recherche Eau et Environnement, Université Montpellier II. Place Eugène Bataillon Montpellier cedex 5, FR, 34095

${ }^{3}$ Escuela Politécnica Nacional, Departamento de Ingeniería Civil y Ambiental, Ladrón de Guevara E11-253, Quito-Ecuador

\begin{abstract}
Aquifers in mountainous volcanic basins are considered the most productive aquifers in Latin America due to a combination of high recharge rates and infiltration capacities at the higher elevations and the storage capacities of the basins. Although topography is considered as the primary driving force for groundwater flows in mountainous terrains, tectonic activity increases the complexity of these groundwater systems by altering the integrity of sedimentary and rock units and the overlying drainage networks. Structural controls affect the primary hydraulic properties of the rock formations by developing in some cases barriers to flow and in others zones of preferential infiltration. A conceptual hydrogeological model was developed based on the integrated analysis of the complex tectonic topographic and geological setting. Two hydrostratigraphic units were identified. The first one is made of a compartmentalized thick unsaturated zone in which preferential vertical flow is developed, due to fracturing. The second hydrostratigraphic unit is the saturated area, which is affected by fracturing. This fracturing gives the aquifer regime a double porosity nature. Hydraulic conductivity values are between $0.01-$
\end{abstract}

${ }^{5}$ Paper in process of submission to the Hydrogeology Journal 
$6.8 \mathrm{~m} /$ day. Groundwater flow follows the regional topographic gradient forming subregional flow systems. Due to dissection and development of local topographic gradients, groundwater partially discharges along the downslope sides of the plateaus, forming local flow systems. Chemical water types are typical of young water of meteoric origin.

Keywords: Flow systems, hydrochemistry, lineament analysis, hydrogeology, fractured aquifers, volcanic aquifers.

\section{INTRODUCTION}

Aquifers in volcanic basins are considered the most productive aquifers in Latin America due to a combination of high recharge rates and infiltration capacities (Custodio 2004) at the higher elevations and the storage capacities of the basins. Metropolitan cities such as Guadalajara (Mexico), Quetzaltenango and Guatemala City (Guatemala), Managua (Nicaragua), Quito (Ecuador), La Paz (Bolivia), and San Jose (Costa Rica) obtain a significant amount of their drinking water from this kind of aquifer setting (Anton 1993). For instance, Mexico City and Guatemala City obtain approximately $70 \%$ of the water from aquifers located in these terrains (Anton 1993). Despite the broad distribution (as depicted on Figure 4.1) and many of these aquifers are being exploited without fully understanding the hydrology and practically no information about future impacts of development and climate change. Moreover, there are many area in Latin America, not only volcanic terrains, with no hydrogeological data (Zektser and Everett 2004).

There are many challenges in the study and assessment of the groundwater resources in mountainous regions in general and volcanic aquifers in particular. 


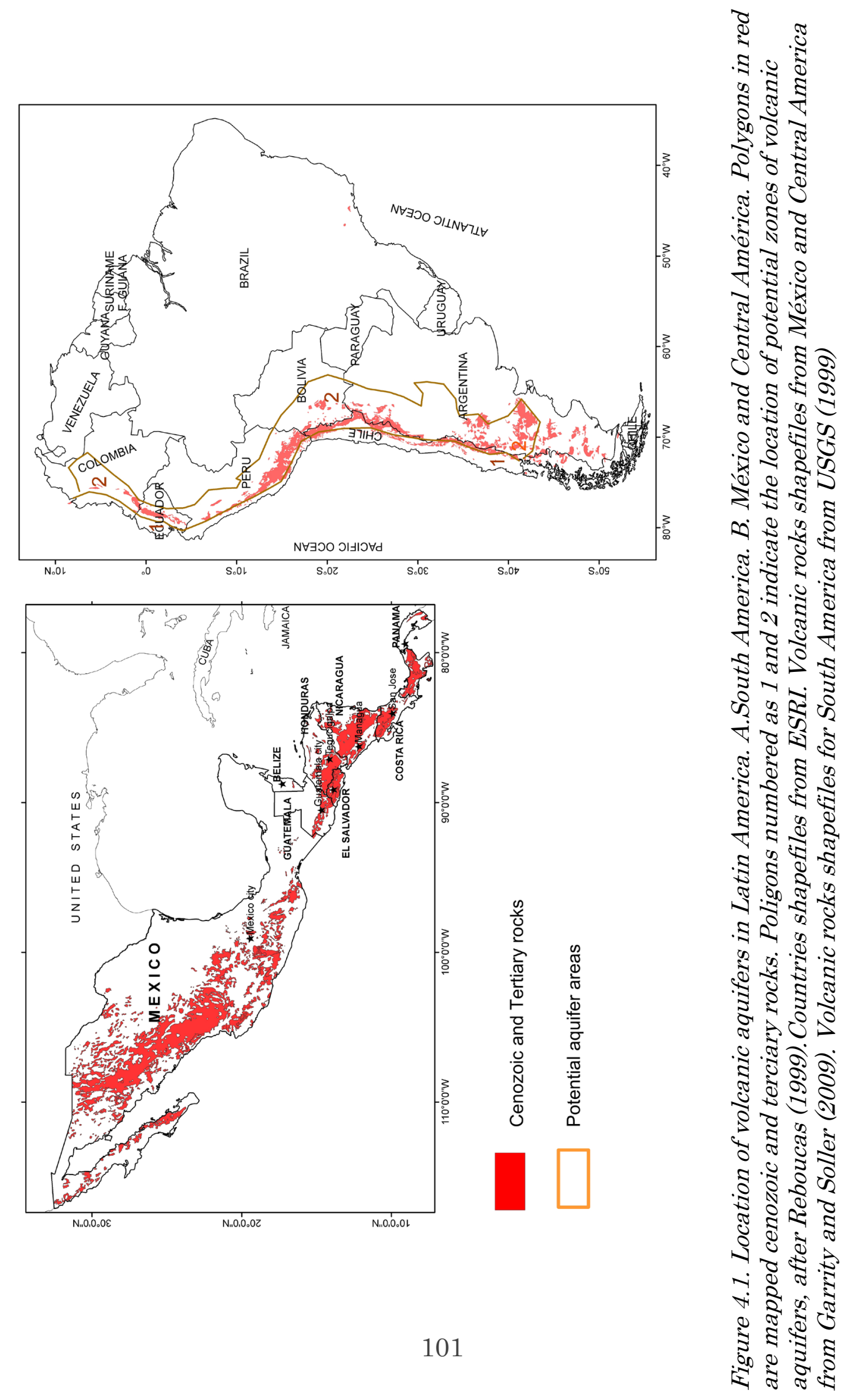


The irregular topography of mountainous terrains implies a complex influence on the hydrology, since topography is considered as the primary driving force for the development of groundwater flow systems (Toth 1971; Zijl 1999). Tectonic activity increases the complexity of these groundwater systems by altering the integrity of rock units and the overlying drainage networks. Structural controls affect the primary hydraulic properties of the rock formations by forming in some cases barriers to flow and in others zones providing zones for preferential infiltration and subterranean flows (Bisson and Lehr 2004; Vsevolozhskii et al. 2001).

In order to more comprehensively understand the complexity of these types of terrains, a multifaceted characterization approach is necessary to improve the knowledge of the hydrogeology. In this study, the multifaceted approach is applied to develop a conceptual hydrogeological model that describes the main aspects of the aquifer so future research and monitoring endeavors can be planned.

The description of the physical conditions of the aquifer system was achieved by identifying the existence of aquifers and aquitards and their $3^{-}$ dimensional (3D) extent, considering the complex topographic terrain surface and the complex tectonic conditions and fracturing, as described by RiosSanchez et al. (2012) and Rios-Sanchez and Gierke (2012). Analysis of singlewell pumping test data, especially time-drawdown and derivative curves (Kirchner and G.J. 1995; Renard 2006; Renard et al. 2009), were used to characterize the hydraulic regime of the aquifer. Springs and water-level data were used to characterize the groundwater flow systems (Mul et al. 2007; Toth 1971; Zijl 1999) occurring in the Plateaus Region. Water-type classification (Appelo and Postma 1999; Stuyfzand 1989; Stuyfzand 1999) was used to investigate the groundwater chemical evolution. The findings 
from the water chemistry study were used to test the likelihood of the flow patterns proposed in the groundwater flow analysis. Environmental isotopic analysis (Clark and Fritz 1997; Manga 2001) helped to verify the origin of groundwater.

A conceptual model was built based on the integrated analysis of the all the relevant aspects that influence the physical and chemical properties of the aquifer and contribute to increasing our understanding of the hydrological processes in mountain aquifers. This knowledge could serve as the foundation for future plans of water development and watershed management in such complex terrains.

\section{LOCATION AND GEOLOGIC SETTING}

The study area is located in the eastern part of the Quito Aquifer System (QAS) shown in Figure 4.2, named as the Plateaus region, due to its topographic characteristics. The QAS is located in the Central Inter-Andean Valley, which is a large and complex tectonic basin; situated between the Cordillera Occidental and Cordillera Real in Northern Ecuador (Villagomez 2003; Winkler et al. 2005). The Plateaus area represents the future development zone of the Quito metropolitan area and also represents an important source for water supplies. Currently, population centers settled on the Plateaus Region obtain all the drinking water from springs. Moreover, water for agriculture is extracted from wells and springs. Approximately $1.4 \%$ of the water for the metropolitan area comes from the Plateaus region, however, the demand is expected to increase in the future years since new urban areas are being built and agricultural activities are expanding. 

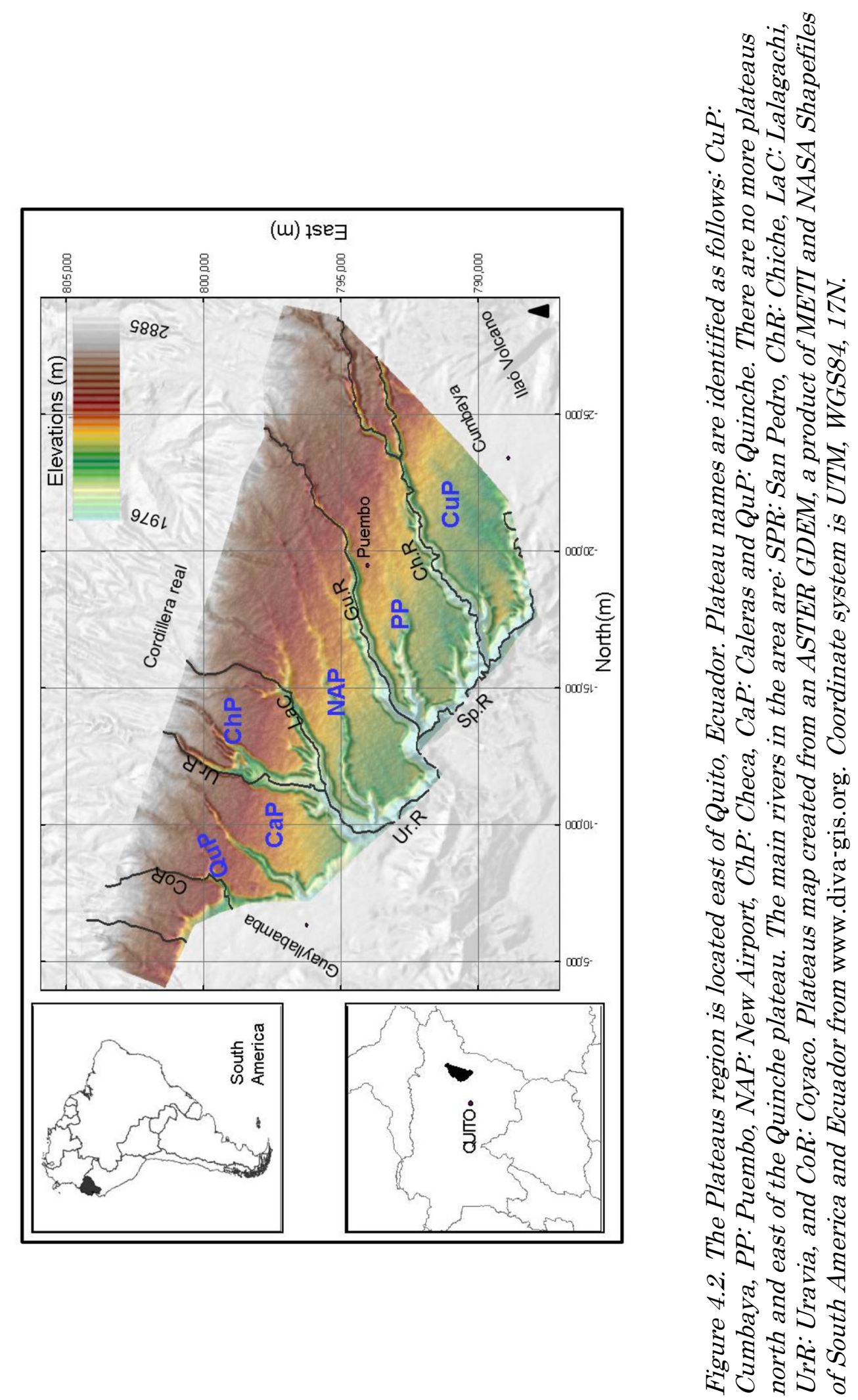
The plateaus are bounded by, as shown in Figure 4.2, the San Pedro (Sp.) and Uravia (Ur.) rivers, along the north, the Guayllabamba Depression along the east; by the foothills of Cordillera Real to the south, and the Ilaló Volcano and Cumbayá Valley to the southwest.

The volcanic and sedimentary deposits on the plateaus form sub-horizontal layers, reported to be over 1000-m thick (Villagomez 2003; Winkler et al. 2005). Figure 4.3 depicts the names, approximate thicknesses, and ages of the geological units existing on the plateaus. The basement of the plateaus is reported to be formed by volcanic rocks of either the Cretaceous Pallatanga unit or the Pleistocene Pisque Formation (Winkler et al. 2005). Detailed information about the lithology on the plateaus is provided by Villagomez (2003) and is summarized here. The basal part of the Pisque Formation is composed of andesitic and basaltic lavas. The upper part is a sequence of fluvial and alluvial deposits. The San Miguel Formation lies on top of the Pisque Formation. Its composition is mostly tuffs with interbedded fluvial deposits. The Guayllabamba formation overlies the San Miguel formation. It is composed from base to top by four sequences of volcanic and sedimentary deposits. The lowest one is composed by of lahar deposits, the next one by volcanic domes, then lava flows, pyroclastic flows and avalanches, and the upper most is composed of alluvial fan deposits. Chiche Formation is found on top of Guayllabamba Formation. It is mainly composed of lacustrine and fluvial deposits interbedded with volcanic deposits. The Cangagua Formation is the shallowest formation on the plateaus. It is mainly composed of volcanic ash and tuff, with intercalated layers of sand and clay.

Detailed tectonic data for the Plateaus Region is unavailable. Indications of tectonic activity for the Plateaus Region are based on the result of the 
lineament analysis and fracture characterization carried out by Rios-Sanchez et al. (2012) and Rios-Sanchez and Gierke (2012). The area is crisscrossed by two sets of lineaments that are mainly oriented NE and by a lesser trend in the N-NW direction. The density of lineaments increases towards the north, numerous lineaments area found on the NAP and PP plateaus (Figure 4.4). NW lineaments are considered to correspond to regional faults since they are controlling the course of the main drainages. Moreover, some of these features have evidences of tectonic activity, such as saddles. NE trending features cut and disrupt the spatial continuity of NW linear features. Among the evidences of tectonic activity for the NE lineaments are $90^{\circ}$ river deflections, development of short NE oriented fractures on the walls of the ravines and the elongation of the plateaus parallel to the NE trending lineaments. The San Pedro Fault and the Uravia Lineament, previously mapped by Villagomez (2003) are marking the north and north-western boundaries. The north-eastern border follows a linear feature as well.

\begin{tabular}{|llll|}
\hline $\begin{array}{l}\text { THICKNESS } \\
(\mathrm{m})\end{array}$ & & $\begin{array}{l}\text { GEOLOGICAL } \\
\text { UNITS }\end{array}$ & AGE (Ma) \\
& & & \\
& & & \\
& & &
\end{tabular}

Figure 4.3. Geological units existing in the Plateaus area (after Winkler et al. 2005). 


\section{GEOMORPHOLOGY AND TOPOGRAPHICAL FEATURES}

Topographic elevations in the plateaus range from 1976 to $2885 \mathrm{~m}$ above mean sea level. The highest elevations are in the eastern areas, along the foothills of Cordillera Real. The lowest elevations are along the San Pedro River to the north and east. Incision has created a series of NW-oriented flat areas separated by deep ravines (Figure 4.2). Slopes along the sides of the ravines are typically between $40-50^{\circ}$ but some places are as steep as $60^{\circ}$. The ravines have a NW deepening and widening trend. The widths of the ravines are generally less than $200 \mathrm{~m}$, although areas are as much as $600^{-} \mathrm{m}$ wide. The deepest (>300 m) dissected areas are closer to the San Pedro and Guayllabamba rivers.

Topographical characteristics of the plateaus are controlled by tectonics. For example, the lowest and highest topographical areas are related to tectonic features. Another example is the fact that the main river valleys do not follow the regional topographic gradient, suggesting a tectonic influence on the development of the drainage. Due to the difference in orientation between topographic gradient and drainage the plateaus exhibit changes in elevation along their width, giving them the appearance of being tilted, as depicted on the profiles of Figure 4.4.

\section{HYDROGEOLOGICAL STRUCTURE}

The characterization of the physical conditions of the aquifer system was achieved by identifying the existence of aquifers and aquitards and their 3dimensional (3D) extent, considering the complex topographic terrain surface. Information on the types and depths of the aquifer layers screened for production were obtained based on information of 27 wells. 

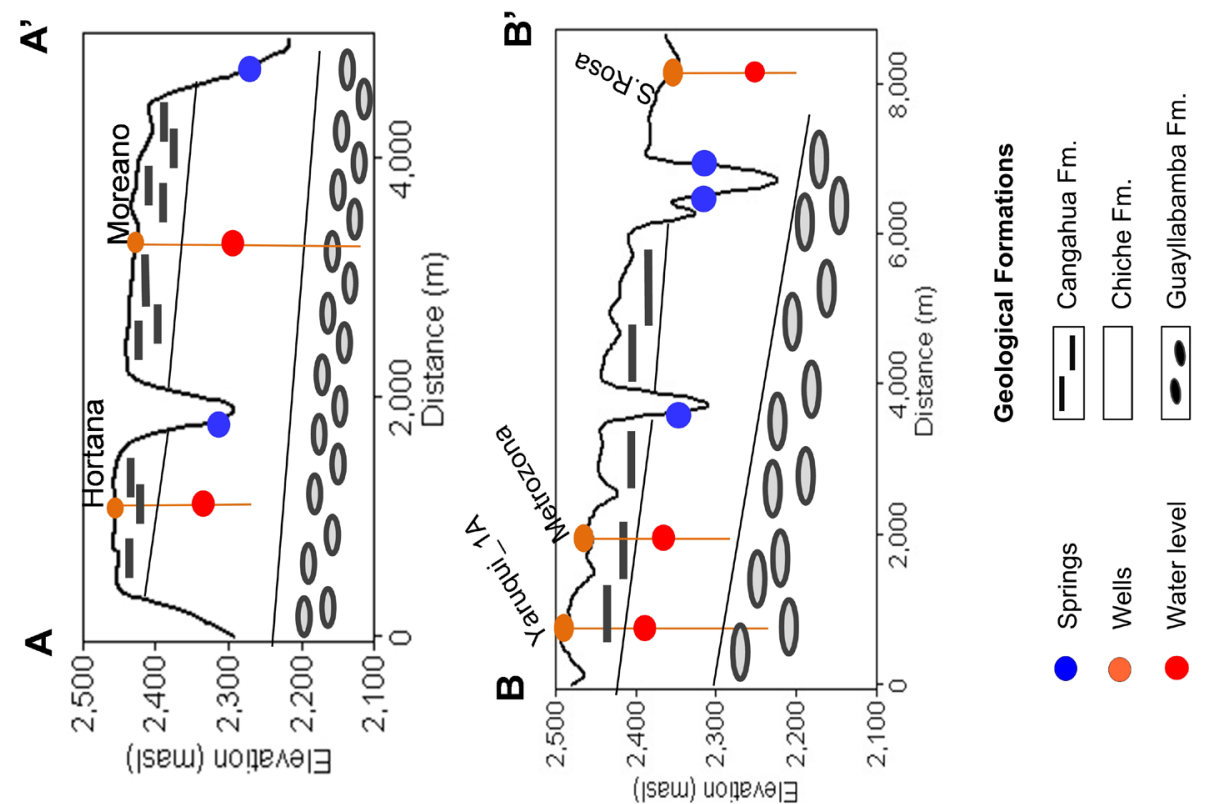

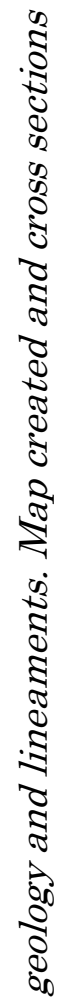

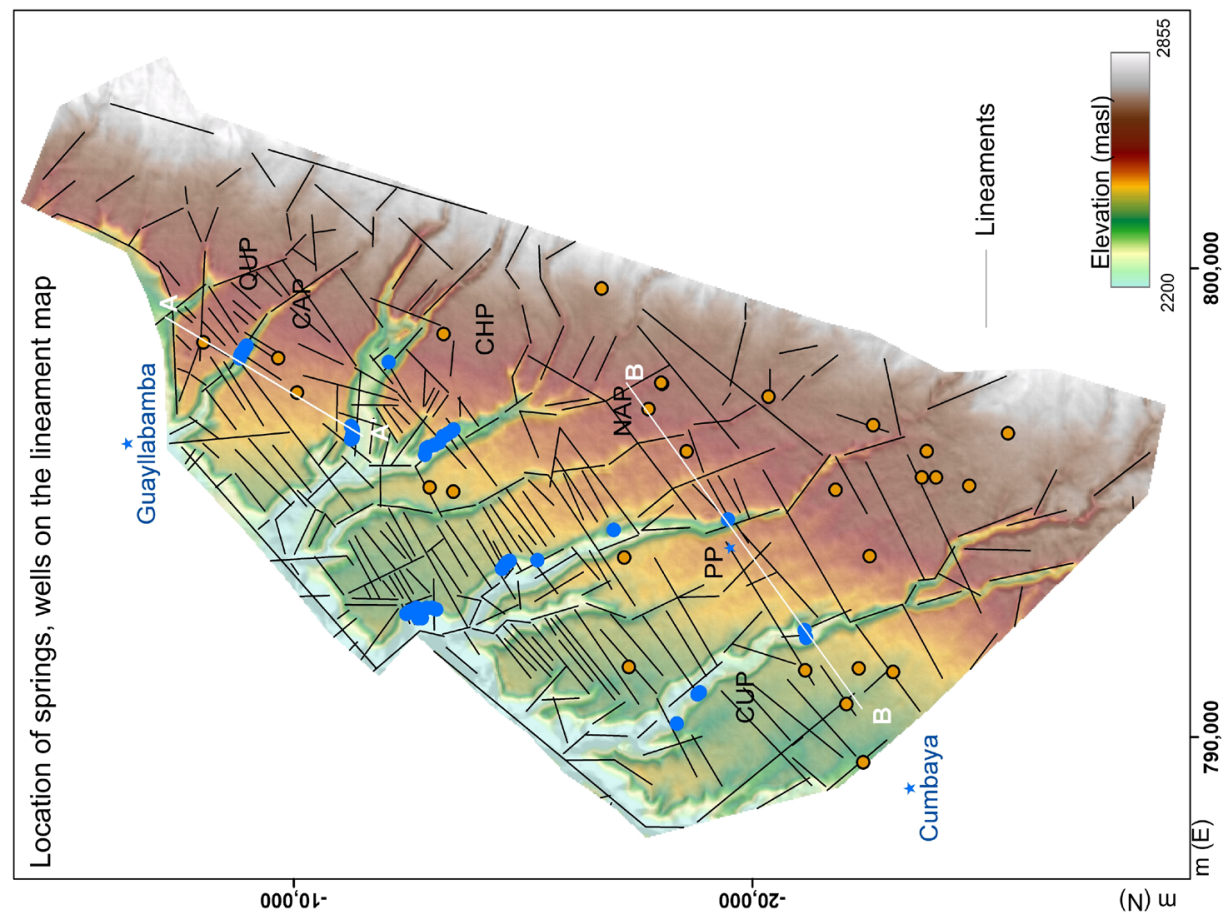


Information about wells was provided in the database of groundwater occurrences that the Quito Water Utility Company - EPMAPS (EPMAPS 2012) has acquired as result of its activities in monitoring and assessing groundwater resources for the QAS.

The plateaus geological units constitute a structurally aquifer complex. It is formed by a set of interbedded permeable and semi-permeable volcanic and sedimentary subhorizontal layers belonging to the Cangagua, Chiche, and Guayllabamba as depicted on Figure 4.4. Although San Miguel Formation is considered to be part of the aquifer system there were not wells deep enough to locate screens in this formation. Wells screened areas are mainly located on the Chiche formation and some on the Guayllabamba formation. Lithology logs and geological descriptions do not indicate any thick impermeable layers within the formations nor separating them. Cross sections on the area (Figure 4.4) indicate that dissection is causing layers of the Cangahua formation and the upper part of the Chiche Formation to be spatially discontinuous. Rios-Sanchez and Gierke (2012) identified fractured areas on top of the plateaus with depths up to $59 \mathrm{~m}( \pm 40)$. There is not information on fracturing and faulting below the river levels.

\section{NATURAL DISCHARGE}

One of the most significant characteristics of the plateaus is the numerous springs that naturally drain the aquifer, the locations of which are depicted on Figure 4.4. Fifty-seven springs are being identified and they are used for drinking water. Most of springs are being monitored by the Quito Water Utility Company (EPMAPS). Springs commonly occur in clusters of up to ten individual springs within a $1-\mathrm{km}$ distance and mostly on the east-facing sides of the ravines. The exception is the springs draining the Cumbaya plateau. 
Springs on this plateau are located on the west facing side of the Chiche river ravine (Figure 4.4). Springs outcrop where the water table intersects the topographic surface. They are occurring in one side of each plateau, mostly due to the influence of the local topography. However, the existence of numerous N45E lineaments and the association of springs to short length fractures (with similar orientation the N45E lineaments) might indicate that the development of secondary porosity is an important controlling factor on the location of the springs. Figure 4.5 depicts examples of short length fractures observed in the field and the location of springs associated to them.
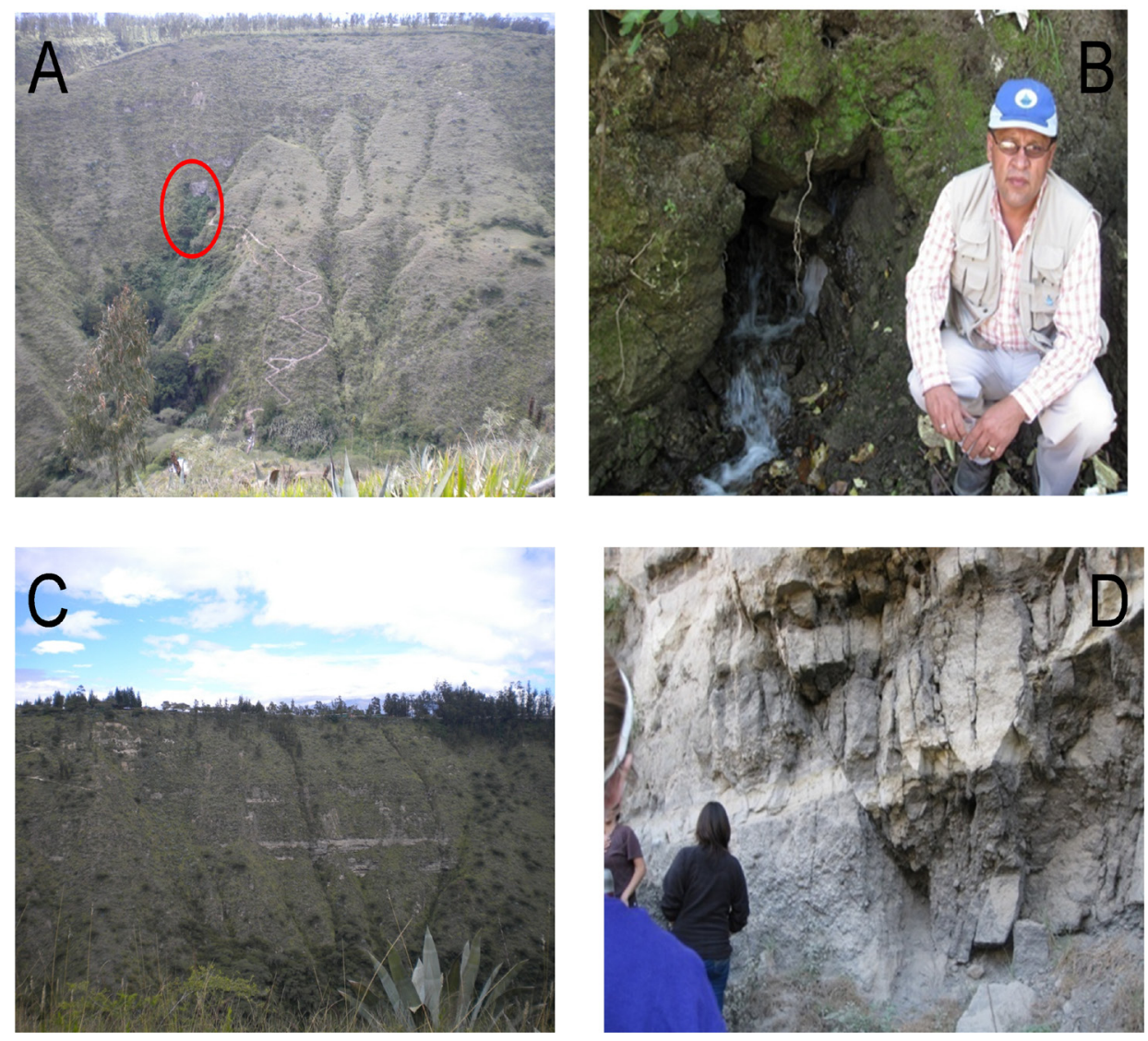

Figure 4.5. Examples of fractures observed on the sides of the ravines. A) Spring on a fractured and deformed zone Guambi river ravine. B) Spring discharge through a fracture on Lalagachi creek ravine C) Fractures on the Chiche River, and D), Faulted zone, Guambi river ravine. 
High variability exists in spring discharge across the plateaus as well as among spring clusters, as illustrated on Figure 4.6. Variations in spring flow within a cluster are likely due to changes in porosity caused by fracturing. Given the short distance rapid lateral changes in lithology are most difficult to encounter.

In order to understand the reasons for the variability on the spring flow, relationships between spring flows, contributing area and changes on the recharge were explored. Ideally on a geologically homogeneous area, the spring flow will depend exclusively on the contributing area and the amount of recharge by precipitation (Hurlow and Bishop 2003).

Theoretical Contributing areas were calculated for the spring clusters using the water-budget method (Bishop 2001). For the calculation, a homogeneous recharge over the plateaus is assumed. Infiltration data was calculated by Alulema (2007). Also, contributing areas were calculated based on the catchment boundaries for each spring cluster. The results of these calculations were plotted against flow discharge, as depicted 4.7.

Contributing areas calculated using the catchment boundaries do to follow a linear trend, as seen for the theoretical calculations (Figure 4.7). The lack of a trend might indicate that infiltration is not homogeneous over the plateaus. Infiltration changes are due to changes on precipitation rate and on geological conditions. Considering that precipitation has been described rather as an homogeneous quantity (Alulema 2007), variation on the properties of the rocks and sediments are most likely the influencing factor affecting the infiltration rate. For the plateaus, fracturing provides a higher permeability area to have higher volumes of water coming out of the aquifers, as compared to seepage areas (Manga 2001), as they are used as rapid flow paths for the water to enter and come out of the aquifer. 

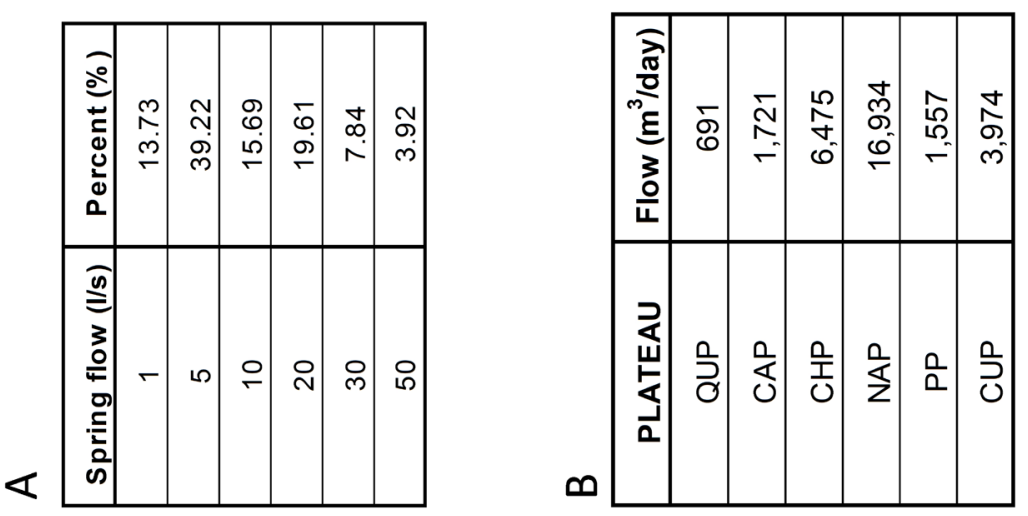

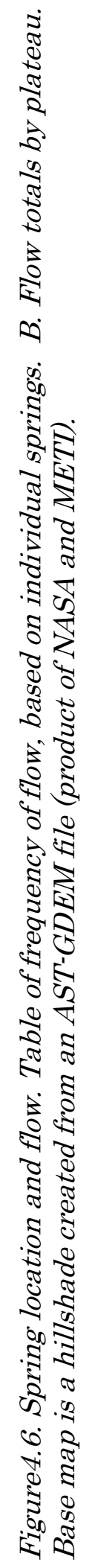

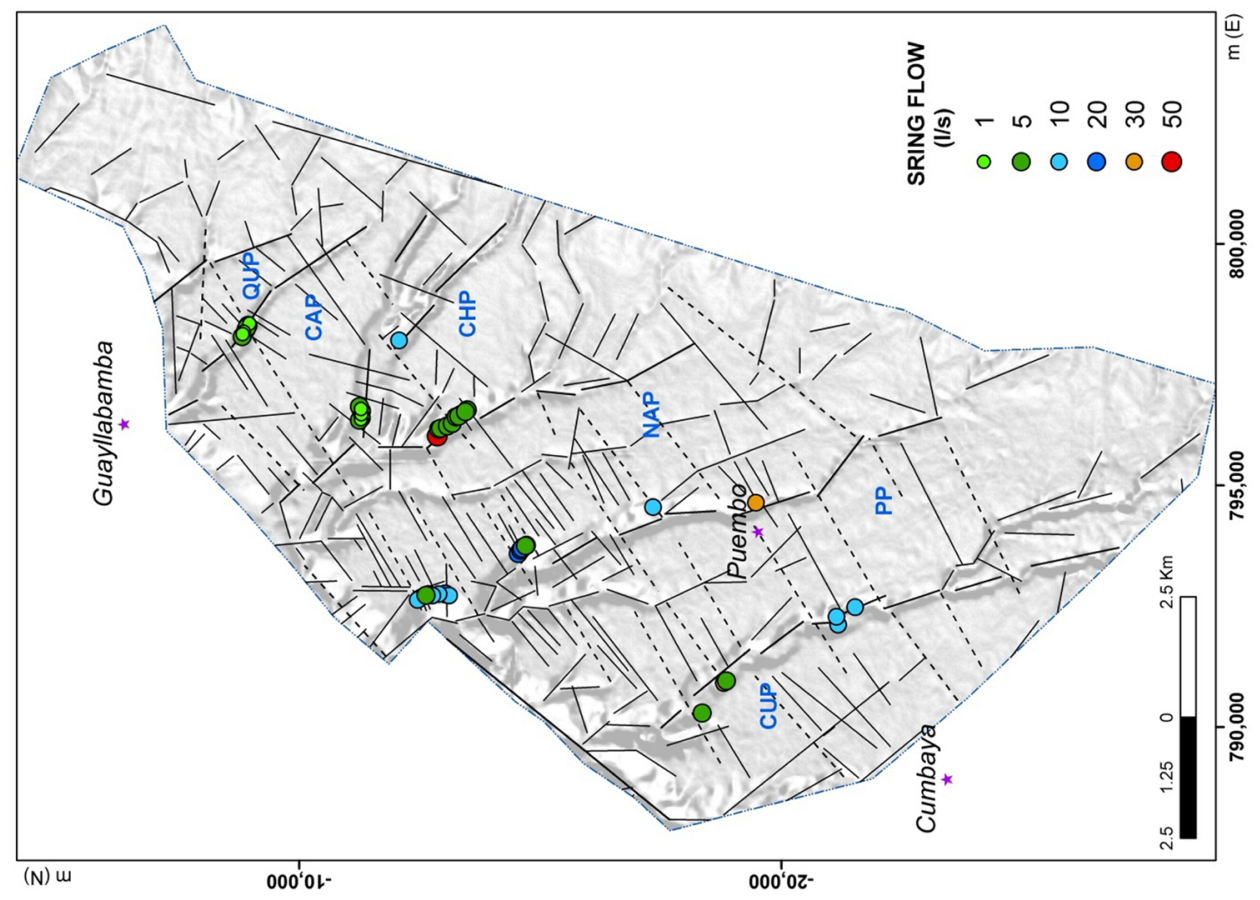




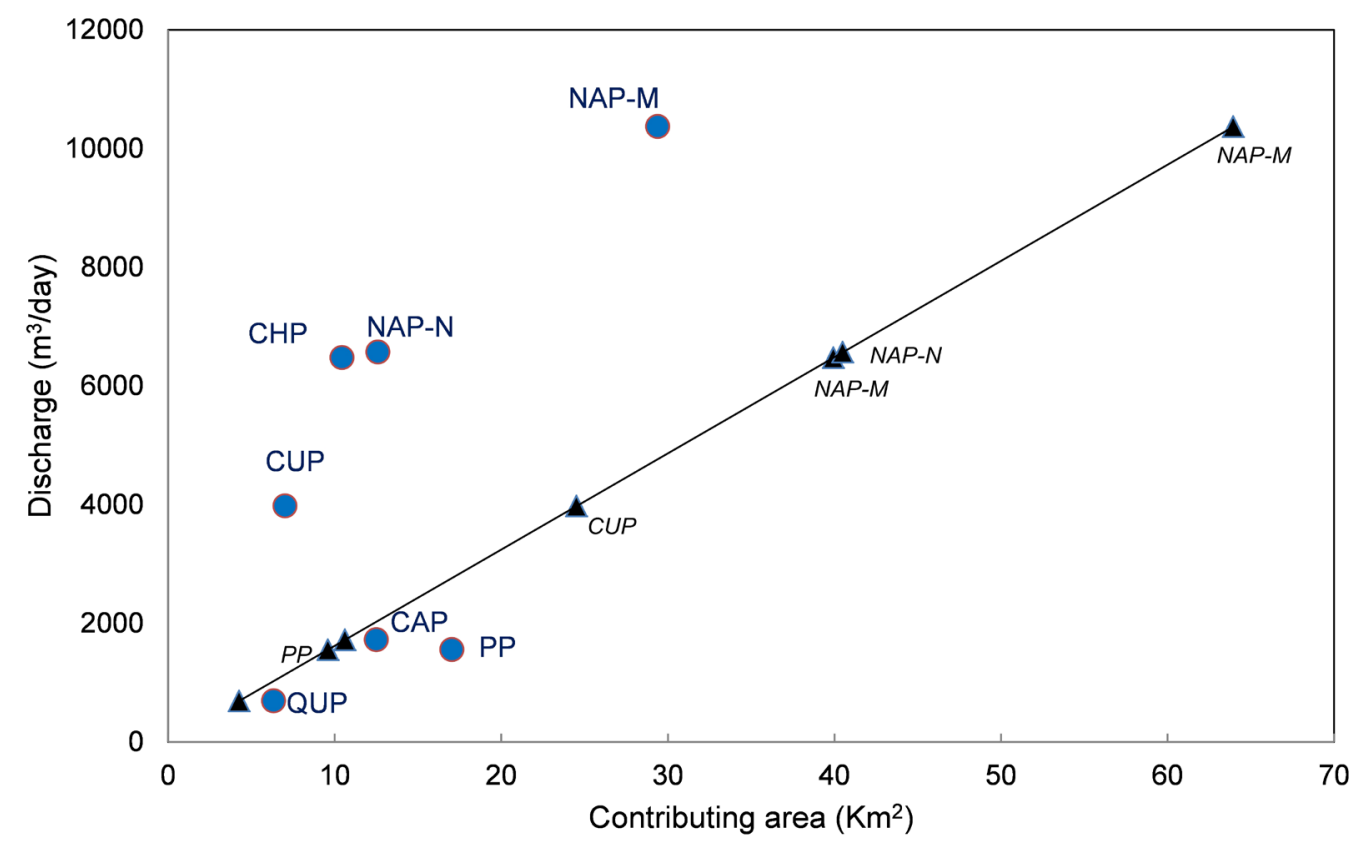

Figure 4.7 Relationship between spring discharge and drainage area. Triangles and the black line indicate the relationship between discharge and theoretical contributing areas. Blue dots indicate the relationship between discharge and the contributing areas measured based on the geometry of the aquifers. NAP-M and $N A P-N$ correspond to the spring clusters located in the middle and northern part of the New Airport Plateau respectively.

Figure 4.7 also indicates that only the springs from CAP and QUP have equivalent contributing areas from both methods. Theoretical contributing areas calculated for CUP, NAP and CHP spring clusters are much larger than the areas measured using the catchment boundaries. In order to compensate for a much smaller contribution area, a higher infiltration rate it is needed to obtain the flows measured on the clusters. As discussed before, higher infiltration rates might be caused for an increase in permeability, compared. For the PP spring cluster, the theoretical contribution is larger than the calculated based on the catchment boundaries. In this case a 
reduction on the infiltration rate is expected, interpreted as reduction on the permeability of the aquifer.

\section{GROUNDWATER LEVELS}

A regional piezometric map was created based on 59 data measurements of water levels obtained from 26 wells and the topographic elevations of 57 springs provided in the database of groundwater occurrences that EPMAPS (2012)has acquired as result of its activities in monitoring and assessing groundwater resources for the QAS. Data from seven springs was obtained from the inventory published online by the National Institute of Hydrology of Ecuador INAMHI (INAMHI 2012). Kriging (Krige and Magri 1982) was used as the method of interpolation. Results of the interpolation are depicted on Figure 4.8. A 2-dimensional perspective of the water table variation is presented as well. It is observed that generally the piezometric map follows the topography. Higher hydraulic heads coincide with the higher topographic areas; lower heads are found towards the lowest parts of the area. The hydraulic gradient is low and does not change much across the plateaus ( $i$ $0.02-0.04)$. The highest hydraulic gradients are observed in the Quinche and Caleras Plateaus.

Due to the irregular spatial distribution of the points, a better representation of the piezometric surface was obtained for the higher topographic areas and for the CUP and PP plateaus (Figure 4.8). On those plateaus the piezometric map represents very well the local topographic gradients and the discharge toward one side of the plateaus. More data is needed to find a better representation for the other plateaus. 

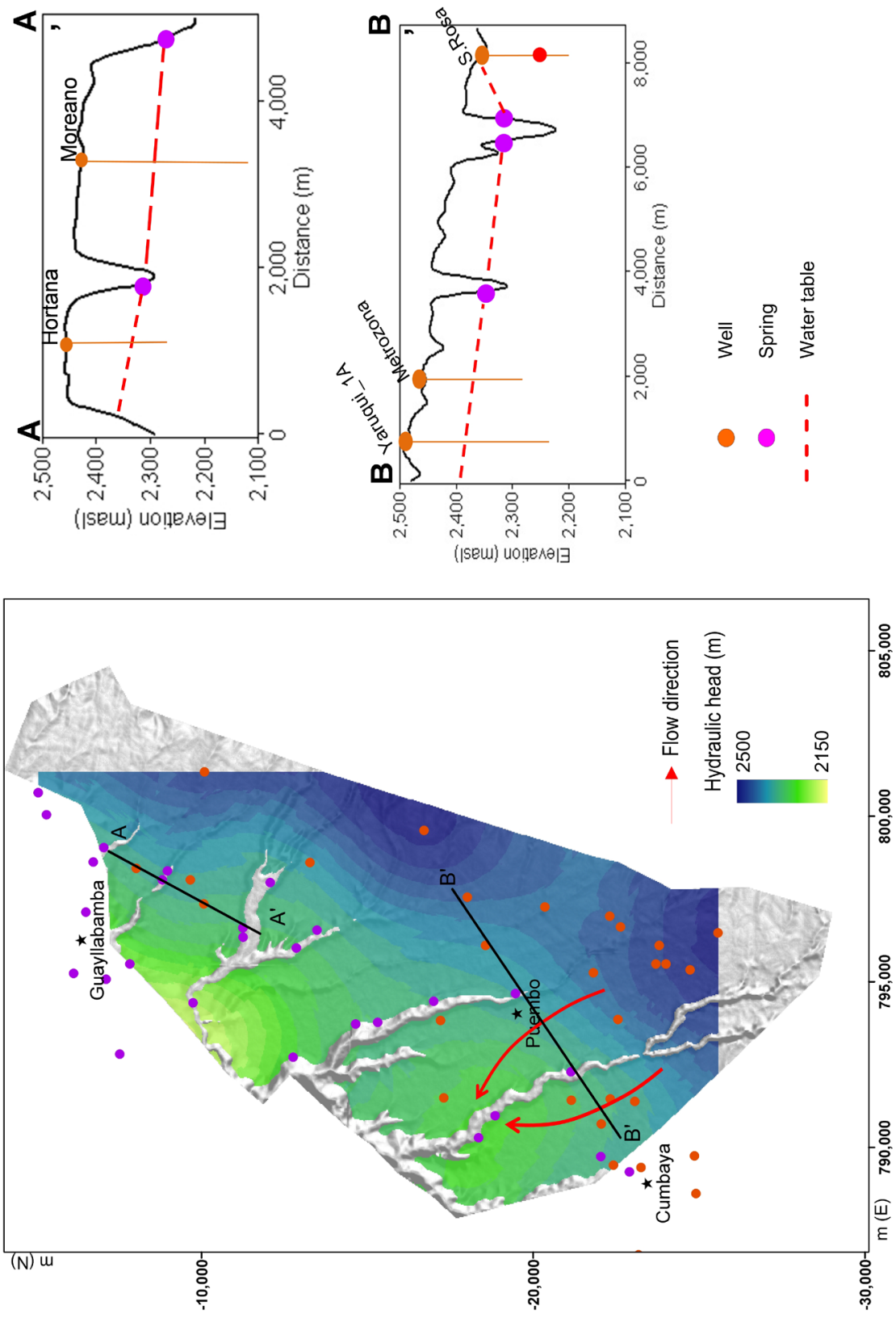

ช

ส

ป

ค1

家

$\frac{\pi}{2} \frac{\pi}{2}$

के

:

주 స్

ฐ

ำ

(口)

ส

蛋 $\frac{\pi}{\sqrt{2}}$

व

帘

ร

为过

ฮิ ฮ

ส ฐ

旅

ปี ส

बे गे

4ิ

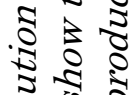

हิ के है

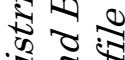

ลิส สิ

$\infty, \pi$

अ क्षे

$\div$.

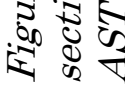




\section{AQUIFER HYDRAULIC PROPERTIES}

Single well constant-discharge pumping test data for the Plateaus region exist for eleven wells. Interpretation of the pumping test aimed to assess the flow regimes for the aquifer and estimate the regional hydraulic conductivity. Interpretation of data was based on time-drawdown and derivative log-log plots (Driscoll 2007; Kirchner and G.J. 1995; Kruseman and Ridder 1994).

These plots were created for each pumped well and then compared to existing models to identify the flow regimes for the aquifer. In order to reduce noise, derivative was calculated from the re-sampled drawdown data using a spline interpolation, as proposed by Renard et al. (2009). Once the hydraulic regime was identified, the hydraulic conductivity was calculated Considering that well storage is normally represented on the early data, curve fitting did not include the first minutes, since the type of aquifer is more like to represented by intermediate data and the presence of boundaries at the late time data (Renard et al. 2009).

Pumping test interpretation was carried out using AQTESOLV PRO v.4.5 (HydroSOLVE Inc, Reston, 2007). On Table 4.1 the hydraulic conductivity values for the analyzed pumping test are indicated. Drawdown and derivatives of the analyzed pumping test are displayed on Figure 4.9. In that figure is observed that most of the wells exhibit the $U$ shape on the derivative curve, typical of dual porosity aquifers (Renard et al. 2009; Studner et al. 1997).

Given the limitations of single well pumping data, numerical calculations were focused on the hydraulic conductivity only, in order to analyze the aquifer productivity and the its spatial variation across the plateaus. On Table 4.1 it is observed that $\mathrm{K}$ values have high variability, ranging from 
$0.015 \mathrm{~m} /$ day in the southernmost part of the Puembo plateau to $6.8 \mathrm{~m} /$ day on the Cumbaya plateau and $2.5 \mathrm{~m} /$ day in the Checa and Caleras Plateaus. The high variability on calculated hydraulic conductivity can be due to changes in the internal granulometry of the aquifer layers, but also to the changes in the degree of fracturing. Based on the physical characteristics of the area and the lineament mapping, fracturing can be considered as the most important factor accounting for the variation in hydraulic conductivity.

Table 4.1. K values obtained from the pumping test interpretation

\begin{tabular}{|c|c|c|c|c|}
\hline PLATEAU & WELL NAME & $\begin{array}{c}\text { PUMPING } \\
\text { TEST } \\
\text { DURATION } \\
\text { (min) }\end{array}$ & Q (1/s) & K (m/day) \\
\hline Cumbaya & Carrizal & 300 & 8 & 6.834 \\
\hline Puembo & Bellaflor & 960 & 10 & 0.500 \\
\cline { 2 - 5 } & SJ. Puembo & 600 & 1.7 & 0.151 \\
\cline { 2 - 5 } & Carnasa & 540 & 5.6 & 0.015 \\
\cline { 2 - 5 } & Calluma & 3200 & 1.04 & 0.015 \\
\hline N.Airport & Yaruqui 1A & 420 & 7.88 & 0.589 \\
\cline { 2 - 5 } & SC.Yaruqui & 360 & 1.5 & 0.166 \\
\cline { 2 - 5 } & Tababela & 340 & 1 & 0.284 \\
\hline Checa & Inv. Floricolas & 2280 & 9.61 & 2.530 \\
\hline Caleras & Moreano & 240 & 6.74 & 1.424 \\
\cline { 2 - 5 } & Urapamba & 4320 & 12 & 0.845 \\
\hline
\end{tabular}



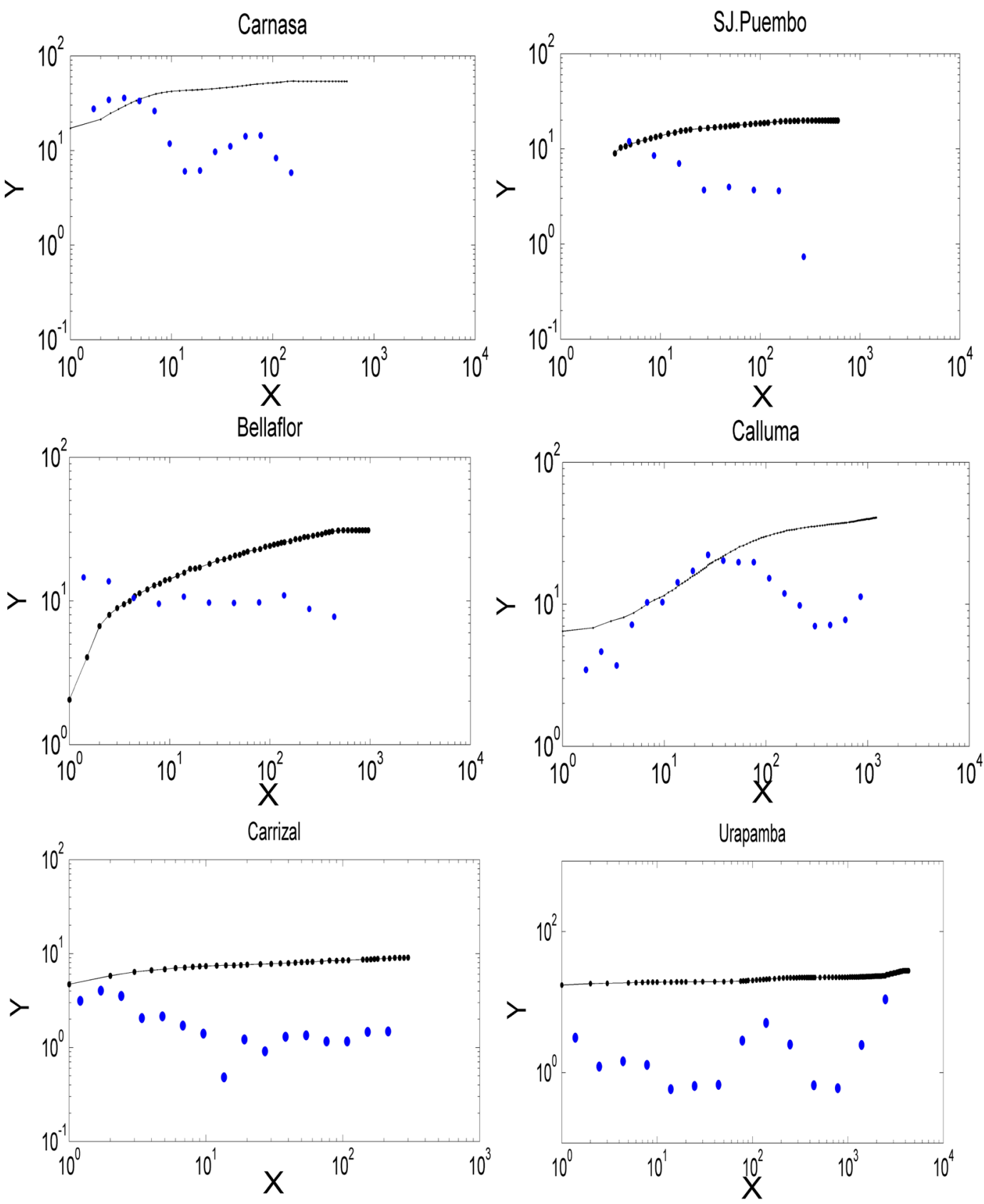

$\bullet \bullet \bullet \bullet$ Drawdown $\bullet \bullet \bullet \bullet$ Derivative

Figure 4.9. Drawdown and time derivative curves for the most representative wells analyzed. $Y$ axis is in (m), $X$ axis is in minutes. U shapes on the derivatives are better observed on long pumping tests such as Carnasa, Calluma and Urapamba wells. 


\section{WATER CHEMISTRY AND AGE DATING}

Hydrochemical analysis was carried out in order to understand the main chemical characteristics of groundwater and to have more information about the flow and evolution, to supplement the information obtained with the water level analysis. The hydrochemical analysis was based on the previously reported chemical data for 24 springs and 28 wells (EPMAPS 2012). Although the majority of the samples analyzed come from the year 2006, data from other dates were used for comparison.

The accuracy of the analysis was assessed based on the ionic balance (Appelo and Postma 1999). The analysis is mainly based on the classification of water samples into water types using the Stuyfzand method (Stuyfzand 1993). The objective of the classification is to reflect in a single code the most important chemical aspects of the water that relate to its origin, flow path, and interactions with the aquifer. The determination of the water types involves the calculation of four parameters: main type, type, subtype and class of water sample, as outlined in Figure 4.10.

On the code, the main type is defined based on the chloride content, since $\mathrm{Cl}^{-}$ is among the most important ions for defining water origins. Type values are based on alkalinity concentrations, which is a good indication of lithogenic mineralization of water. Subtypes are defined based on the predominant anion and cation in the sample. The class code is based on the Base Exchange index (Bex). The aim of Bex indices is to evaluate whether saline or fresh water is entering into the aquifer. Stuyfzand's Bex index for non-dolomitic aquifers is calculated as $\mathrm{BEX}=\mathrm{Na}+\mathrm{K}+\mathrm{Mg}-1.076 \mathrm{Cl}(\mathrm{meq} / \mathrm{L}) \mathrm{Na}+\mathrm{K}+\mathrm{Mg}$ are measured in the sample and then analyzed in relation to the similarity and deviation of the Bex index values. 


\section{G 1-CaHCO3+}

(M) (T)

(ST)

(B)

\begin{tabular}{|c|c|c|c|c|c|}
\hline COMPONENT & $\begin{array}{l}\text { PARAMETER } \\
\text { USED }\end{array}$ & \multicolumn{2}{|c|}{ VALUES } & RELEVANCY & OBSERVATIONS \\
\hline M: Main Type & $\begin{array}{l}\text { Chloride } \\
\text { content } \\
\text { (meq/L) }\end{array}$ & $\begin{array}{l}\text { G:Extremely } \\
\text { fresh } \\
\text { g: Very fresh } \\
\text { F: Fresh } \\
\text { f: fresh- } \\
\text { brackish }\end{array}$ & $\begin{array}{l}\text { B: Brackish } \\
\text { b: Brackish-salt } \\
\text { S: Salt } \\
\text { H: Hyperhaline }\end{array}$ & $\begin{array}{l}\text { Origin (meteoric, sea } \\
\text { water) }\end{array}$ & $\begin{array}{l}\text { Also indicates } \\
\text { thalassogenic } \\
\text { mineralization }\end{array}$ \\
\hline T: Type & $\begin{array}{l}\text { Alkalinity } \\
\text { (meq } / L)\end{array}$ & $\begin{array}{l}\text { * Very low } \\
0 \text { Low } \\
1 \text { Moderately } \\
\text { low } \\
2 \text { Moderate } \\
3 \text { Moderately } \\
\text { high } \\
4 \text { High }\end{array}$ & $\begin{array}{l}5 \text { Very high } \\
6 \text { Rather extreme } \\
7 \text { Extreme } \\
8 \text { Very extreme } \\
9 \text { Extraordinarly } \\
\text { extreme }\end{array}$ & $\begin{array}{l}\text { Lithogenic } \\
\text { mineralization }\end{array}$ & $\begin{array}{l}\text { Indicates the extent of } \\
\text { interaction with e.g } \\
\mathrm{CaCO} 3 \text { and } \mathrm{CH} 2 \mathrm{O}\end{array}$ \\
\hline ST: Subtype & $\begin{array}{l}\text { Most important } \\
\text { cation and } \\
\text { anion }\end{array}$ & \multicolumn{2}{|c|}{$\begin{array}{l}\text { Cations: } \\
\text { Al, } \mathrm{H}, \mathrm{Fe}, \mathrm{Mn}, \mathrm{Ca}, \mathrm{Mg}, \mathrm{Na} . \mathrm{K}, \mathrm{NH} 4 \\
\text { Anions } \\
\mathrm{HCO} 3, \mathrm{CO} 3, \mathrm{Cl}, \mathrm{NO} 2, \mathrm{NO} 3, \mathrm{SO} 4\end{array}$} & Overall composition & $\begin{array}{l}\text { The method used to } \\
\text { obtain the most } \\
\text { important ions are } \\
\text { included in annex } 2 \text {. }\end{array}$ \\
\hline B: Class & Bex index & \multicolumn{2}{|l|}{$\begin{array}{l}\text { - Deficit } \\
\text { - Equilibrium } \\
+ \text { Surplus }\end{array}$} & $\begin{array}{l}\text { Salinization - } \\
\text { freshening } \\
\text { Dissolution - uptake }\end{array}$ & \\
\hline
\end{tabular}

Figure 4.10. Description of parameters on the Stuyfzand water classification system

Negative (-) value on the class indicates salinization is taking place. A positive value indicates fresh water is entering into the aquifer. The index not only indicates the direction of the reaction (salinization or freshening) but also calculates the magnitude of the cation exchange reaction (Stuyfzand 1989). For aquifers in silica-predominant terrains, positive values for the class are obtained because of the dissolution of minerals that contain $\mathrm{Na}, \mathrm{K}$, or $\mathrm{Mg}$ and the interpretation of the class can be misleading (Stuyfzand 1989). Subtypes are similar to the traditional assignment of water type, based on the predominant ions. However, in this method it does not require for an anion or cation to be $>50 \%$ of the sum of anions or cations to be used as the 
name of the water type. Identification of subtypes in this fashion let water types derived from processes like air pollution, acidification, or excessive application of fertilizers to be obtained. Detailed information about the method is given on (Stuyfzand 1989; Stuyfzand 1999).

Classification results for the Plateaus area are presented on Figure 4.11. Water typed obtained can be divided into mainly two groups. Wells and spring water from the Caleras cluster are mainly g2-CaHCO3 - g2-MgHCO3. The rest of the springs are g3-NaHCO3. The interpretation of the code indicates that wells water is very fresh (Main type: $g$ ), with moderate values of alkalinity (type=2). The class value (+) indicates the intrusion of freshwater, however for the case of volcanic terrains dissolution of $\mathrm{Na}, \mathrm{K}$ or Mg minerals can also produce this value (Stuyfzand 1999). The overall classification would then indicate the water is of precipitation origin, with relatively short residence times within the aquifer. The higher values of alkalinity for the springs suggest longer times of circulation as compared to well water.

Stiff diagrams (Appelo and Postma 1999) were included in the map of Figure 4.11 to better describe the variations of the major ions among the samples. The change in the size Stiff diagrams area related to the degree of mineralization of the water. As observed on Figure 4.11, the increase on mineralization is observed from the recharge to the discharge areas Stiff diagrams indicate that $\mathrm{Na}$ is the as dominant ion on the spring water. It might be the result of cation exchange between the rock and the water, favored by the longer time of circulation. This is in accordance with the location of wells that are closer to the recharge areas and the location of springs located at the discharge areas of the local flow systems. 


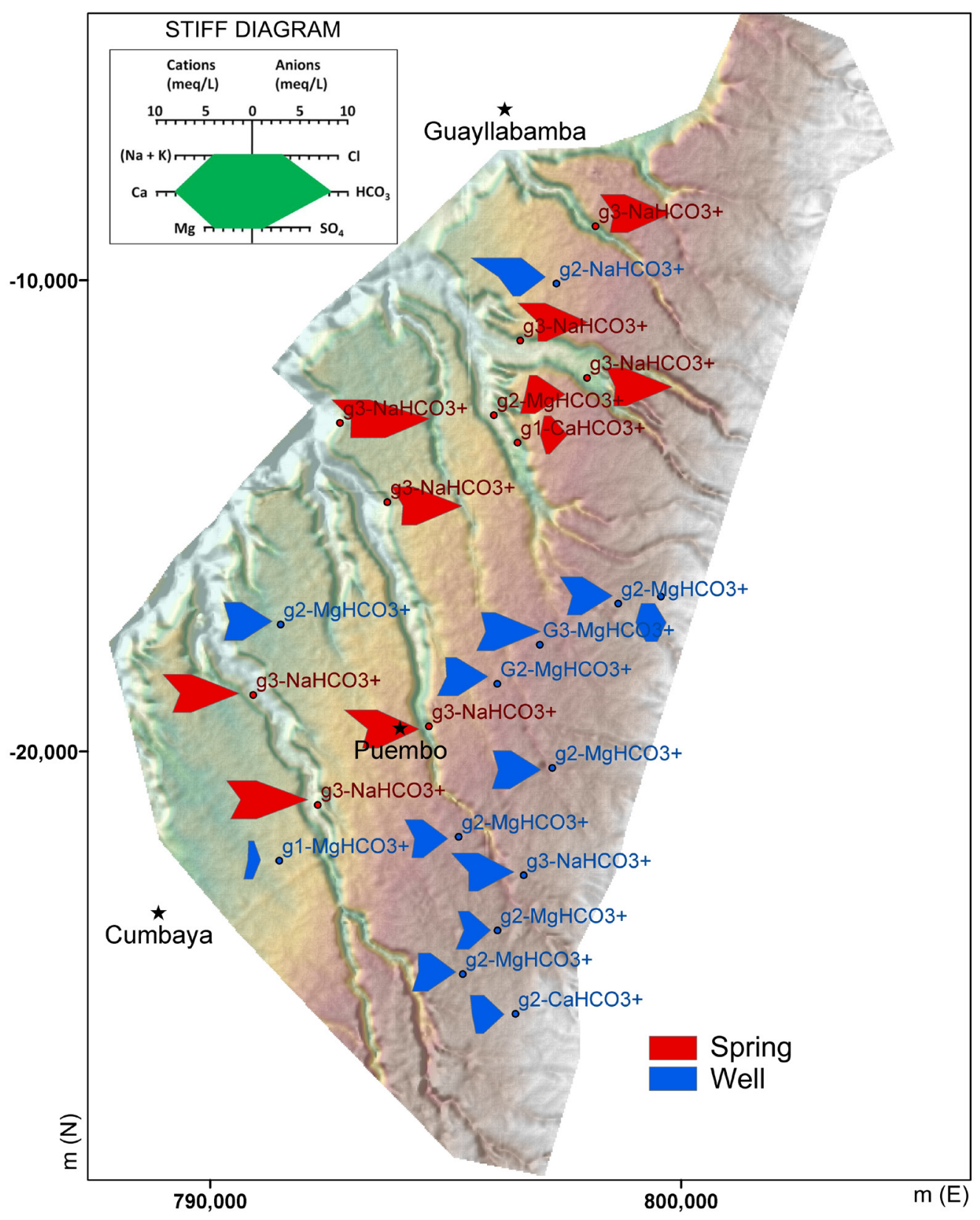

Figure 4.11. Stuyfzand water types and Stiff diagrams. Red polygons correspond to well samples and blue to spring samples. Map created on a an elevation and hillshade derived from a $30 \mathrm{M} A S T$-GDEM file (product of NASA and METI) 


\section{Isotopic analysis}

Environmental isotopic analysis of $18 \mathrm{O}$ and ${ }^{2} \mathrm{H}$ was carried out on nine springs. Six of them are from the main spring clusters and three come from the area north of the Plateaus. Samples for analysis were taken in August, 2011. Lab analysis was carried out by the University of Washington. Data results indicate a very little variation on the isotopic composition of the springs sampled. $\delta 2 \mathrm{H}$ values are between $-75.63950 / 00$ to $-78.26210 / 00$. $818 \mathrm{O}$ varies between -10.3865 to $-11.14460 / 00$ suggesting the same origin. Comparison of $818 \mathrm{O}$ and ${ }^{82} \mathrm{H}$ values to the local meteoric water line (LMWL), deviations are not observed (Figure 4.12). This indicates that the mean isotopic composition of spring water is similar to recent precipitation. Regarding the recharge elevation, Manciati (2012) established that water is recharged at elevations between 2300 to 2400 masl. The estimations were done using additional data samples for an area adjacent to the study area. Moreover, for the spring Chirimoyas (located on the Chiche river ravine) Manciati (2012).reports positive ${ }^{3} \mathrm{H}$ contents, and a $100 \%$ of ${ }^{14} \mathrm{C}$ activity. Manciati (2012) indicates that those number correspond with very young waters, less than 60 years.

\section{CONCEPTUAL MODEL OF THE AQUIFER SYSTEM}

The Plateaus area can be conceptualized as a tectonic aquifer complex, formed by a set of interbedded permeable and semi-permeable layers belonging to the San Miguel, Guayllabamba, Chiche and Cangahua formations. Lithology logs and geological descriptions do not indicate any thick impermeable layers within the formations nor separating them, favoring hydraulic communication between them. 


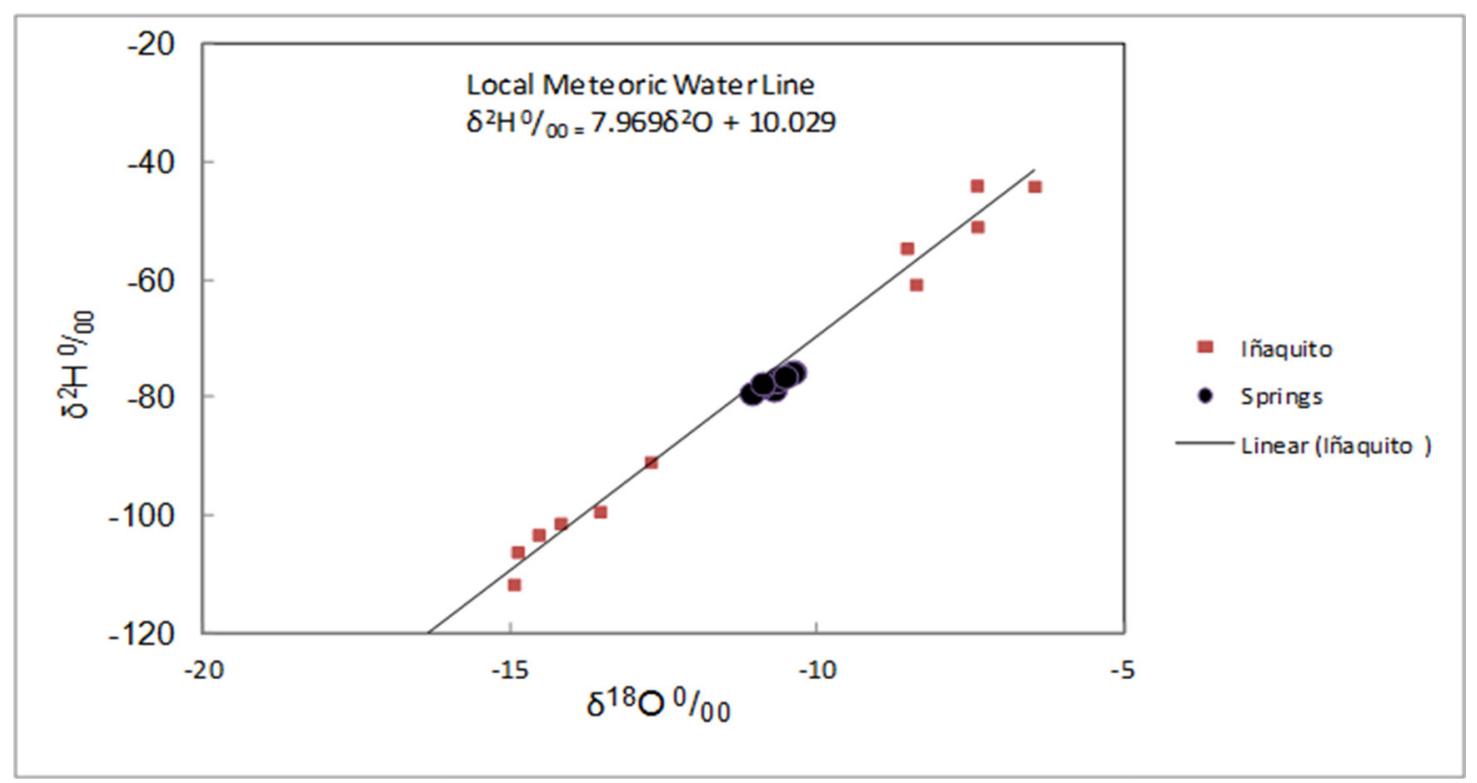

Figure 4.12. Stable isotope distributions of oxygen-18 and deuterium from spring samples. All of the samples analyzed plot along the Local Meteoric Water Line.

Two main hydrostratigraphic units have been characterized in this study. The ash deposits of Cangahua formation and the upper part of the Chiche form the unsaturated unit (USZ). The lower part of the Chiche Formation, Guayllabamba Formation and possibly the San Miguel formation form the main aquifer unit. Both units are considered as double porosity aquifers. Fracturing and faulting are the cause for the development of secondary porosity. Areas of higher permeability occur in the fractures and faults. The changes in the degree of fracturing give the aquifer a high degree of anisotropy, as reflected on the high variation of hydraulic conductivity.

Due to the depth of the water table and dissection, the USZ hydrostratigraphic units is compartmentalized. Moreover, areas of perched aquifers might be developed. Dissection also causes the development of 
isolated aquifer layers with limited water resources on the second hydrostratigraphic unit.

Main recharge zones are considered to coincide with the higher topographic areas. Water infiltrates and flows north-westerly, parallel and then diagonal to each plateau. Part of the water discharges on the ravines, forming local flow systems. The other part continues flowing through the lowest topographic areas on the plateaus, located on the north and north-western part. This flow component can be considered as the intermediate flow system (Figure 4.13).

The young age of water and the infiltration elevation suggest a higher rate of infiltration on the plateaus. Geophysics data and fractures indicate that vertical flow might be happening on the USZ.

\section{Influence of tectonics on the hydrogeology of the plateaus}

A summary of the influence of the tectonics on the flow of groundwater of the plateaus can be described as: (1)NE- oriented regional tectonic features created the major topographic highs (foothills of Cordillera Real) and lows (San Pedro Fault and most likely Guayllabamba S lineaments). These topographic highs and lows are forming the recharge and discharge zones respectively for the intermediate flow system. (2) NW-oriented faults and lineaments were the paths for the dissection that gave origin to the plateaulike morphology. The combinations of the SE-NW regional topographical gradients, with local NE-SW gradients on each plateau create the tilting of each plateau. Local flow systems are developed on each plateau. Discharge occurs on the local topographic highs. Natural discharge zones on those plateaus occur where fractured zones emerge from the lower sides of the plateaus (Figure 4.14). 


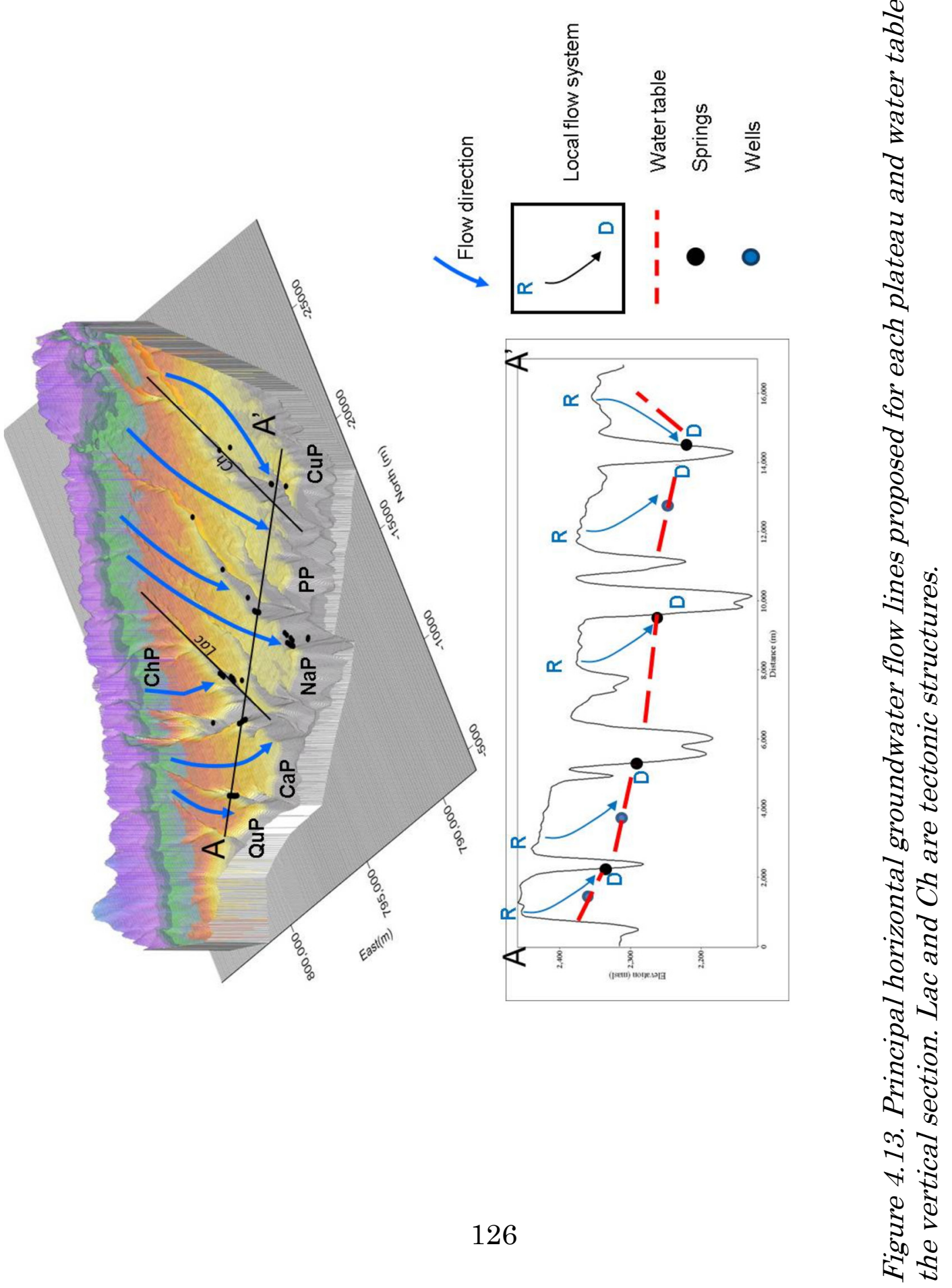




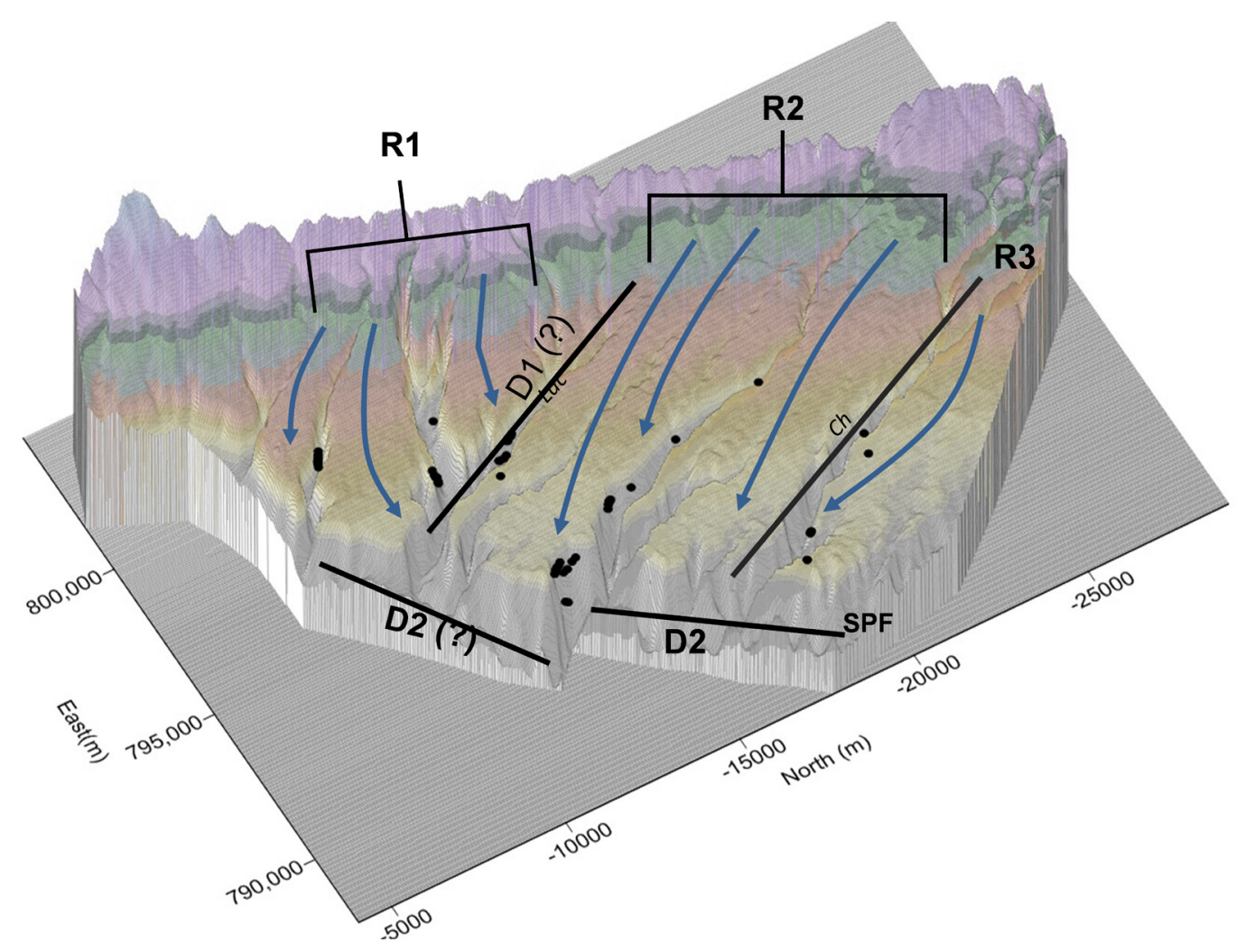

Figure 4.14. Recharge $(R)$ and potentially discharge $(D)$ zones for the intermediate flow systems proposed to exist in the Plateaus, and their relationship to tectonic structures. Blue arrows indicate the main flow direction

\section{CONCLUSIONS AND DISCUSSION}

The multifaceted approach used in this study demonstrated to be effective for characterizing the subsurface hydrology of the tectonic and topographic complex aquifers in this volcanic terrain. Each aspect contributed to develop a conceptual model that permitted understand key aspects of the aquifer functioning and can be used as the reference for future investigations. 
For the study of volcanic aquifers in mountainous terrains of Latin America topography and tectonics are playing important roles in the physical characteristics and the flow and should be included as part of hydrogeological studies.

The plateaus area is a complex tectonic/topographic zone. The topographic characteristics of the area are believed to be of tectonic origin. These topographic/tectonic features are controlling the development the aquifer spatial distribution and the groundwater flow.

In a regional basis, two main hydrostratigraphic units were identified on the plateaus. The first one is the thick unsaturated zone. The saturated zone is considered a single hydrostratigraphic unit given the fact that the any of the existing geological units do not have any significant impermeable layer that could give some sort of hydraulic isolation. Moreover, the data available does not suggest significant changes in the properties with depth. Due to dissection, isolated aquifer layers on the upper part of the Chiche formation exist. These areas are considered with limited water resources and might affect the productivity of the wells when they are screened.

Besides the primary permeability given to the system by the nature of the sediments, secondary porosity/permeability exists in the aquifers due to fractures and faults. The main hydraulic regime identified based on pumping test analysis is a double porosity aquifer.

The USZ unit is formed by compartmentalized areas with depths of $\sim 100 \mathrm{~m}$ in which perched aquifers might exist (Rios-Sanchez and Gierke 2012).

Fracturing characteristics of the USZ zone favor a much higher porosity and potentially the development of vertical flows. This makes the USZ an easy path not only for recharge, but for contaminants to reach the aquifer. 
Groundwater flow follows the NW regional topographic gradient. However due to dissection and the tilting of the plateaus groundwater is partially discharged into the walls of the ravines forming local flow systems. The groundwater flow following the regional topographic trend is considered to be forming intermediate flow systems.

Springs occur where the water table is intersecting the topographic surface and fractures are opening the path for the water to come out of the aquifer in a concentrated amount sufficient to appear distinct from the diffuse and imperceptible discharges across non fractured areas.

Groundwater types suggest that water is of meteoric origin. Water types and isotopic data indicate that the circulation times are short suggesting a young age for the water. Chemical variations agreed with the groundwater flow proposed. Water mineralization is low in recharge areas and gradually is increasing toward the discharge zones.

\section{ACKNOWLEDGMENTS}

This material is based upon work supported by the National Science Foundation under Grant No. 0530109. We are also grateful to the Water Utility Company of Quito (EPMAPS) and Oscar Larrea, head of the Quito Aquifer Division, for providing the QuickBird images, reports, and logistical and equipment support during the field work.

\section{REFERENCES CITED}

Alulema, R. (2007). Estudio hidrogeologico acuifero Pifo - El Quinche, Ecuador, Empresa Publica de Agua Potable y Saneamiento Basico de Quito.

Anton, D. J. (1993). Thirsty Cities, urban environments and water supply in Latin America. IDRC, The International Development Research Centre, Canada. 
Appelo, C. A. J. and D. Postma (1999). Geochemistry, groundwater and pollution. Rotterdam, The Netherlands, A.A BALKEMA.

Bishop, C. E. (2001). Delineation of drinking water source protection zones for Warm Spring, a public-water-supply spring, Iron County, Utah. U. G. Survey. Report of Investigation.

Bisson, R. A. and J. H. Lehr (2004). Modern groundwater exploration. Discovering new water resources in consolidated rocks using innovative hydrogeologic concepts, exploration, drilling, aquifer testing, and management methods. New Jersey, John Wiley \& Sons.

Clark, I. and P. Fritz (1997). Environmental isotopes in hydrogeology, CRC Press.

Custodio, E., Ed. (2004). Hydrogeology of Volcanic Rocks. Groundwater studies: an international guide for hydrogeological investigations. Paris, UNESCO.

Driscoll, F. G. (2007). Groundwater and Wells: A comprehensive study of groundwater and the technologies used to locate, extract, treat, and protect this resource. New Brighton, MN, Johnson Screens.

EPMAPS (2012). Groundwater Database. Q. A. D. Quito Water Utility Company. Quito, Ecuador.

Hurlow, H. A. and C. E. Bishop (2003). Recharge areas and geologic controls for the courthouse-sevenmile spring system, Western Arches National Park, Grand County, Utah, Utah Geological Survey. Special study.

INAMHI. (2012). "Inventario de pozos y vertientes del Ecuador." 2012, from http://186.42.174.237/estaciones/inventario_pozos.pdf.

Kirchner, J. and v. T. G.J. (1995). "Proposed guidelines for the execution, evaluation, and interpretation of pumping tests in fractured formations." Water SA 21(3): 187-200.

Krige, D. and E. Magri (1982). "Studies of the effects of outliers and data transformation on variogram estimates for a base metal and a gold ore body." Journal of the International Association for Mathematical Geology 14(6): 557564.

Kruseman, G. P. and N. A. D. Ridder (1994). Analyisis and evaluation of pumping test data. Wageningen, The Netherlands, International Institute for Land Reclamation and Improvement.

Manciati, C. (2012). Modelación del acuífero Ilaló-Cumbaya-Tumbaco. Montpellier, France, Universidad de Montpellier II.

Manga, M. (2001). "Using springs to study groundwater flow and active geologic processes." Annual Review of Earth and Planetary Sciences 29(1): 201-228.

Mul, M. L., R. K. Mutiibwa, J. W. A. Foppen, S. Uhlenbrook and H. H. G. Savenije (2007). "Identification of groundwater flow systems using geological mapping and chemical spring analysis in South Pare Mountains, Tanzania." Physics and Chemistry of the Earth, Parts A/B/C 32(15-18): 1015-1022.

Renard, P. (2006). Hydraulics of Wells and Well Testing. Encyclopedia of Hydrological Sciences, John Wiley \& Sons, Ltd.

Renard, P., D. Glenz and M. Mejias (2009). "Understanding diagnostic plots for welltest interpretation." Hydrogeology Journal 17(3): 589-600. 
Rios-Sanchez, M. and J. Gierke (2012). Geophysical methods for fracture detection on mountainous volcanic aquifers of the plateaus area, Quito Ecuador. . Houghton, Michigan Technological University.

Rios-Sanchez, M., J. Gierke and T. Muñoz-Martínez (2012). Hydrogeological characterization of the Plateaus region of the Quito Aquifer System using remote sensing, digital geomorphology, and geophysics. . 2012 World Environmental and Water Resources Congress, Albuquerque,New Mexico.

Studner, M., G. Zangl and F. Komlosi (1997). "A modern concept simplifying the interpretation of pumping tests." Transaction on Ecology and the Environment 14.

Stuyfzand, P. J. (1989). A new hydrochemical classification of water types. Regional Characterization of Water Quality, Baltimore, IAHS.

Stuyfzand, P. J. (1993). Hydrochemistry and hydrology of the coastal dune area of the Western Netherlands. Geology. Amsterdam, Vrige Universiteit. PhD.

Stuyfzand, P. J. (1999). "Patterns in groundwater chemistry resulting from groundwater flow." Hydrogeology Journal 7(1): 15-27.

Toth, J. (1971). "Groundwater Discharge: A common generator of diverse geologic and morphologic phenomena." International Association of Scientific Hydrology Bulletin 16(1): 7-24.

Villagomez, D. (2003). Evolución geológica Plio-cuaternaria del Valle Interandino Central en Ecuador (Zona de Quito-Guayllabamba-San Antonio). Escuela de Ingeniería. Quito, Escuela Politécnica Nacional. Ing. Geólogo.

Vsevolozhskii, V. A., R. P. Kochetkova and F. Fidelli (2001). "Principles of hydrogeological zoning by the conditions of formation and the distribution of the natural resources of fresh ground water." Water Resources 30(3): 233-245.

Winkler, W., D. Villagómez, R. Spikings, P. Abegglen, S. Tobler and A. Egüez (2005). "The Chota basin and its significance for the inception and tectonic setting of the inter-Andean depression in Ecuador." Journal of South American Earth Sciences 19(1): 5-19.

Zektser, I. S. and L. G. Everett (2004). Groundwater resources of the world and their use. Paris, UNESCO.

Zijl, W. (1999). "Scale aspects of groundwater flow and transport systems." Hydrogeology Journal 7(1): 139-150. 


\title{
APPENDIX I
}

PROCEEDINGS PAPER

HYDROGEOLOGICAL CHARACTERIZATION OF THE PLATEAUS REGION OF THE QUITO AQUIFER SYSTEM USING REMOTE SENSING, DIGITAL GEOMORPHOLOGY, AND GEOPHYSICS ${ }^{6}$

\author{
Miriam Rios-Sanchez ${ }^{1}$, John S. Gierke ${ }^{1}$, Teresa Muñoz-Martínez ${ }^{2}$ \\ ${ }^{1}$ Department of Geological and Mining Engineering and Sciences, Michigan \\ Technological University, 1400 Townsend Dr., Houghton, MI 49931.
}

2Empresa Publica Municipal de Agua Potable y Saneamiento de Quito. Avenida Mariana de Jesus entre Alemania e Italia. Quito, Ecuador

\begin{abstract}
Remote sensing techniques can be used in the characterization of landscapes for assessing groundwater resources. Digital terrain analysis has been used broadly for study subsurface geology, especially analysis of topographic features and their relationship to tectonic and structural phenomena. Structural discontinuities such as faults are expressed in a DEM as a linear feature, representing the intersection of a fracture plane and land surface. Besides, lineaments, faults originate morphotectonic structures such as depressions, asymmetric slopes across valleys and ridgelines axis. There are morphological evidences of tectonics that are represented by a point feature that may have a spatial continuity due to the same origin. This could happen especially on soft rocks that do not easily record deformations. Geophysical surveys are especially appropriate for confirming the presence, extent, and orientation of geological lineaments, as well as for detecting the presence of
\end{abstract}

6 The following appendix has been published in the proceedings of the 2012 World Environmental and Water Resources Congress. Alburquerque,NM.. With permission from ASCE 
water in the fractures. The use of $2 \mathrm{D}$ resistivity profiling is widespread as a tool to identify aquifer layers in sedimentary rocks and volcanic terrains and also to detect water bearing fractures The VLF method has been applied successfully to map the resistivity contrast in fractured zones. Based on the RS lineament mapping, complemented with the digital morphological analysis and geophysics, fracturing patterns were characterized for the Plateaus region of the Quito Aquifer System (QAS). The aquifer is located in the Central Inter-Andean Valley of Ecuador, a region affected by active volcanism and faulting and characterized by basins filled with series of volcanic deposits and primary and reworked sedimentary rocks. By combining our results with those from previous geological studies and hydrogeological data, the impact of topography and fracturing on the hydrogeology of the plateaus was assessed.

\section{INTRODUCTION}

Aquifers in active tectonic areas are subject to structural controls that can superimpose secondary effects on the primary hydraulic properties of the rock formations by creating zones of preferential infiltration, subsurface flows, or serving as barriers to groundwater flow (Bisson and Lehr 2004; Vsevolozhskii et al. 2001). Surface expressions of structural controls in the form of drainage alignments, linear topographic trends, and vegetation anomalies are among the features that can be readily identified on satellites images.Also, many of those features can be identified on Digital Elevation Models (DEMs), especially when those structures have largely affected the topography of the region

Remote Sensing tools (RS) combined with digital terrain analysis (DTA) offer a comprehensive way to map lineaments of geological origin. By mapping lineaments and assessing their topographical expressions, a characterization of fracturing and faulting can be achieved. Geophysical surveys are valuable for confirming the presence, extent, and orientation of geological lineaments, as well as for detecting the presence of water in the fractures. Analysis of 
spring data is an additional tool that can enhance the understanding of the contributions of local and regional fracturing to the hydrogeology.

Generally there is a misconception that since groundwater is a hidden resource, it is impossible to study with satellite images due to the fact that signals of satellite sensors penetrate normally only a few centimeters into the ground. However, features related to the existence and movement of water underground can readily be interpreted by using images capturing from different parts of the electromagnetic spectrum. Applications of remote sensing to groundwater include: geology/hydrogeology mapping; detection of lineaments with which groundwater occurrence is associated; evaluation of discharge and recharge areas and flow systems by mapping of geomorphology, soil and land cover. Remotely sensed data offer the possibility of providing synoptic views of large areas at different times and scales, which can be used in regional hydrogeological studies and provide supporting data for monitoring and numerical modeling ground.

Imagery derived from instruments sensing radiation from the visible, near infrared, thermal, and microwave parts of the electromagnetic spectrum are most often used for groundwater. Bruning et al, (2011) demonstrated an integrated approach to map lineaments in non-ideal conditions, where extensive vegetation and anthropogenic features are present and frequent cloud cover limits the availability of optical satellite data. Bruning et al. (2011) analyzed several types of remotely sensed imagery (ASTER, QuickBird, LANDSAT ETM+, RADARSAT-1) and a digital elevation model (DEM). Several digital image processes were applied to the images in order to create an effective and efficient method for lineament analysis for groundwater exploration in volcanic terrains. Twelve lineament interpretations were synthesized to create a raster image of lineament-zone 
coincidence in order to present the level of agreement among the different interpretations. A final map was achieved by restricting mapped lineaments to those that were coincident in at least 4 interpretations.

Digital terrain analysis has been used broadly for automatically mapping lineaments and geomorphotectonic and hydrogeological assessment.

Structural discontinuities such as faults are expressed in a DEM as a linear feature, representing the intersection of a fracture plane and land surface. Moreover, faults cause geological forms such as depressions, asymmetric slopes across valleys and ridgelines. Faulting also produces changes in streams such as deflection and offsetting that indicate the direction of relative displacement of the fault. However, for areas with soft rocks, where deformation is not easily display, the use of tectonic indicators can help to complement the mapping of faults and fractures

Geophysical surveys are especially appropriate for confirming the presence, extent, and orientation of geological lineaments, as well as for detecting the presence of water in the fractures. The use of 2 -dimensional resistivity profiling is commonly used as a tool to identify aquifer layers in sedimentary rocks and volcanic terrains and to map lateral variations in lithology or water quality. The method is also applied to detect water bearing fractures and weathered areas in hard rock aquifers to site tube wells. Very Low Frequency - Electromagnetic Methods (VLF-EM or VLF) has been applied successfully to map fractures zones behaving as "conductors", not only for hydrogeology, but also for ore exploration

This paper discusses the remote sensing analysis (RSA) and digital terrain analysis (DTAA) approaches used to map in detail the fracture networks existing in the Plateaus area of the Quito Aquifer System of Ecuador (Figure 
5.1). The assessment of the expression of fracturing underground is performed based on resistivity profiling and VLF-EM surveys. Relationships between springs and the lineaments are presented as a starting point to describe the impact of the tectonics on the morphology and hydrology of the study area. The remote sensing-based protocol and digital terrain analysis followed is based on the methodology described on Rios-Sanchez et al. (2012).

\section{STUDY AREA}

The plateaus region is part of the Quito Aquifer System (QAS). QAS is located in the Central Inter-Andean Valley (CIAV), which is a large and complex tectonic basin, situated between the Cordillera Occidental and Cordillera Real in Northern Ecuador (Villagomez et al. 2002). The plateaus are a group of $\mathrm{NW}$-oriented flat areas (slopes less than $5^{\circ}$ ), separated by wide ravines (Figure 5.1). The widths of the ravines are generally less than $200 \mathrm{~m}$, although locally can reach up to $600 \mathrm{~m}$. The ravines have a NW deepening trend, reaching depths of $300 \mathrm{~m}$ in the Guayllabamba River. Topographical elevations range from 2300 to $2600 \mathrm{~m}$. Slopes along the sides of the ravines are typically between $40^{-} 50^{\circ}$, but locally can be as steep as $60^{\circ}$. A number of springs discharge on the sides of the ravines and serve as important sources for water supplies for the Quito Metropolitan Area. The Plateaus boundaries, as depicted in Figure 1, are marked by the San Pedro Fault and the Guayllabamba depression to the north and west, by the foothills of Cordillera Real to the east and the Ilaló Volcano and Cumbayá Valley to the southwest. The thickness of the sedimentary/volcanic cover in the plateaus region is estimated to reach more than $500 \mathrm{~m}$. The deposits on the plateaus are composed of a sequence of subhorizontal layers, originating from different 

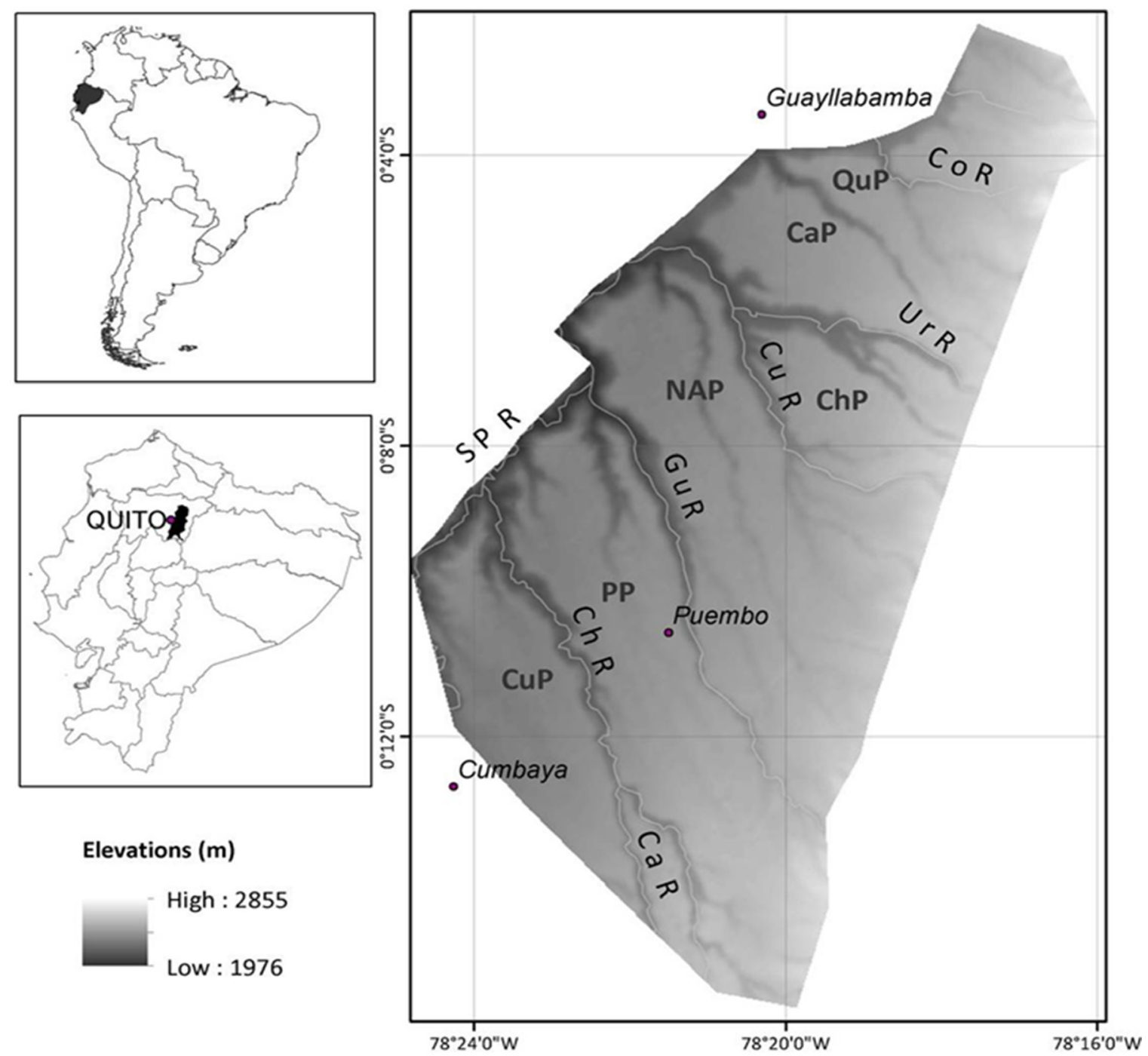

Figure 5.1. Location map. The plateaus zone is located east of Quito, Ecuador. Plateau names are identified as follows: CaP: Cumbaya, PP: Puembo, NAP: New Airport, ChP: Checa, CaP: Caleras and QuP: Quinche. There are no more plateaus north and east of the Quinche plateau. The main rivers in the area are: SPR: San Pedro, ChR: Chiche, CaR: Cariyacu, CuR:Cutuchi; UrR: Uravia and CoR: Coyaco. Plateaus map created from an ASTER GDEM, a product of METI and NASA.Shapefiles of South America and Ecuador from www.diva-gis.org

periods of Pleistocene volcanic and sedimentary activity. The basement of the plateaus is thought to be formed by rocks of the Pisque Formation 
(Villagomez et al. 2002), which is composed of at its lower part by lavas and breccias, overlain by layers of tuff and lahar deposits.

The uppermost part is formed by sediments derived from alluvial fans. The San Miguel Formation is composed of layers of sandstones, siltstones and tuffs deposits. However, none of those formations have been mapped. The oldest geological unit mapped in the region is the Guayllabamba Formation. It is composed from base to top by four sequences of deposits, the lowest one is composed by of lahar deposits; the second one by volcanic domes; the third one by lava flows, pyroclastic flows and avalanches; and the upper one is composed by alluvial fans. The Chiche Formation overlays the Guayllabamba Formation and is mainly composed of lacustrine and fluvial deposits (siltstone, claystone and sandstone and eventually conglomerates) interbedded with volcanic deposits (tuffs and lahars). The Chiche Formation thickness varies between 114 to $219 \mathrm{~m}$. The top geological unit on the plateaus is composed by volcanic ash and tuff, with intercalated layers of sand and clay, called the Cangagua Formation. This layer has an average thickness of $60 \mathrm{~m}$

\section{METHODS}

Identification of fractures, faults, and discontinuities started with a regional lineament map. This map was refined using fine spatial-resolution satellite imagery and DEMs. Morphotectonic features were used to corroborate the tectonic nature of those lineaments. In order characterize the depth and spatial orientation of fractures $2 \mathrm{D}$ resistivity and VLF-EM profiling was carried out. Finally, spring locations were superimposed on the map in order 
to assess the relationship between lineaments and the hydrogeology of the plateaus.

The mapping started with a regional lineament map created by Rios-Sanchez et al. (in prep). That map was created based on combined RSA and DTAA approaches. By using field recognition and high spatial-resolution imagery (ASTER VNIR, Quickbird, and Google Earth) (Digital-Globe 2008; Google 2010; NASA-LPDAAC 2008), the detail of that map was enhanced. Previously unmapped lineaments were observed in satellite imagery as short length linear features within the ravines. Due to the intensive agriculture and human development, the continuity of those features on top of the plateaus was not easily defined. Nevertheless a tectonic origin was suspected for those lineaments considering the large number, the trend in the orientation of those features, and their association to morphotectonic features such as saddles, fractures channel bends and near-orthogonal stream junctions. In order to explore the spatial continuity of the short lineaments, the DEMderived Aspect Map was used for the extrapolation(NASA-LPDAAC 2010) . The changes in aspect display linear features that correspond well to the regional lineaments. The Aspect Map also displayed linear features that have a similar trend of the short lineaments but in a much higher amount. Lineaments to be included in the detailed map of the plateaus were selected considering features on the Aspect Map that coincided with the short lineaments.

In order to analyze the spatial concentration of lineaments, areal density was calculated using Arc Map 9.3. A rose diagram was created to analyze the spatial distribution of lineament orientations in the Plateaus. 
The interpreted lineaments were further assessed using shallow geophysics methods. Two-dimensional resistivity and VLF-EM surveys were carried out. Most of the traverses selected to run the surveys were oriented N/S-NW/SE aiming to characterize lateral variations of electrical resistivity or electromagnetic anomalies (conductive bodies), due to the predominance of E/W-SW/NE trending lineaments. Inversion was performed in both types of surveys in order to resolve vertical linear changes in resistivity. Resistivity profiles were overlain on the lineament map to determine the degree of correspondence.

Finally, springs were mapped on the lineament map. Also locations of springs were located on topographic profiles. Flow data and electrical conductivity of the water was analyzed

\section{RESULTS AND DISCUSSION}

A total of 162 lineaments were mapped in the plateaus across the entire study area, as shown in Figure 3. The average lineament length is $1573 \mathrm{~m}$. The predominant lineament orientation is $\mathrm{N} 45 \mathrm{E}$. There is a second trend $\mathrm{N}^{-}$ NW, as indicated in the rose diagram (insert (a) in Figure 5. 2). The density lineament map (insert (b) in Figure 5.2) shows a non-uniform distribution. Density is lower in the Eastern and Southeastern parts of the area and increases towards the Northwest. Areas with the highest density of lineaments are located on the New Airport (NAP) and Puembo (PP) Plateaus. Most of those lineaments are parallel to the lineaments that mark off the Northwestern boundary of the plateaus. 

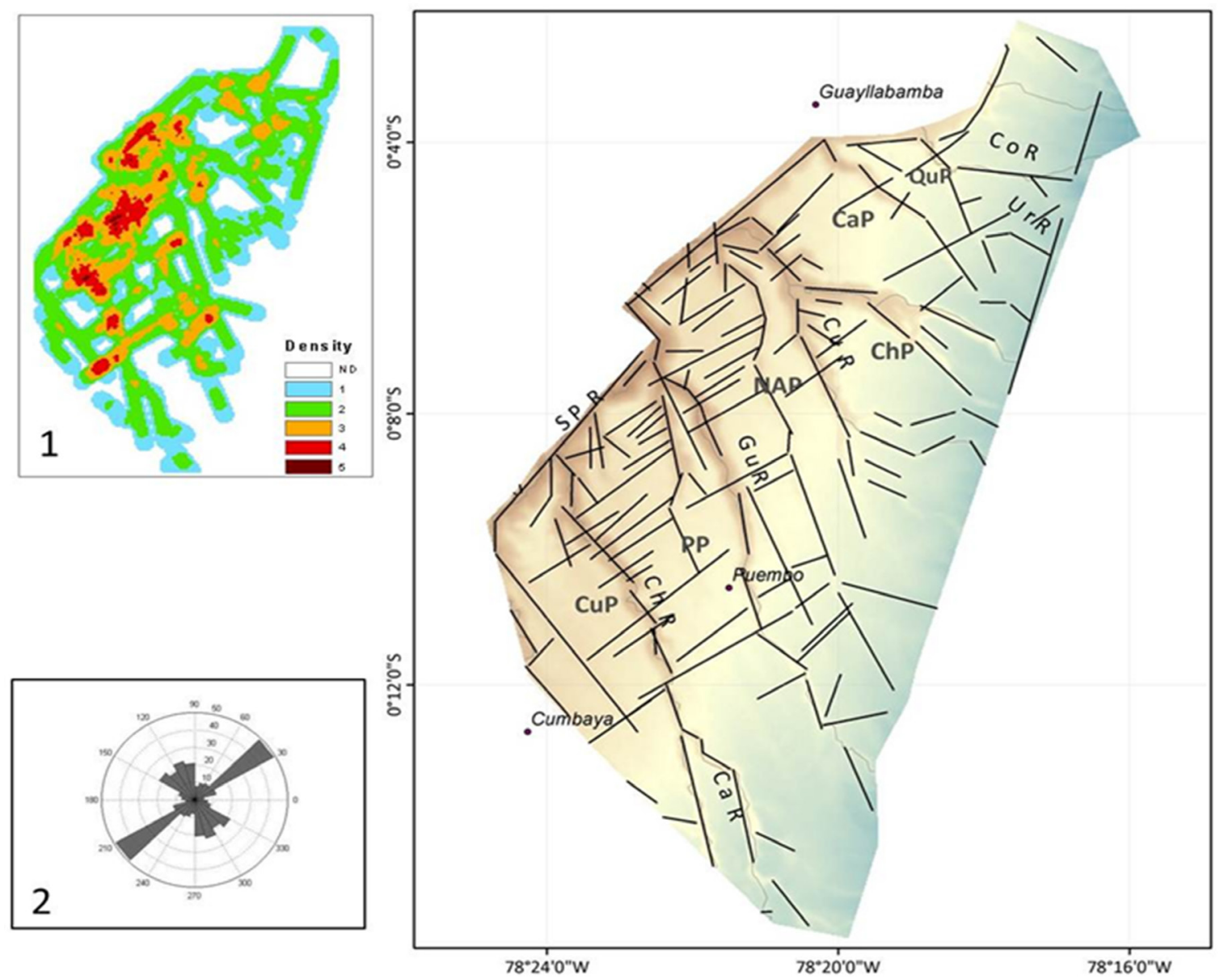

Figure 5.2. Detailed lineament map of the plateaus. 1 Density of lineaments. 2. Rose Diagram Lineaments display on a topographic map created from an ASTER GDEM, a product of METIand NASA

N-NW lineaments control the main drainages and are considered regional features. Many of the regional lineaments are not readily observed on high spatial-resolution imagery. N-NE lineaments are controlling the course of San Pedro River (SPR) and most of the first- and second-order drainages.

Lineaments that are marking off the north-western boundary of the plateaus region are recognized as the San Pedro Fault (SPF). Some of the N-NE 

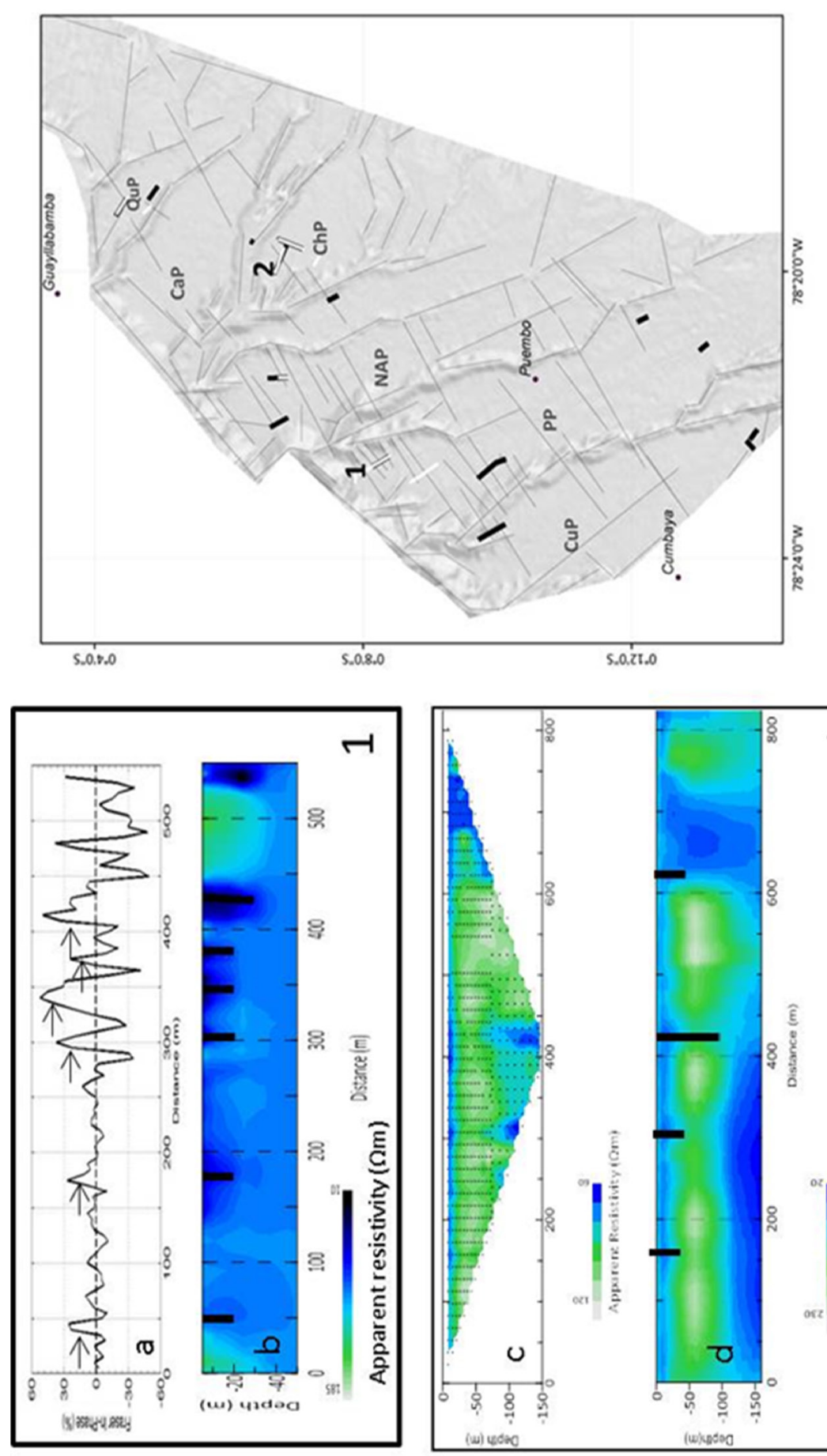

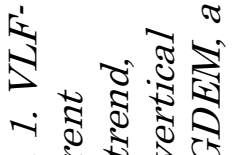

ร สิ สิ

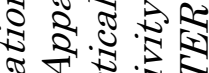

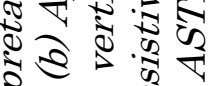

बi

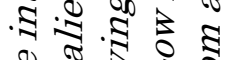

离

ชั สิ

$\frac{1}{2} 8$ y

ส.

政

ป

क ช

है

ป

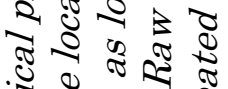

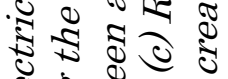

ช.

ช.

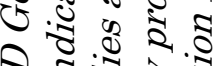

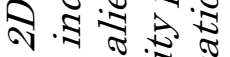

ป

च

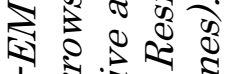

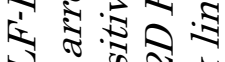

ㄱํ के ते

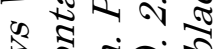

ब. ปิ के है

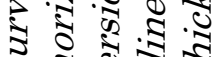

क व

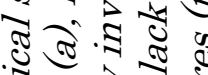

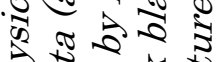

$\overrightarrow{2} \approx \widetilde{0}$

ป

$\infty \pi \frac{\pi}{\pi} \cdot \pi$ क $\frac{\pi}{4}$

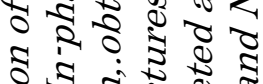

ริ

ช

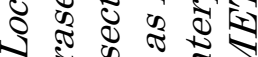

मे 2 .

9.

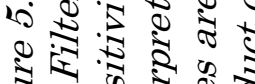

क人

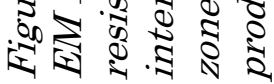


lineaments are located in areas where the NW lineaments change slightly in direction.Positive anomalies were identified in the VLF-EM Fraser-filtered profiles by analyzing the inverted apparent resistivity profiles (Figure 5.3). Some anomalies were able to be interpreted as saturated fracture zones, due to their clear expression on the section as vertical features and lower resistivity values. Likewise, all 2D geoelectrical sections display vertical narrow zones of low resistivities that could be interpreted as fracture zones (Figure 5.3). The depth of the fractures, according to the geoelectrical sections, varies from 20 to $90 \mathrm{~m}$.

However, maximum depth is limited by the length of the survey and the quality of data. Almost $90 \%$ of the fracture features have a dip angle near vertical. When overlying the Lineament Map with the 2D resistivity and VLF-EM profiles, it was found that $30 \%$ of the features identified with the geophysics methods correspond to lineaments.

In Figure 5.4, the location of the springs on the plateaus is presented. Springs appear mainly in clusters in the ravines, where NW and $\mathrm{NE}$ lineaments intersect. Some of the NE lineaments, due to their short lengths, do not appear as mapped features. Although springs are located in the ravines, they are not located on the lowest part of the river valleys. Rather they are located on the slopes, almost at the middle elevation. Springs appear on the Eastern sides of the ravines, except for Chirimoyas and Chiche, which are located on the Western side of the ravine. It seems springs discharge parallel to the topographic gradient of the plateaus (see Figure 4). The higher spring elevations are located in the North part of the plateaus. The lowest areas are located toward the San Pedro River following a southwestern tendency. Spring flows vary between $0.48 \mathrm{l} / \mathrm{s}$ to $50 \mathrm{l} / \mathrm{s}$. Most of the springcluster areas have a high variability in the flows that the springs are producing. However Quinche and Caleras clusters have flows smaller than 
6.4 l/s. Although the spring locations seem to coincide with lineaments, there is not a direct association between the flow rates and density/orientation of fracturing.

For areas with human development and agriculture, DEMs provided more information about lineaments than RS tools. However, due to the fact that this is a very complex tectonic region and it has an intensive agriculture development, linear features do not always correspond to a geological cause. Geomorphology and field work was very important for identifying the lineaments considered of geologic origin.

The lineament map created in this study indicates that tectonics is influencing the morphology of the plateaus. Lineaments seem to be affecting the drainage network.

VLF-EM and 2D geoelectrical profiles are effective methods to assess the existence of vertical anomalies that are affecting the hydrology of the region. Vertical changes in electrical resistivity were observed across the area representing changes in the properties of the aquifers existing in the Plateaus.

The correlation between the lineaments mapped using the RSA and DTAA protocols to linear features from the geophysical surveys indicates that lineaments correspond to fractured areas within the plateaus. The number of vertical features associated with fractures detected using geophysics is higher than in the lineament maps. This could be due to the ability of geophysical methods to detect smaller changes in the properties of the rocks, represented by changes in water content or lithological variations, than the changes that are manifested and identified with the RS or DEM tools. 


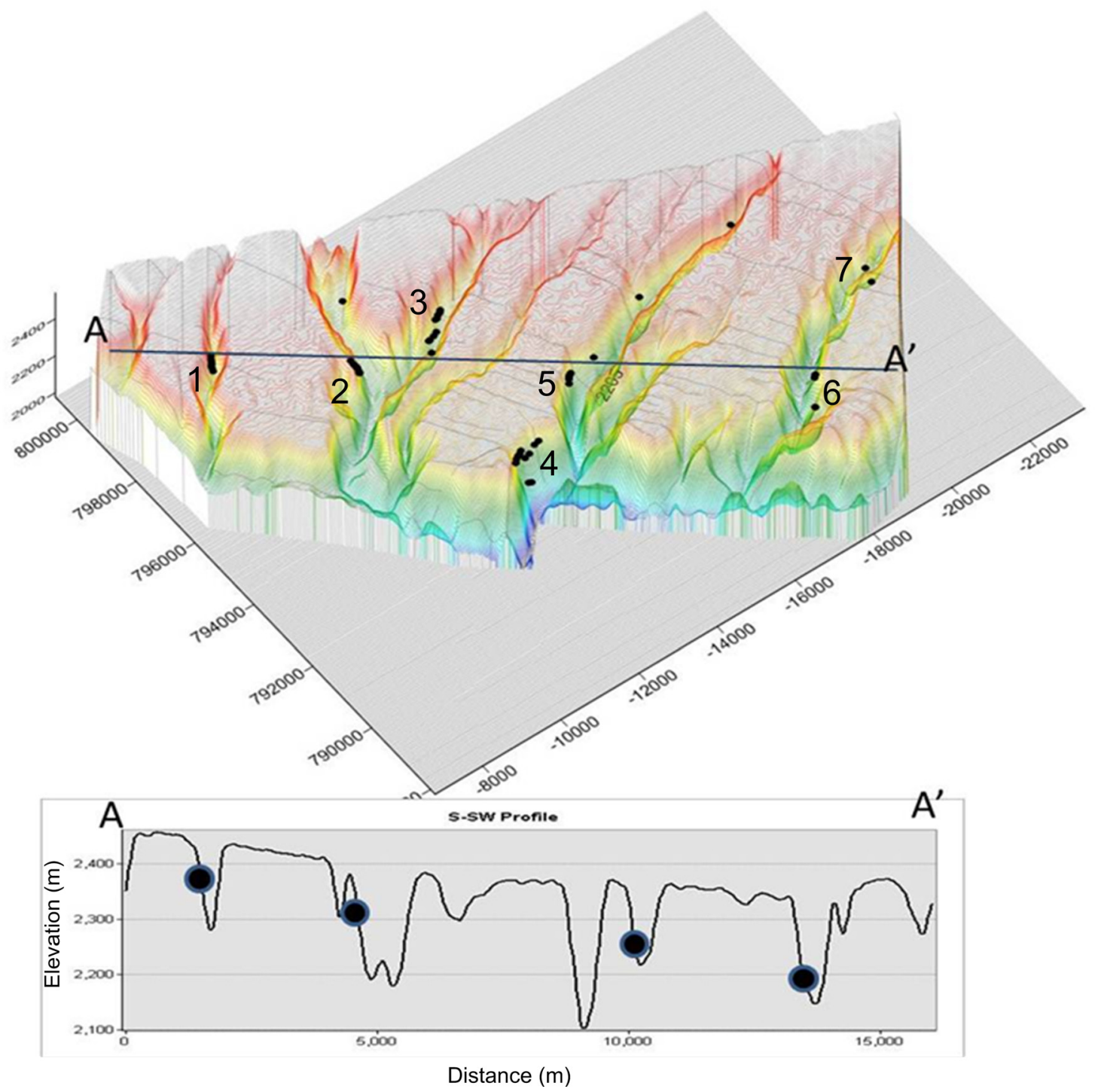

Figure 5.4: Location of the springs in relation to individual plateaus and lineaments. Numbers indicate the spring cluster: 1. Quinche; 2. Caleras; 3.Pizuña; 4. New Airport; 5.Guambi; 6:Chirimoyas and 7.Chiche. The bottom figure has a topographic profile and the location of some springs of the cluster. Springs and lineaments plotted in a $3 D$ relief map created from an ASTER GDEM, a product of METI and $N A S A$

The association of springs to lineaments, or intersection of fractures and lineaments, suggest that the discharge of the aquifer through springs is 
mainly controlled by fracturing and faulting. Faults and fractures are representing paths for infiltration or exfiltration of water. Topography is

playing a very important role as well. Since the plateaus east of Chiche River are tilted to the west, discharge is taking place mostly from the Western sides of the plateaus. Cumbaya Plateau is tilted to the east, so springs appear on the eastern side. The location of the springs, way above of the river valley might indicate that they are not associated with the base flow.

\section{CONCLUSION}

By using a combination of RSA/DTA, digital geomorphology tools and field work, a detailed lineament map of the Plateaus Region of the Quito Aquifer System was created. The approach used in this study permitted the discovery of a new set of lineaments that are affecting the hydrology of this region.

The inclusion of high spatial resolution imagery in the analysis was very important since short length features were visible only in this kind of imagery. These short linear features provided the support to extract linear features on the aspect map.

Positive anomalies on the Fraser filtered VLF-EM data, associated with low apparent electrical resistivity values on the inverted sections were interpreted as potential fracture zones. Likewise, narrow vertical areas of low resistivity, observed in the $2 \mathrm{D}$ geoelectrical profiles were associated to potential fractured zones. Those areas were identified to depths from 20 to 90 $\mathrm{m}$.

The identification of faults that are controlling the topography of the Plateaus and the mapping of a high density of lineaments indicate that the aquifers are significantly affected by secondary porosity, and this assertion is supported by the locations of springs. The topographic gradient and 
tectonism are controlling the location of springs. Moreover the location of springs in areas of intersection of lineaments indicates that tectonism is playing a very important role on the hydrology of the region.

\section{ACKNOWLEDGMENTS}

This material is based upon work supported by the National Science Foundation under Grant No. 0530109.

Water Utility Company of Quito (EPMAPS) and Oscar Larrea, head of the Quito Aquifer Division, for providing the Quickbird images, reports and support with during the field work

\section{REFERENCES CITED}

Alulema, R. (2007). Estudio Hidrogeologico Acuifero Pifo - El Quinche, Empresa Publica de Agua Potable y Saneamiento Basico de Quito.

Arenas, M. A. (2006). Lineament Extraction from Digital Terrain Models. Case Study San Antonio del Sur Area, South-Eastern Cuba. Enschede, International Institute for Geo-Information Science and Earth Observation. Master of Science.

Bakosur, A. T. and M. E. Candansayar (2003). "Enhancing VLF data for qualitative interpretation: An example of massive chalcopyrite exploration." The Leading Edge. Tulsa, OK 22((6)): 568-570

Beamish, D. (2000). "Quantitative 2D VLF data interpretation." Journal of Applied Geophysics 45(1): 33-47.

Becker, M. W. (2006). "Potential for satellite remote sensing of groundwater." Groundwater 44(2): 12.

Bisson, R. A. and J. H. Lehr (2004). Modern groundwater exploration. Discovering new water resources in consolidated rocks using innovative hydrogeologic concepts, exploration, drilling, aquifer testing, and management methods. New Jersey, John Wiley \& Sons.

Bruning, J. N., Gierke, J. S., McLean and A. L. (2011). An Approach to Lineament Analysis for Groundwater Exploration in Nicaragua. Bethesda, MD, ETATSUNIS, American Society for Photogrammetry and Remote Sensing.

Custodio, E., Ed. (2004). Groundwater studies: an international guide for hydrogeological investigations. IHP-VI Series on Groundwater, 3. UNESCO. Paris 2004 Groundwater studies: an international guide for hydrogeological investigations. Paris, UNESCO. 
Digital-Globe (2008). QuickBird scenes r2_c2_p004_dvd08_2, r3c1_p004_dvd09,r1c2_p004_dvd07;r1c1_p004_dvd07,r2c2_p004_dvd08_1,r4c 1_p004_dvd10,r4c1_p001_cd11,r3c2_p004_dvd9 and r4c2_p004_dvd10 Longmonton, Colorado.

Google. (2010). "Google Earth Pro (Version 5.1.3535.3218).

Hijmans, R. (2011). "DIVA-GIS. A geographic information system for the management and analysis of genetic resources data.", 2001.

Jordan, G., B. M. L. Meijninger, D. J. J. v. Hinsbergen, J. E. Meulenkamp and P. M. v. Dijk (2005). "Extraction of morphotectonic features from DEMs: Development and applications for study areas in Hungary and NW Greece." International Journal of Applied Earth Observation and Geoinformation 7(3): 163-182.

Keller, E. A. and N. Pinter (1996). Active tectonics: Earthquakes, uplift, and landscape, Prentice Hall (Upper Saddle River N.J).

Meijerink, A. M. J., D. Bannert, O. Batelaan, M. W. Lubczynski and T. Pointet (2007). Remote sensing applications to groundwater. Paris, UNESCO.

Monteiro Santos, F. A., A. Mateus, J. Figueiras and M. A. Gonçalves (2006). "Mapping groundwater contamination around a landfill facility using the VLF-EM method -- A case study." Journal of Applied Geophysics 60(2): 115125.

NASA-LPDAAC (2008). Land Processes Distributed Active Center.AST_L1B_00302052007154358_20080607143256_4202.hdfUSGS/Eart h Resources Observation and Science (EROS) Center Sioux Falls, South Dakota.2008.

NASA-LPDAAC (2010). Land Processes Distributed Active Center. ASTGTM_N00W079_dem.tif and ASTGTM_N00W78_dem.tif. USGS/Earth Resources Observation and Science (EROS) Center Sioux Falls, South Dakota.2010

Revil, A., A. Finizola, F. Sortino and M. Ripepe (2004). "Geophysical investigations at Stromboli volcano, Italy: implications for ground water flow and paroxysmal activity." Geophysical Journal International 157(1): 426-440.

Ricchetti, E. and M. Palombella (2005). Application of Landsat 7 ETM+ imagery for geological lineament analysis of Southern Italy. Geoscience and Remote Sensing Symposium, 2005. IGARSS '05. Proceedings. 2005 IEEE International.

Rios-Sanchez, M., J. S. Gierke and A. L. McLean (2012). Utilizing digital image processing techniques to identify and characterize fracture patterns in the Quito, Ecuador aquifer system. Houghton, MI, Michigan Technological University.

Sang-Ho, Y. and W. M. Moon (2001). Lineament extraction from DEM using drainage network. Geoscience and Remote Sensing Symposium, 2001. IGARSS '01. IEEE 2001 International.

Seta, M. D., M. D. Monte, P. Fredi and E. L. Palmieri (2004). "Quantitative morphotectonic analysis as a tool for detecting deformation patterns in softrock terrains: a case study from the southern Marches, Italy / Analyse morphotectonique quantitative dans une province lithologique enregistrant 
mal les déformations : les Marches méridionales, Italie." Géomorphologie : relief, processus, environnement: 267-284.

Singh, K. K. K., A. K. Singh, K. B. Singh and A. Sinha (2006). "2D resistivity imaging survey for siting water-supply tube wells in metamorphic terrains: A case study of CMRI campus, Dhanbad, India." The Leading Edge 25(12): 1458-1460.

Solomon, S. and F. Quiel (2006). "Groundwater study using remote sensing and geographic information systems (GIS) in the central highlands of Eritrea." Hydrogeology Journal 14: 12 .

Tsiboah, T. (2002). 2D Resistivity and Time-Domain EM in aquifer mapping: a case study, north of Lake Naivasha, Kenya. Enschede, ITC. International Institute for Geo-information Science and Earth Observation. Master of Science: 128.

Villagomez, D. (2003). Evolución geológica Plio-cuaternaria del Valle Interandino Central en Ecuador (Zona de Quito-Guayllabamba-San Antonio). Escuela de Ingeniería. Quito, Escuela Politécnica Nacional. Ing. Geóologo.

Villagomez, D., A. Eguez, W. Winkler and R. Spikings (2002). Plio-quaternary sedimentary and tectonic evolution of the central inter-andean valley in Ecuador. ParisToulouse, Institut de recherche pour le développement. IRD Université Paul Sabatier. Andean geodynamics: extended abstracts: 689-692.

Vsevolozhskii, V. A., R. P. Kochetkova and F. Fidelli (2001). "Principles of hydrogeological zoning by the conditions of formation and the distribution of the natural resources of fresh ground water." Water Resources 30(3): 233-245.

Zektser, I. S. and L. G. Everett (2004). Groundwater resources of the world and their use. Paris, UNESCO. 


\title{
APPENDIX II
}

\section{TRANSLATION OF THE PROCEEDINGS PAPER: IMPACTS OF TECTONICS ON THE HYDROGEOLOGY OF THE QUITO AQUIFER SYSTEM, ECUADOR 7}

\author{
Miriam Rios-Sanchez ${ }^{1}$, John S. Gierke ${ }^{1}$, Teresa Muñoz ${ }^{2}$, Oscar Larrea ${ }^{2}$ \\ ${ }^{1}$ Department of Geological and Mining Engineering and Sciences, Michigan \\ Technological University, 1400 Townsend Dr., Houghton, MI 49931 \\ 2 Dpto de Acuiferos, Empresa Pública Metropolitana de Agua Potable y \\ Saneamiento, Av Mariana de Jesús entre Alemania e Italia, Quito-Ecuador
}

\section{ABSTRACT}

The Quito Aquifer System (QAS) is a volcanic and sedimentary aquifer complex located in a very complex tectonic basin. Although these aquifers are mainly of primary porosity, tectonism is believed to be affecting the hydrogeology of the region. As an initial step to evaluate the tectonics of the area, a lineament mapping was created with a combined approach using remote sensing (coincidence analysis) and digital terrain analysis techniques. Piezometric maps were created and overlain on the lineament map. The relationship between lineaments, topography and groundwater flow indicate that tectonism is playing an important role in the hydrogeological conditions of the QAS. Many faults and lineaments are behaving as groundwater divides, such as the Quito Fault toward the southern part of Quito City. Other faults behave as exflitration zones.

KEYWORDS: Quito Aquifer System, Remote sensing, digital terrain analysis, hydrogeology, coincidence analysis.

\section{INTRODUCTION}

7 Translation of the paper published in the proceedings of the IX Latin American Conference of Hydrogeology. Cartagena de Indias, Colombia, 2012. With permission of GECAIH 
Mountainous aquifers in volcanic areas of Latin-America represent an important source of drinking water for cities such as Guatemala (Guatemala); Guadalajara and Mexico (Mexico), Quito (Ecuador) and La Paz (Bolivia) (Anton 1993). Although most of those aquifers are located in active tectonic basins, the influence of tectonism on the hydrology of many of these mountain watersheds has not been evaluated (Rios-Sanchez et al. 2012). Faults and fractures can modify the porosity and permeability of the aquifer formations. Also they influence geomorphic and topographic development of the basin, impacting directly on the configuration of groundwater flow systems (Bisson and Lehr 2004). Remote sensing techniques (RSA) have been widely used in mapping lineaments for geology, geomorphology and hydrogeology (Becker 2006; Meijerink et al. 2007). Digital terrain models and digital products derived have been used as well for lineament mapping (Florinsky 1996; Jordan et al. 2005). Due to the large spatial coverage and the existence of different spectral resolution provided on single bands or combination of them, remotely sensed products such as satellite images and DEMs are very convenient tools for regional mapping of not only topography, but for aspects such as geology, soil humidity, etc.

The initials steps to study the tectonic characteristics of a volcanic terrain were based on a lineament analysis plus the characterization of topographical conditions and geomorphology. Hydraulic head data, hydrochemistry and other hydrogeological parameters supplemented the information needed to obtain a description of the groundwater flow at a regional scale.

The study area is the Quito Aquifer System (QAS), located in the middle basin of Ecuador's central Andean valley (Figure 6.1). The basin has a tectonic origin. 

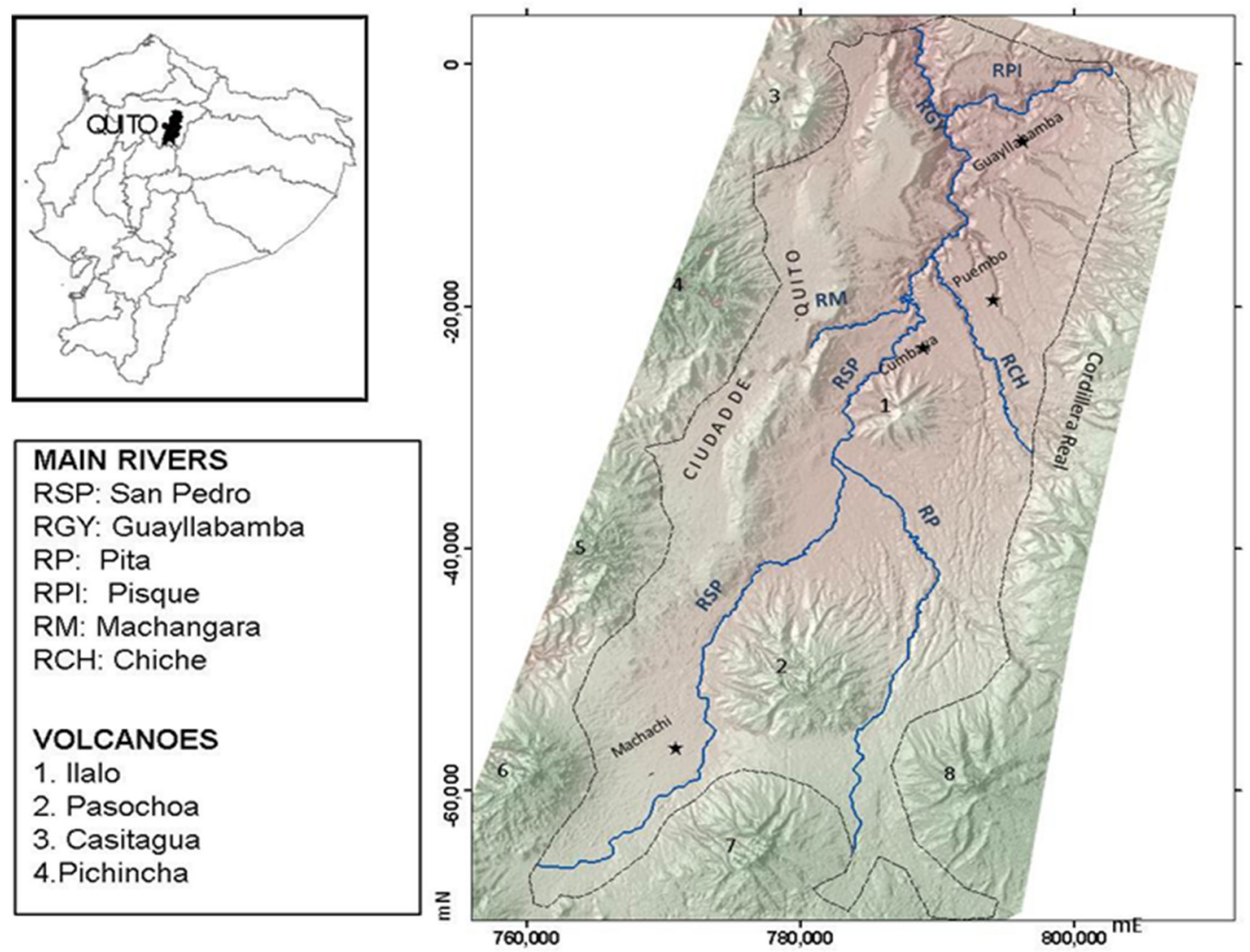

MAIN RIVERS

RSP: San Pedro

RGY: Guayllabamba

RP: Pita

RPI: Pisque

RM: Machangara

$\mathrm{RCH}$ : Chiche

VOLCANOES

1. Ilalo

2. Pasochoa

3. Casitagua

4.Pichincha

70,000

780,000

Figure 6.1.Location of the study area. Towns and volcanoes names are displayed on the map. Map created on a hillshade created from an ASTER-DEM (property of NASA and METI). Coordinate sytem: UTM-WGS84_17N. Sources: DEM: WWw. wist.com. Ecuador shapefile downloaded from: www.diva-gis.org/datadown

For the DTA approach, lineaments were extracted in a systematic fashion. Lineament extraction start with the simplest DEM product: the CSM color scheme map. The lineament map was overlain on the hillshade map to find additional lineaments. The process is repeated for the slope, filtered aspect and the second-derivative maps. The final lineament map for the QAS was obtained by the union of the maps generated by the RSA and the DTA approaches. A detailed description of this methodology is described in RiosSanchez et al (2012). 
In order to identify areas of natural discharge that are associated with fractures and faults, spring locations were pinpointed on the lineament map. Spring data came from the groundwater database published online by the National Institute of Meteorology and Hydrology of Ecuador and from the groundwater database from the national water utility and sanitation company of Quito, Ecuador- EPMAPS .

A regional ground water flow analysis was performed using the topographic elevation data sources and piezometric level data from EPMAPS. Regional piezometric maps from well and spring data were created for the entire QAS. Local piezometric maps were produced for those regions that have hydrogeological studies. Regional and local maps were compared and evaluated according to their ability to characterize the regional groundwater flow for the QAS. Flow maps were superimposed onto the lineament map to analyze possible relationships between the flow and the tectonics. The drainage-feature map was overlain onto those maps as well. Sub-regions with particular flow characteristics were identified. Tectonic structures that are influencing the hydrogeology of the area on a regional scale were identified as well.

\section{RESULTS AND DISCUSSION}

Six hundred five lineaments were extracted on the QAS. The lineaments predominant orientation is NNW. A number of lineaments were identified as faults, which were mapped in previous studies. The most significant are the Quito Fault (QF) and San Pedro Fault (SPF), depicted in Figure 6.2.

Generally speaking, $50 \%$ of the lineaments are associated with drainages. All the major rivers of the area, such as San Pedro, Guayllabamba Pisque, 
Machangara, Chiche and Pita, are associated with tectonic features. When overlying springs and lineaments, it was found that $54 \%$ of the springs are associated with a tectonic feature (Figure 6.2). Areas with the highest number of springs associated with faults or lineaments are found in the San Antonio valley, north of Quito; on the Puembo plateaus, in the northeast of the QAS and along the lineaments associated to Machangara River (Figure $6.2)$.

The piezometric maps constructed based on well and spring data from local studies represent the groundwater flow conditions on the QAS in a better fashion. Piezometric maps created based on the monitoring network of spatially distributed data throughout the region did not produce satisfactory results. The high density of points is necessary to have a good representation of the flow on the QAS, considering that the system is very intricate. There are many natural barriers such as volcanic edifices that interfere with the spatial continuity of the aquifers. Besides, the irregular topography gives origin to numerous local flows (Toth 1984). Moreover, regional faults are creating more complexity not only on the topographic conditions but also on the properties of the aquifers.

Local piezometric maps were used along with topography to differentiate subregions of local groundwater flow, depicted in Figure 6.3. Besides, tectonic features that are influencing the tectonic development of these sub-regions were identified as well The identification of flow systems is best defined for the areas of the QAS having more information. These areas are the metropolitan area and the region located north of Pasochoa volcano. 


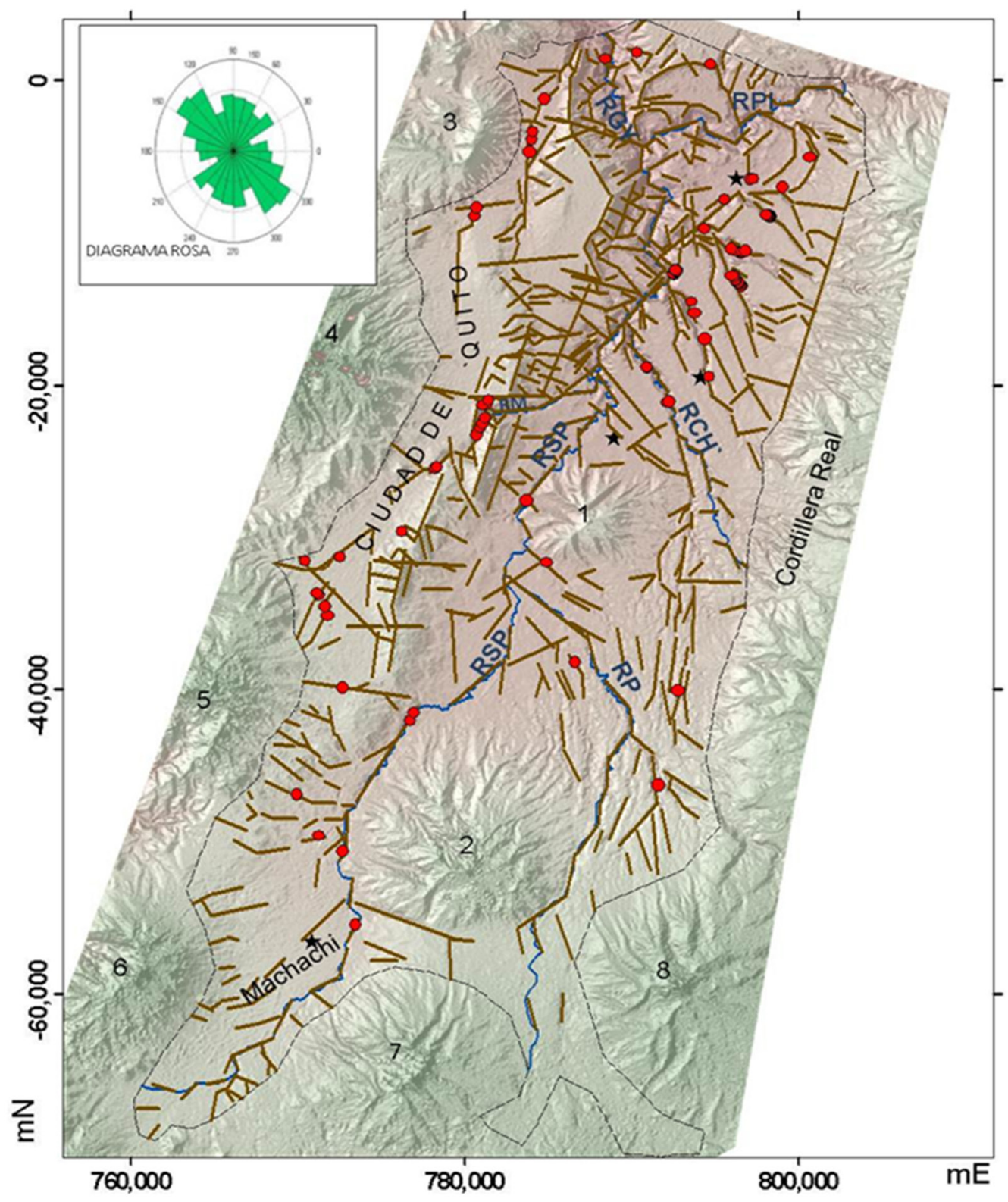

Figure 6.2. Lineaments and springs (red dots) associated to lineaments or faults. Abbreviation of river names and volcanoes id are similar to those on Figure 1. Coordinate sytem: UTM-WGS84_17N. Sources: DEM: WWW.wist.com. Ecuador shapefile downloaded from: www.diva-gis.org/datadown 


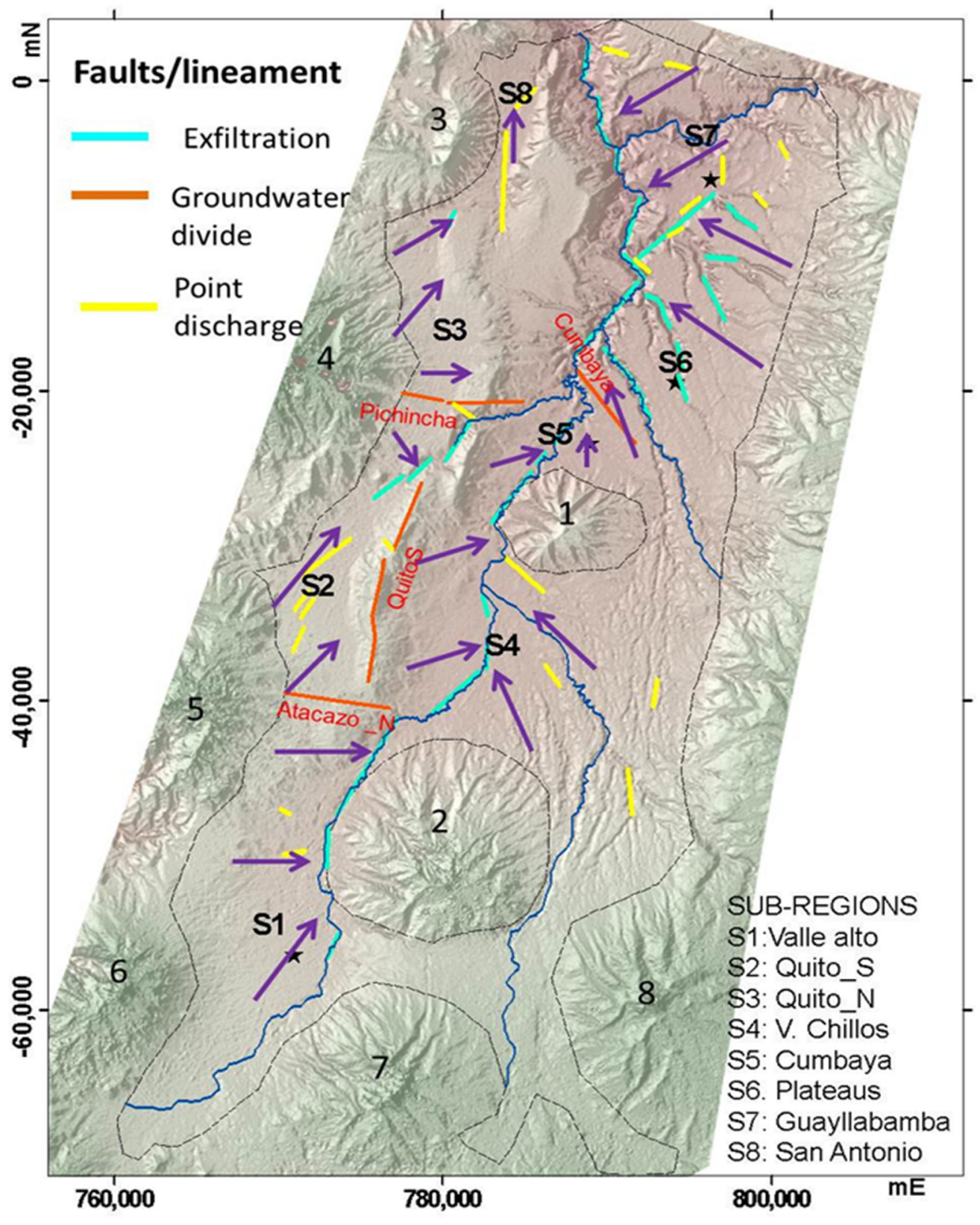

Figure 6.3 Ground water flow systems in the $Q A S$ and their relationship to tectonic features and the main rivers. Map created on a hillshade derived from a $30 \mathrm{~m}$ ASTER DEM (product of METI and NASA). Map Projection: UTM, WGS 84, $17 N$ 
Here is a brief description of the flow systems differentiated.

The first local flow system identified is located on Valle alto (S1 in Figure 6.3), on the southwest of the QAS, nearby the town of Machachi. The flow has a northeast trend in the south part of the sub-region to a W-E trend on the north Recharge areas are located to the west, on the slopes of Corazon volcano (6 in Figure 6.3) and on the foothills of the south-eastern face of Atacazo volcano (5 in Figure 6.3). The exfiltration zone is associated with the lineaments that are controlling the courses of the tributary streams to the San Pedro River to the south. There is not enough information to establish the contribution to the flow coming from the eastern part.

The second local system is localized on the southern part of Quito City (S2 in Figure 6.3). The flow has two components. The first one has a NE flow direction. Recharge originates on the northeast face of Atacazo volcano (5 in Figure 6.3). The discharge is expected to happen following the lineaments associated with the Machángara River. The second component of the flow has a SE direction. Recharge is originated to the southeast slope of Pichincha volcano. The discharge area is toward the lineaments that are associated with the Machángara River as wells. Piezometric data suggest a northwest flow trend, recharging from the Quito fault zone, but there is not sufficient data to corroborate it.

The third flow system is located in the northern part of Quito city (S3 on Figure 6.3). The flow direction is $\mathrm{E}$ to NE. The recharge zone is located on the northeastern face of Pichincha volcano (4 on Figure 6.3). The Quito Fault does not seem to act as an impermeable barrier since the piezometric data suggest that water flows towards Catequila plateau. 
The fourth local flow system is located in the Chillos Valley (S4 in Figure 6.3). The main flow direction is NE and NW. The recharge areas for this system are considered to be on eastern flanks of the southernmost part of Quito Fault and the northern face of Pasochoa Volcano (2 in Figure 6.3). It is not clear where the recharge area in the east is located. The interpolated data did not give enough information to define completely. There are indications that the lineaments associated with the Cariyacu River could be acting as a groundwater divide given the fact that those lineaments have springs associated with them. More information is necessary to verify this boundary.

The fifth flow system is in the Tumbaco Cumbaya Valley (S5 in figure 6.3). This small area located north of Ilalo volcano is one of the most complex and more detailed studies area required to fully characterize the flow. With the available data, three main flow tendencies were recognized. The first flow trend has a northwest direction. The infiltration area is located on the eastern walls of the Quito Fault zone. The discharge of this section of the flow goes to San Pedro River. The second trend follows a north direction, discharging into San Pedro River as well. The third trend has a northeastern direction, discharging into Chiche River. The recharge area for the last two flow sections are the foothills of Ilalo Volcano.

The sixth flow system is located on the plateaus (6 in Figure 6.3). The flow direction follows a northwest trend. The discharge area is located on the foothills of the Cordillera Real. The main discharge is expected to be on the northeastern part of San Pedro River and the lineaments defining the southern edge of Guayllabamba Depression. Considering that discharge zones exist with the river valleys within the plateaus, the flow system described here is an intermediate flow system. Local flow systems are 
developed on each individual plateau. Detailed information on the flow characteristics of this area is found in Rios-Sanchez et al. (2012b).

The seventh flow system is located on the Guayllabamba Depression (S7 on figure 6.3). Current data indicate a southwest flow direction. Recharge comes from the southern face of Mojanda Volcano and likely from the northeastern Plateaus. The discharge is toward the river Guayllabamba.

The eighth flow system is identified in the area of San Antonio (S8 in Figure 6.3). The main flow direction is N. However, recharge from the northeastern face of Casitagua Volcano is expected to happen as well. There is indication of flow coming from the Quito north flow system. Detailed information would be necessary to verify these hypotheses. The southeastern part of the QAS does not have enough information to characterize the groundwater flow.

In summary, faults and lineaments are influencing the development of surface and subsurface flow within the QAS. Some tectonic features are believed to be exfiltration zones. Examples are the lineaments associated with the main drainages on the southwestern part of the QAS. Also lineaments associated to the main drainages (San Pedro River, Guayllabamba, Machangara, Chiche and San Antonio) are considered to be behaving as discharge zones. Lineaments that are likely behaving as a groundwater divide are the Atacazo-N, Pichincha and Cumbaya. The Quito Fault, on the southern part, is likely behaving as a groundwater divide. On its northern part, the data suggest a more permeable behavior. 


\section{CONCLUSIONS}

The QAS is being affected by tectonism. Besides volcanism, faults and lineaments are influencing the flow configuration for this aquifer system. Given the tectonic complexity of this system, a water level monitoring network with more measurements stations are necessary to be designed. Most of the flows characterized in this study are considered local flow systems. The exception would be the Plateaus region, in which local and intermediate systems are developed. There is not enough data to outline the groundwater flow for the southeastern part of the QAS.

It is unknown what role the plateau area of Catequila has on the hydrogeological system. Part of the discharge of the Quito_N flow systems is going toward this plateau. Also, given its elevation and geographic localization, the plateau it could be part of the recharge zone for the subsystem of San Antonio. However, there is not hydrogeological data to verify these hypotheses

\section{ACKNOWLEDGMENTS}

This material is based upon work supported by the National Science Foundation under Grant No. 0530109.

Water Utility Company of Quito (EPMAPS) and Oscar Larrea, head of the Quito Aquifer Division, for providing the Quickbird images, reports and support with during the field work

\section{REFERENCES CITED}

Becker, M. W. (2006). "Potential for satellite remote sensing of groundwater." Groundwater 44(2): 12.

Bisson, R. A. and J. H. Lehr (2004). Modern groundwater exploration. Discovering new water resources in consolidated rocks using innovative hydrogeologic 
concepts, exploration, drilling, aquifer testing, and management methods. New Jersey, John Wiley \& Sons.

Bruning, J. N., Gierke, J. S., McLean and A. L. (2011). "An approach to lineament analysis for groundwater exploration in Nicaragua." Photogrammetric engineering and remote sensing 77(5): 11.

EPMAPS (2012). Groundwater Database. Q. A. D. Quito Water Utility Company. Quito, Ecuador.

Florinsky, I. V. (1996). "Quantitative topographic method of fault morphology recognition." Geomorphology 16(2): 103-119.

INAMHI. (2012). "Inventario de pozos y vertientes del Ecuador." 2012, from http://186.42.174.237/estaciones/inventario_pozos.pdf.

Jordan, G. (2003). "Morphometric analysis and tectonic interpretation of digital terrain data: a case study." Earth Surface Processes and Landforms 28(8): 807-822.

Jordan, G., B. M. L. Meijninger, D. J. J. v. Hinsbergen, J. E. Meulenkamp and P. M. v. Dijk (2005). "Extraction of morphotectonic features from DEMs: Development and applications for study areas in Hungary and NW Greece." International Journal of Applied Earth Observation and Geoinformation 7(3): 163-182.

Meijerink, A. M. J., D. Bannert, O. Batelaan, M. W. Lubczynski and T. Pointet (2007). Remote sensing applications to groundwater. Paris, UNESCO.

Rios-Sanchez, M., J. Gierke and A. L. MacLean (2012). Utilizing digital image processing techniques to identify and characterize fracture patterns in the Quito, Ecuador aquifer system. Houghton, MI, Michigan Technological University.

Villagomez, D. (2003). Evolución geológica Plio-cuaternaria del Valle Interandino Central en Ecuador (Zona de Quito-Guayllabamba-San Antonio). Escuela de Ingeniería. Quito, Escuela Politécnica Nacional. Ing. Geólogo. 